\title{
Properties and function of somatostatin-containing inhibitory interneurons in the somatosensory cortex of the mouse
}

Yunyong Ma

West Virginia University

Follow this and additional works at: https://researchrepository.wvu.edu/etd

\section{Recommended Citation}

$\mathrm{Ma}$, Yunyong, "Properties and function of somatostatin-containing inhibitory interneurons in the somatosensory cortex of the mouse" (2008). Graduate Theses, Dissertations, and Problem Reports. 4400.

https://researchrepository.wvu.edu/etd/4400

This Dissertation is protected by copyright and/or related rights. It has been brought to you by the The Research Repository @ WVU with permission from the rights-holder(s). You are free to use this Dissertation in any way that is permitted by the copyright and related rights legislation that applies to your use. For other uses you must obtain permission from the rights-holder(s) directly, unless additional rights are indicated by a Creative Commons license in the record and/ or on the work itself. This Dissertation has been accepted for inclusion in WVU Graduate Theses, Dissertations, and Problem Reports collection by an authorized administrator of The Research Repository @ WVU.

For more information, please contact researchrepository@mail.wvu.edu. 


\title{
Properties and function of somatostatin-containing inhibitory interneurons in the somatosensory cortex of the mouse
}

\author{
Yunyong Ma \\ Dissertation submitted to the \\ School of Medicine \\ at West Virginia University \\ in partial fulfillment of the requirements \\ for the degree of
}

Doctor of Philosophy

in

Neuroscience

Ariel Agmon, Ph.D., Chair

Bernard Schreurs Ph.D.

Kevin Daly, Ph.D.

George Spirou, Ph.D.

Benjamin Ramsden Ph.D

Department of Neurobiology and Anatomy

Morgantown, West Virginia

2007

Keywords: GABAergic, somatostatin-containing, interneuron, inhibition, network, transgenic mice, barrel cortex.

Copyright 2007 by Yunyong Ma. All rights reserved. 


\section{ABSTRACT \\ Properties and function of somatostatin-containing inhibitory interneurons in the somatosensory cortex of the mouse}

\section{Yunyong Ma}

GABAergic inhibitory interneurons play a pivotal role in balancing neuronal activity in the neocortex. They can be classified into different classes according to their variable morphological, electrophysiological, and neurochemical properties, including two major groups: parvalbumin-containing (PV+), fast-spiking (FS) cells and somatostatincontaining $(\mathrm{SOM}+)$ cells. Using transgenic mice, we identified two subgroups, distinct by all criteria, of SOM+ cells in the somatosensory (barrel) cortex of the mouse, one (called X94) in layer 4 and 5B, and the other one (X98) in deep layers (Ma et al., 2006). We found that X98 cells were calbindin-expressing $(\mathrm{CB}+)$, infragranular, layer 1-targeting "Martinotti" cells, and had a propensity to fire low-threshold calcium spikes, whereas X94 cells did not express CB, targeted mostly layer 4, discharged in stuttering pattern and with quasi "fast-spiking" properties. In the barrel cortex, it was previously shown that $\mathrm{SOM}+$ cells mediate disynaptic inhibition in supragranular and infragranular layers. However, the roles of layer $4 \mathrm{SOM}+$ cells remain largely unknown. We used dual wholecell recording to elucidate the synaptic circuits in layer 4 and the function of layer 4 $\mathrm{SOM}+$ cells during cortical network activities. We found that layer 4 "X94" SOM+ cells received strongly facilitating excitatory input and generated relatively slow rising inhibitory postsynaptic currents (IPSCs) compared to those evoked by FS cells. Strikingly, our data showed that SOM+ cells mediated strong synaptic inhibition of FS cells with connection probability greater than $90 \%$ in layer 4 , but received very little reciprocal inhibition from FS cells, and no reciprocal inhibition from other SOM+ cells. Moreover, $100 \%$ of recorded SOM+-SOM+ cell pairs were electrically coupled with higher coupling ratio compared to that of electrically coupled FS cell pairs. In order to examine the functions of $\mathrm{SOM}+$ cells, we applied $0 \mathrm{Mg}^{2+}$ artificial cerebrospinal fluid (ACSF) to induce episodes of cortical network activity and observed that, during episodes of network activity, SOM+ cells fired robustly and synchronously, and produced strong inhibition of regular-spiking (RS) excitatory cells and inhibitory FS cells, especially the latter. Taken together, our data reveal that SOM+ cells in the barrel cortex can be subdivided into different subtypes, and that layer $4 \mathrm{SOM}+$ cells exert a powerful inhibitory effect during high frequency network activity. 


\section{Acknowledgements}

I would like to express my cordial appreciation to my mentor Dr. Ariel Agmon. In the past more than six years, you have taught me not only literal knowledge but also, more importantly, how to explore a scientific project in a scientific way. Thank you for your guidance and patience to help me get through my graduate studies. Your diligence and motivation impressed me greatly and will continue to motivate me in the future.

To my committee members Dr. George Spirou, Dr. Bernard Schreurs, Dr. Kevin Daly, thank you very much for your support, guidance and encouragement. To Dr. Benjamin Ramsden, I sincerely thank you for your time to talk with me about student life, besides scientific help.

I am indebted to Dr. Albert Berrebi and Dr. George Spirou for helping me with my future career. Also, I would like to thank Dr. Berrebi and Dr. Dey for bringing me into this great graduate program and giving me constant support at different study stages. Thanks to Dr. Culberson, Dr. Pope and Dr. Klink for your help in the teaching and courses.

Thanks also to Hang Hu and Cary Johnson for your wonderful assistance and to Joshua Barker and Zhenjun Tan for your friendship.

To my parents, thank you for filling me with love and courage that are leading my life.

And most importantly, I would like to thank my wife, Jun Chen. You have been making the life colorful and joyful. I could not have done this without you. 


\section{Table of Contents}

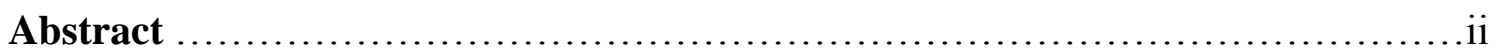

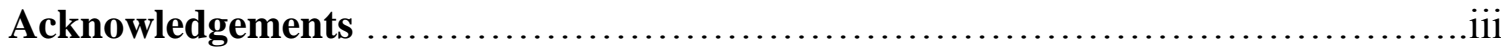

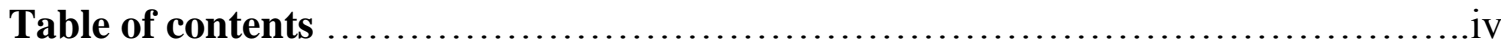

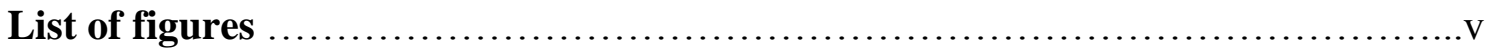

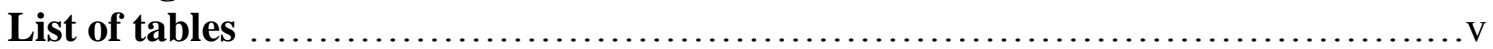

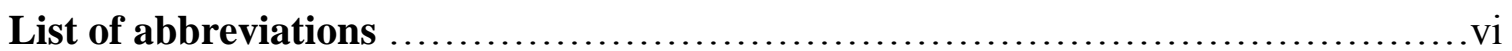

Chapter 1: Introduction (Literature Review)

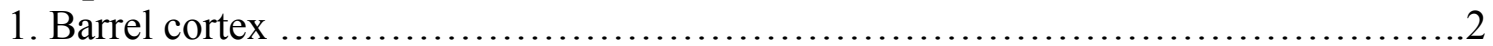

2. Categorization and properties of neocortical interneurons ....................... 5

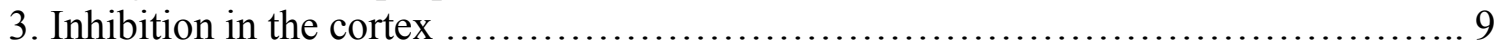

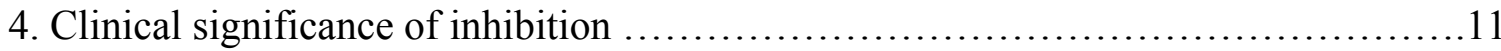

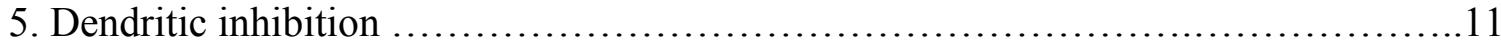

6. Electrical coupling / gap junctions ............................................ 13

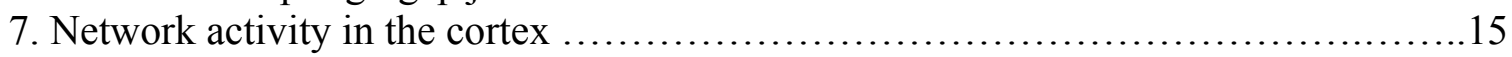

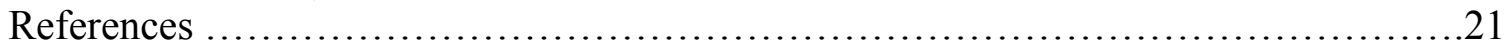

Chapter 2: Subtypes of somatostatin-containing GABAergic interneurons (SOM+ cells) in the barrel cortex

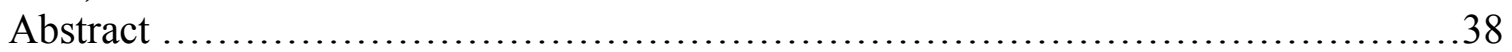

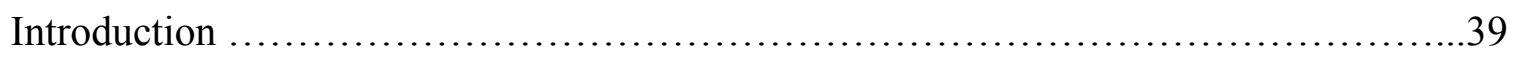

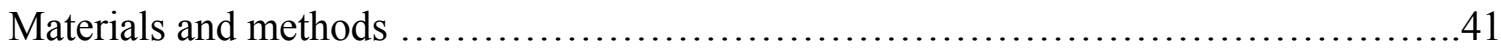

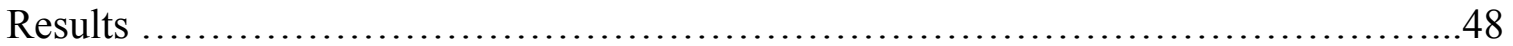

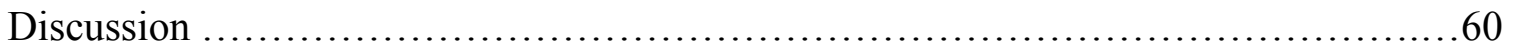

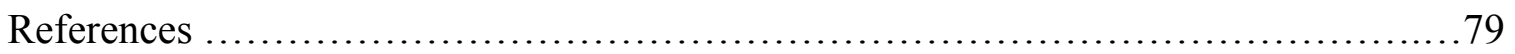

Chapter 3: Synaptic properties and functions of layer $4 \mathrm{SOM}+$ cells in the barrel cortex

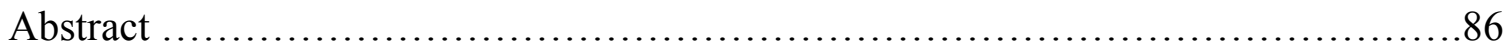

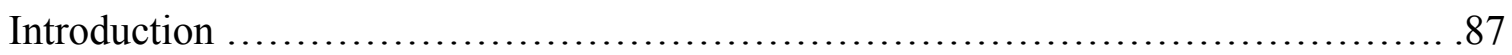

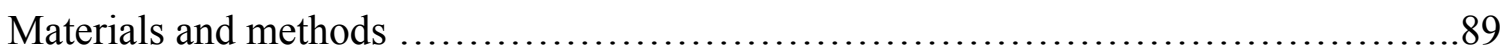

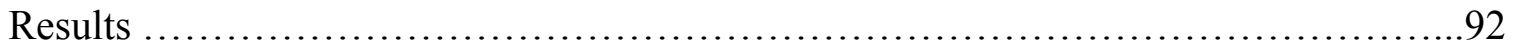

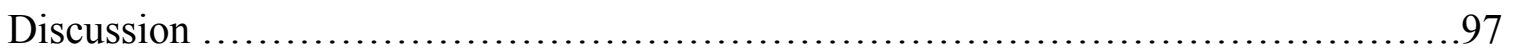

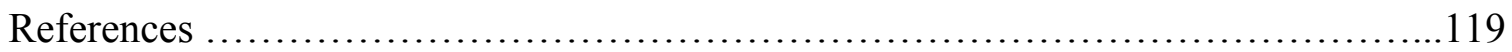

Chapter 4: General Discussion

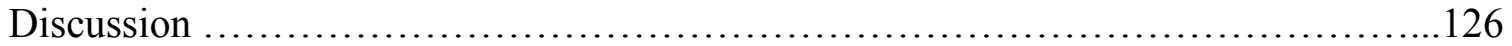

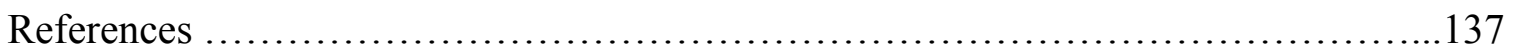

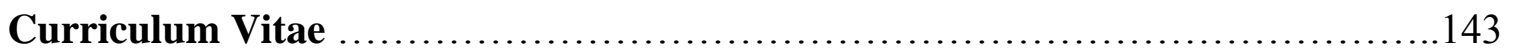




\section{List of Figures}

\section{Chapter 1}

1.1 Summarized trigeminal pathway and cortical circuit diagram $\ldots \ldots \ldots \ldots \ldots \ldots \ldots \ldots \ldots$

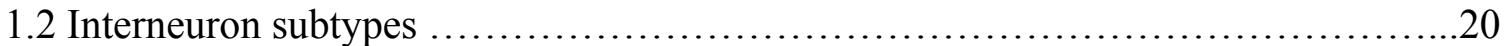

\section{Chapter 2}

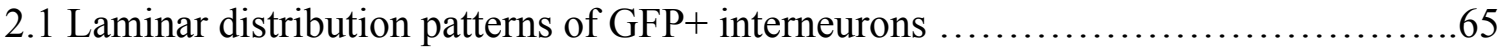

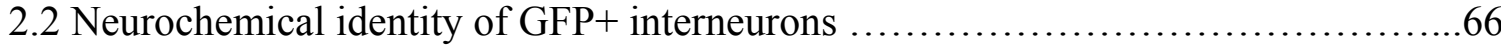

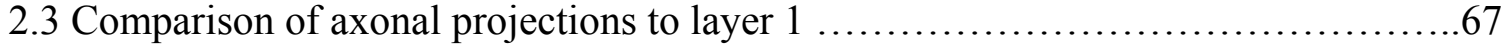

2.4 Morphological reconstructions of representative GFP+ neurons ....................68

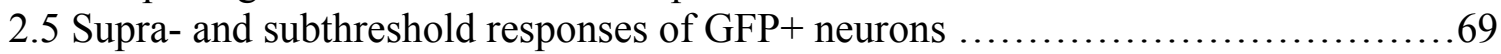

2.6 The ionic basis of the rebound burst ............................................ 71

2.7 Multivariate analysis of electrophysiological parameters ........................72

\section{Chapter 3}

3.1 Identification of different studied cell types .................................... 107

3.2 Studied synaptic connections and their connection probabilities...................108

3.3 Facilitation of evoked unitary EPSPs generated in SOM+ cells by RS cells compared with depression of those in FS cells .......................................... 109

3.4 Well-sustained inhibitory output of SOM+ cells compared to the depressing output of FS cells

3.5 Stronger electrical coupling between SOM+ cells compared to that between FS cells

3.6 Comparison of the kinetics of IPSCs generated by SOM+ cells and FS cells .......112

3.7 Differential inhibition on RS and FS cells evoked by SOM+ cells

3.8 Differential activation of SOM+ and FS cells during episodes of network activity in $0 \mathrm{Mg}^{2+} \mathrm{ACSF}$

3.9 Responses of SOM+ and RS cells during episodes of network activity in $0 \mathrm{Mg}^{2+}$ ACSF

3.10 Correlated voltage responses of a pair of SOM+ cells during an episode of network activity

\section{Chapter 4}

4.1 Modified cortical circuit diagram shown in Fig. 1.1

\section{List of Tables}

\section{Chapter 2}

2.1 Overlap between GFP and SOM, CB and NPY expression, by line and by laminar position .................................................................. 75

2.2 Values for 15 electrophysiological parameters analyzed for each neuron ............76

2.3 Summary of the phenotypic differences between X94 and X98 neurons .............78 


\section{Chapter 3}

3.1 Summary of IPSC parameters mediated by four types of inhibitory synapses ..... 116 


\section{List of Abbreviations}

$\begin{array}{ll}\text { 5-HT } & \text { serotonin } \\ \text { ACSF } & \text { artificial cerebrospinal fluid } \\ \text { AHP } & \text { afterhyperpolarization } \\ \text { AP } & \text { action potential } \\ \text { BSNP } & \text { burst-spiking nonpyramidal } \\ \text { CB } & \text { calbindin } \\ \text { CCK } & \text { cholecystokinin } \\ \text { CR } & \text { calretinin } \\ \text { EPSP } & \text { excitatory postsynaptic potential } \\ \text { E } \text { Cl- } & \text { reversal potential of chloride current } \\ \text { eEPSP } & \text { evoked excitatory postsynaptic potential } \\ \text { FS } & \text { fast-spiking } \\ \text { GABA } & \text { r-aminobutyric acid } \\ \text { GFP } & \text { green fluorescent protein } \\ \text { I } & \text { transient A-type potassium current } \\ \text { IB } & \text { intrinsically burst spiking } \\ \text { Ih } & \text { hyperpolarization-activated cation channel } \\ \text { IPSC } & \text { inhibitory postsynaptic current } \\ \text { IPSP } & \text { inhibitory postsynaptic potential } \\ \text { KCC2 } & \text { K }{ }^{+} \text {-Cl-cotransporter } 2 \\ \text { LTS } & \text { low-threshold spiking } \\ \text { MB } & \text { multipolar-bursting } \\ \text { mGluR } & \text { metabotropic glutamate receptor } \\ \text { MWE } & \text { multiple whisker excitation } \\ \text { NKCC1 } & \text { Na -K }{ }^{+} \text {-2Cl- cotransporter 1 } \\ \text { NPY } & \text { neuropeptide Y } \\ \text { O-LM } & \text { oriens-lacunosum moleculare } \\ \text { PrV } & \text { principal sensory nucleus } \\ \text { PV } & \text { parvalbumin } \\ \text { RMP } & \text { resting membrane potential } \\ \text { SME } & \text { single whisker excitation } \\ \text { RS } & \text { regular-spiking } \\ \text { RSNP } & \text { regular-spiking nonpyramidal } \\ \text { RTN } & \text { thalamic reticular nucleus } \\ \text { RTR } & \text { recovery test response } \\ \text { SOM } & \text { somatostatin } \\ \text { SpV } & \text { spinal trigeminal nucleus } \\ \text { uEPSP } & \text { unitary excitatory postsynaptic potential } \\ \text { VB } & \text { ventrobasal thalamus } \\ \text { VIP } & \text { vasoactive intestinal peptide } \\ & \end{array}$


This page is intentionally blank. 
Chapter One

Introduction 


\section{LITERATURE REVIEW}

\section{Introduction}

The cerebral cortex is considered to be the most complex structure in the central nervous system, participating in many complicated brain functions including thought, language, memory, attention and consciousness. The cerebral cortex is composed of the neocortex, the hippocampus and the olfactory cortex, which are differentiated into six, five and three layers, respectively. Because the cellular composition and organization in all three cortices are similar, comparisons of cellular properties are commonly done between them. The neocortex has up to hundreds of billions (depending on species) of neurons that belong to two main types - excitatory cells, consisting of $70-80 \%$ of neocortical neurons, and inhibitory neurons, making up the remaining $20-30 \%$. The former use glutamate as their neurotransmitter and have extensive local axonal arborizations and make distant axonal projections; the latter release $\gamma$-aminobutyric acid (GABA) and generally have only local axonal arborizations. My research project relates to inhibitory interneurons and their functional role in the neocortex of the mouse.

\section{Neural circuitry of barrel cortex}

Because nocturnal rodents, such as rats and mice, use their facial vibrissae to explore their external environment in darkness, they evolved with highly developed corresponding neocortex. In 1970, Woolsey and Van der Loos (Woolsey and Van der Loos, 1970) first described in detail that groups of cells in layer 4 of the primary somatosensory cortex of rodents were arranged in "barrel" shape, consisting of a cellsparse center and a cell-dense wall, separated from each other by septa. Thereupon, this

cortical region was named "barrel cortex". To date, the barrel cortex has become a particularly suitable model for various neurobiological studies, such as cortical information processing, cortical circuitry development, as well as cortical plasticity.

There is a three-order neuronal transmission pathway between the peripheral vibrissae and their counterpart area in the barrel cortex (pathways 1, 2, 3, 4 and 5 in Fig. 1.1). First order relay neurons are trigeminal ganglion cells, which have sensory terminals 
innervating each whisker follicle on the rodent's face, and they make output synaptic contacts with (pathway 1) three trigeminal sensory nuclei - principal sensory nucleus (Pr5), nucleus interpolaris (Sp5I) and nucleus caudalis (Sp5C) in the brainstem, the latter two residing in spinal trigeminal nucleus (Sp5). Second order neurons in Pr5 and Sp5 relay the sensory inputs to contralateral thalamic nuclei (pathway 2), specifically, the ventral posterior medial nucleus (VPM) and the medial portion of the posterior thalamic nucleus (POm). As third-order neurons, relay neurons in VPM transfer the sensory inputs to layer 5B (pathway 3) and the barrels in layer 4 (pathway 4) of the primary somatosensory cortex, this being considered the "lemniscal" somatosensory pathway (Ahissar et al, 2000; Diamond, 1995). POm relays sensory inputs from several vibrissae to the septal regions between the barrels (pathway 5) and most likely serves as part of a multi-barrel communication pathway, called the "paralemniscal" somatosensory pathway (Ahissar et al, 2000; Diamond, 1995). There is a topographic, one-to-one relationship within the trigeminal pathway. That is, each facial whisker has its own corresponding barrelette (in Pr5, Sp5I, Sp5C), barreloid (in VPM), and cortical barrel (in layer 4 of barrel cortex) (Van der Loos, 1976; Diamond et al., 1992). Thus, each barrel primarily represents one contralateral mystacial vibrissa.

Similar to other sensory cortical areas, there are 6 layers in the barrel cortex, and it is arranged precisely in a columnar pattern (Bureau et al., 2004) and form sophisticatedly organized circuits (Thomson and Deuchars, 1997; Thomson et al., 2002a, 2002b; Thomson and Bannister, 2003; Haeusler and Maass, 2007). Major connection pathways are summarized in Fig. 1.1. Layer 4, the "granular" layer, is the main recipient of thalamic input from VPM (pathway 4); but axons from VPM also branch extensively and form terminal clusters in layer 5B (pathway 3) (Bernardo and Woolsey, 1987; Jensen and Killackey, 1987; Agmon et al., 1993). Excitatory neurons are labeled in red in Fig. 1.1. Unlike the classical pyramidal cells, distributed mostly in layers 2,3,5 and 6, there are two other types of excitatory neurons in layer 4 - spiny stellate cells and star pyramidal cells - whose dendritic arbors are largely confined to layer 4 (Lubke et al., 2000). Within a single barrel, interconnections between excitatory neurons are reliable and efficient (Feldmeyer et al., 1999) (pathway 6), even though some differences exist between these 
two types of excitatory neurons (Cowan and Stricker, 2004), allowing layer 4 to function as an amplifier for the afferent thalamic input (Douglas et al., 1991; Feldmeyer et al., 1999). Also, there are two main types of inhibitory interneurons in layer 4 - parvalbumincontaining $(\mathrm{PV}+)$, fast-spiking $(\mathrm{FS})$ cells and somatostatin-containing $(\mathrm{SOM}+)$ cells (marked in blue and green, respectively, in Fig. 1.1). In layer 4, excitatory and inhibitory cells are mutually interconnected (Beierlein et al., 2003) (pathways 7 and 8) and both classes receive excitatory input from VPM (pathway 4) (Agmon and Connors, 1992; Porter et al., 2001). Additionally, thalamocortical projections can excite layer 5B SOM+ cells. The latter project their axons to layer 4 (Ma et al., 2006; Tan et al., PNAS, in press) (pathway 18). From layer 4, sensory information is relayed mainly to layers $2 / 3$ by axons of spiny stellate cells (Petersen and Sakmann, 2001; Shepherd and Svoboda, 2005) (pathway 9). In contrast to the strong connections between layer 4 excitatory cells, the projections from layer 4 spiny cells to layers 2/3 pyramidal cells are weak (Feldmeyer et al., 2002), implying that layer 4 spiny neuron to layers $2 / 3$ pyramidal cell synapses act as a gate for the lateral spread of corticocortical excitation in layers $2 / 3$. Layers $2 / 3$ pyramidal cells also receive excitatory inputs from neighboring barrels (Wirth and Luscher, 2004) (pathway 10). Inhibitory inputs received by layers $2 / 3$ pyramidal cells are both from interneurons in their home layer and from layer 4 (Porter et al., 2001) (pathway 11). Pyramidal cells in layers $2 / 3$ project their axons to layer 5 (Thomson and Bannister, 2003) (pathway 13). Layers 2/3 pyramidal cells also selectively send excitatory inputs to layer 4 interneurons (Watts and Thomson, 2005) (pathway 12). Layer 5A pyramidal cells project to the caudate nucleus, motor cortex and secondary somatosensory cortex, and layer 5B pyramidal cells gives rise to the main subcortical outputs, from barrel cortex, to the brainstem and spinal cord. Layers 3, 5A and 5B pyramidal cells send dendritic tufts to layer 1, where they receive diverse inputs such as back-projections from higher-order cortical areas (Zeki and Shipp, 1988) (pathway 14). The dendritic tufts in layer 1 can also be contacted by inhibitory Martinotti cells, which are distributed in layers 2,3,5 and 6, and characterized by their layer 1-targeting axonal projections (Wang et al., 2004; Ma et al., 2006; Silberberg and Markram, 2007) (pathway 15). Corticothalamic pyramidal cells in layer 6 have apical dendrites distribution in layer 4 and send axonal projections to VPM of the thalamus and collaterals to layer 4 (Zhang 
and Deschenes, 1998) (pathways 16 and 17). In Chapter 3, I will describe novel results which expand our knowledge of the circuitry within layer 4 .

\section{Categorization and properties of neocortical interneurons}

In rats, a neocortical column of about $0.3 \mathrm{~mm}$ in diameter contains roughly 7,500 neurons (100 neurons in layer I; 2,150 in layer II/III; 1,500 in layer IV; 1,250 in layer V and 2,500 in layer VI) (Ren et al., 1992; Beaulieu, 1993). Among these, excitatory cells have relatively stereotyped anatomical, physiological and molecular properties, with only slight differences in firing patterns, morphologies and connection patterns (Mason and Larkman, 1990; Agmon and Connors, 1992; Wang et al., 2006; Le Be et al., 2007). In contrast, GABAergic inhibitory interneurons are highly variable in their morphological, electrophysiological, synaptic and molecular properties, and these properties have been used to classify them into subtypes (see reviews, McBain and Fisahn, 2001; Markram et al., 2004). It should be noted that results summarized in this section are from different cortical areas including visual cortex, barrel cortex, hippocampus and, in particular, frontal cortex.

Morphological properties: Morphological properties, specifically dendritic and axonal distributions, normally indicate the input source and output direction, respectively, of a given neuron. Interneurons possess aspiny dendrites and diverse dendritic and axonal arborization patterns, especially the latter. For example, basket cells have basket-like axonal clustering around the postsynaptic somata (Kisvarday et al., 1985; Kisvarday et al., 1993; Kisvarday et al., 2002; Wang et al., 2002); "chandelier" cells are characterized by their chandelier-like, short vertical rows of boutons, targeting axon initial segments. "Martinotti" cells (MCs) have ascending axons, which enter layer 1 and give rise to horizontal collaterals (Wahle, 1993; Kawaguchi and Kubota, 1996), making synaptic connections with dendritic tufts of pyramidal cells (Kawaguchi and Kubota, 1997; Wang et al., 2004; Ma et al., 2006). In order to prevent unnecessary confusion, please let me place some constraint on the term "Martinotti" cells in the neocortex. MCs were firstly

found in deep layers of the neocortex, and defined by their layer 1-targeting axonal projection (Fairen et al., 1984). Later, layer 1-targeting axonal projections from 
interneurons in other layers were found. In this dissertation I refer to Martinotti cells as layer 1-projecting interneurons, regardless of their somatic locations. Oriens-lacunosum moleculare (O-LM) cells in the hippocampus are the counterpart cell type in the hippocampus and also send axons to distal dendritic terminals area in the stratum moleculare (equivalent of cortical layer 1). Double bouquet cells are another type of dendritic targeting inhibitory interneurons and they have featured fascicular axons (DeFelipe et al., 1990).

Unlike the morphological classification above, which is based on axonal arborizations of inhibitory interneurons, bipolar and bitufted cells (Peters, 1990) are identified by their characteristic dendritic arborizations. These interneurons have primary dendrites emerging from opposite sides of the soma to form a bipolar or bitufted morphology. Their axons, however have distinct features (Peters, 1990; DeFelipe et al., 1990; Kawaguchi and Kubota, 1997). Neurogliaform cells have short and finely beaded, rarely branched, radiating dendrites and highly branched, interwound dense axonal arborization (Kawaguchi and Kubota, 1997; Simon et al., 2005).

Electrophysiological properties: Electrophysiological responses reflect the passive and active membrane properties of a given interneuron, which are crucial in integrating inputs and generating outputs. Electrophysiologically, GABAergic interneurons can be categorized into several groups. Fast-spiking (FS) cells have lower input resistances, faster membrane time constants, exceptionally narrow spike widths, brief and deep afterhyperpolarizations (AHP), abrupt onset of repetitive discharges, high thresholds and maximal firing frequencies, and little or no spike frequency adaptation (McCormick et al., 1985; Kawaguchi, 1995; Kawaguchi and Kubota, 1997; Galarreta and Hestrin, 1999; Gibson et al., 1999). Low-threshold spiking (LTS) cells, which are also known as burstspiking nonpyramidal (BSNP) cells, typically discharge a burst riding on a depolarizing hump when injected with depolarizing current at hyperpolarized membrane potentials (Kawaguchi, 1995; Kawaguchi and Kubota, 1996; Kawaguchi and Kubota, 1997; Goldberg et al., 2004). Regular-spiking nonpyramidal (RSNP) cells show strong spike frequency adaptation, especially for the first several spikes (Kawaguchi, 1995; Kawaguchi and Kubota, 1996; Kawaguchi and Kubota, 1997). Late-spiking (LS) cells 
exhibit slowly depolarizing ramp depolarizations to near threshold, and include neurogliaform cells (Kawaguchi, 1995; Kawaguchi and Kubota, 1997). Irregular-spiking (IS) cells fire an initial spike burst followed by irregularly spaced action potentials (APs) (Cauli et al., 1997; Porter et al., 1998).

Molecular properties: Neuropeptides including somatostatin (SOM), vasoactive intestinal peptide (VIP), neuropeptide Y (NPY), cholecystokinin (CCK), as well as calcium-binding proteins including parvalbumin (PV), calbindin (CB), calretinin (CR) are co-expressed in GABAergic interneurons (Hendry et al., 1984; Toledo-Rodriguez et al., 2005) and used to classify them. Calcium-binding proteins participate in regulating amplitude and kinetics of calcium concentration (Baimbridge et al., 1992; Chard et al., 1993; Lee et al., 2000), thus also controlling synaptic plasticity (Caillard et al., 2000), while neuropeptides usually play neuromodulatory roles (Vidal and Zieglgansberger, 1989). According to their expression profiles, three main groups of cortical interneurons are recognized: $\mathrm{PV}$-containing $(\mathrm{PV}+)$ cells, SOM-containing $(\mathrm{SOM}+)$ cells and $\mathrm{CR} / \mathrm{VIP}-$ containing (CR+/VIP+) cells (Kubota et al., 1994; Kawaguchi and Kubota, 1996; Gonchar and Burkhalter, 1997; Kawaguchi and Kondo, 2002). There are also other identifying constituents of specific subtypes of inhibitory interneurons, including potassium channels (Chow et al., 1999; Rudy and McBain, 2001; Baranauskas et al., 2003), endocannabinoid receptors (CB1) (Tsou et al., 1998; Marsicano and Lutz, 1999; Katona et al., 1999; Bacci et al., 2004; Galarreta et al., 2004), AMPA receptors (Hestrin, 1993; Rozov et al., 2001), metabotropic glutamate receptors (mGluR) (Stinehelfer et al., 2000), $\mathrm{GABA}_{\mathrm{A}}$ receptors (Bacci et al., 2003) and seretonin (5-HT) receptors (Hornung and Celio, 1992; Morales and Bloom, 1997; Porter et al., 1999; Ferezou et al., 2002), and others.

Taken together, based on a combination of multiple properties, three major subgroups of GABAergic interneurons are recognized.

1) $\mathrm{PV}+/ \mathrm{FS}$ basket cells and chandelier cells: the former innervate somata and proximal dendrites of postsynaptic target cells and control the gain of summated synaptic potentials, in turn controlling the discharge patterns (Fig. 1.2) (Kawaguchi and Kubota, 1996; 
Meskenaite, 1997; Maccaferri et al., 2000, Tamas et al., 2000; Pouille and Scanziani, 2001; Wang et al., 2002); the latter form synapses exclusively on axon initial segments and are specialized to efficiently curtail spiking output (Fig. 1.2) (Somogyi et al., 1982; Buhl et al., 1994; Zhu et al., 2004). It should be noted that PV+ cells are not always FS cells, and include multipolar-bursting (MB) cells (Blatow et al., 2003).

2) SOM+/LTS/RSNP/Martinotti cells: Often described as bitufted, their axons terminate on distal portions of dendrites of postsynaptic targets (Fig. 1.2) (Maccaferri et al., 2000; Wang et al., 2004; Silberberg and Markram, 2007) and affect local dendritic integration, by affecting dendritic calcium spiking (Miles et al., 1996; Larkum et al., 1999a, 1999b), regulate backpropagating sodium spikes (Tsubokawa and Ross, 1996; Buzsaki et al., 1996), or interact locally with excitatory afferents (Vida et al., 1998). This group of interneurons corresponds to O-LM cells in the hippocampus.

3) $\mathrm{CR} / \mathrm{VIP}+/ \mathrm{IS}$ : These are mostly bipolar cells with vertically oriented descending axons. They target vertically oriented dendrites of pyramidal cells (Peters A, 1990) (Fig. 1.2) or (in the hippocampus) other interneurons (Gulyas et al., 1996).

Additionally, two small groups of interneurons have been described: LS neurogliaform cells, which mostly target dendrites, and large CCK-basket cells, which make synaptic contacts on other cell bodies and dendrites, and which co-express CB1 receptors. Unsupervised gene expression cluster analysis (Toledo-Rodriguez et al., 2004) and developmental observations (Flames and Marin, 2005; Wonders and Anderson, 2006) strongly support the above categorization. In sum, based on neurochemical, genetic, developmental, and molecular results (Soltesz, 2005), we propose that molecular properties might be the most practical clue for classification of GABAergic interneurons.

\section{Transgenic technology applied to cortical interneurons}

Due to the high variability of interneuron types, investigators began to use transgenic animals, in which GFP expression is restricted to subpopulations of interneurons, to explore them (Oliva et al., 2000; Chattopadhyaya et al., 2004; Lopez-Bendito et al., 2004; Ma et al., 2006). Transgenic animals have several outstanding advantages for interneuron studies. First, without the benefit of GFP expression, the identification of the cell type of a given recorded cell is difficult, since it is typically possible to examine only a limited 
number of features in any given cell. However, as described above, the properties of interneurons are highly variable, and many features are needed for proper classification. Second, to some degree, post-hoc immunohistochemical staining of neurochemical markers can be confounded by false-negatives (due to wash-out of intracellular components during the recording). Third, in functional studies of specific types of interneurons, it would be much more efficient to know the cell type identity prior to the recording, instead of post-hoc identification. Transgenic animals allow the same cell type to be reproducibly identified in different animals and to be visualized and targeted for electrophysiological recording.

While several previous studies examined the properties of inhibitory interneurons in the barrel cortex, such as Martinotti cells (Wang et al., 2004), layer 5 LTS cells (Goldberg et al., 2004) and layer 4 interneurons (Gibson et al., 1999; Porter et al., 2001; Amitai et al., 2002; Beierlein et al., 2003; Gibson et al., 2005), there has been no systematic study in the barrel cortex of any neurochemical subgroup of interneurons based on multiple criteria. Neocortical SOM+ interneurons appear considerably more variable than PV+ interneurons (Kawaguchi and Shindou, 1998; Wang et al., 2004). For example, PV+ interneurons mostly exhibit non-adapting fast-spiking firing pattern; while $\mathrm{SOM}+$ interneurons display adapting, including bursting and irregular spiking, as well as nonadapting firing pattern. Until our recent work, it was not known whether the heterogeneity of SOM+ cell properties reflected within-group variability or existence of diverse subtypes. My first research project examined the properties of $\mathrm{SOM}+$ cells, identified with transgenic mice technology, to address the question of whether SOM+ cells residing in different layers belong to different subtypes. The results (Ma et al., 2006) are presented in Chapter Two of this dissertation.

\section{Inhibition in the cortex}

Inhibitory interneurons use GABA as the main neurotransmitter to perform their inhibitory function. There are two major types of GABA receptors: ionotropic $\mathrm{GABA}_{\mathrm{A}}$ and metabotropic $\mathrm{GABA}_{B}$ receptors. The $\mathrm{GABA}_{\mathrm{A}}$ receptor consists of five protein subunits including, typically two $\alpha$, two $\beta$ and one variable fifth subunit (Farrar et al., 
1999); the different combinations of multiple isoforms of subunits allow a great level of functional diversity (Wisden et al., 1992; McKernan and Whiting, 1996). The five subunits of $\mathrm{GABA}_{\mathrm{A}}$ receptors are arranged in a circle to directly form an ion channel, which has high permeability to chloride ions. $\mathrm{GABA}_{\mathrm{A}}$ receptors mediate fast chloride currents, which generate the main inhibitory effect. $\mathrm{GABA}_{\mathrm{B}}$ receptors are capable of regulating calcium and potassium channels through activation of guanine nucleotide binding proteins, and mediate slow postsynaptic inhibition (Tamas et al., 2003; Simon et al., 2005) or presynaptic modulation of transmitter release (Ohliger-Frerking et al., 2003).

The nature of fast inhibition, predominant in the cerebral cortex, is determined by the reversal potential of the chloride current $\left(\mathrm{E}_{\mathrm{Cl}}\right)$. Three types of effects exist:

1) A hyperpolarizing effect, in which $\mathrm{E}_{\mathrm{Cl}-}<$ resting membrane potential (RMP);

2) A shunting effect, in which RMP $\leq \mathrm{E}_{\mathrm{Cl}-}<$ action potential threshold. Shunting is achieved by an increase in membrane conductance. It is thought to decrease the gain between neural inputs and outputs (the slope of the input-output curve) (Ulrich, 2003).

3) A depolarizing effect, in which $\mathrm{E}_{\mathrm{Cl}-} \geq$ action potential threshold.

The chloride gradient across the cell membrane determines the reversal potential of $\mathrm{GABA}_{\mathrm{A}}$ receptors mediated currents. Two transporters - the $\mathrm{Na}^{+}-\mathrm{K}^{+}-2 \mathrm{Cl}$ - cotransporter 1 (NKCC1) and the $\mathrm{K}^{+}-\mathrm{Cl}$-cotransporter $2(\mathrm{KCC} 2)$ regulate the chloride gradient - the former pumps chloride into neurons and the latter extrudes it. Because in the neonate, the expression ratio of $\mathrm{NKCC} 1 / \mathrm{KCC} 2$ is higher compared to that in animals older than approximate two weeks, the impact of opening $\mathrm{GABA}_{\mathrm{A}}$ receptors is depolarizing (Daw et al., 2007). After about two weeks of age, the effect becomes shunting and hyperpolarizing. Furthermore, when coincident with excitatory postsynaptic potentials (EPSPs), the effect of inhibitory postsynaptic potentials (IPSPs) will be hyperpolarization. On the other hand, when targeted cells are in a hyperpolarized situation, IPSPs may have a depolarizing effect and may facilitate action potential generation (Gulledge and Stuart, 2003).

Besides the fast, phasic inhibition mentioned above, $\mathrm{GABA}_{\mathrm{A}}$ receptors also mediate another form of inhibitory effect - tonic inhibition, which involves the activation of the 
extrasynaptic $\mathrm{GABA}_{\mathrm{A}}$ receptors by ambient GABA. Ambient GABA could come from spillover of GABA from the synaptic cleft, or nonvesicular release (Semyanov et al., 2004; Farrant and Nusser, 2005). Tonic inhibition persistently increases the membrane input conductance, thus decreasing the sensitivity of the affected cells to synaptic inputs. In contrast with the phasic shunting effect mentioned previously, tonic inhibition is long-lasting and does not involve temporally precise processing.

At the network level, inhibitory interneurons can synchronize neuronal activity through $\mathrm{GABA}_{\mathrm{A}}$ receptor-mediated IPSPs (Whittington et al., 1995; Bartos et al., 2002). It has been suggested that the time course of $\mathrm{GABA}_{\mathrm{A}}$ receptor-mediated inhibitory responses determines the frequency of some forms of network oscillations (Whittington et al., 1995; Jefferys et al., 1996).

\section{Clinical significance of inhibition}

Dysfunction of inhibition in the cerebral cortex is considered to be involved in multiple clinical diseases. First, epilepsy is related to deficits in the GABAergic system. Reduction in GABAergic inhibition occurs in epilepsy (Ribak et al., 1979; Esclapez and Trottier, 1989), and pharmacological suppression of $\mathrm{GABA}_{\mathrm{A}}$ receptors produces seizurelike activity (Kim et al., 1993; Wells et al., 2000). An association between mutations in the $\mathrm{GABA}_{\mathrm{A}}$ receptor and epilepsy is also established (Baulac et al., 2001). Second, alteration in GABAergic transmission contributes to the pathophysiology of schizophrenia. Specifically, the axon terminals of chandelier neurons are reduced substantially in the prefrontal cortex in post-mortem brains of schizophrenic subjects (Lewis et al., 1999). Third, suppression of GABAergic function can generate pathology mirroring autism, suggesting the involvement of suppressed GABAergic function in autism (Hussman, 2001). Fourth, impaired intracortical inhibition is reported to underlie symptomatology of attention deficit / hyperactivity disorder in children (Moll et al., 2000) and adults (Richter et al., 2007). Additionally, GABAergic inhibition is also involved in anxiety disorders and other neurological diseases (Wong et al., 2003). 


\section{Dendritic inhibition}

Because SOM+ cells preferentially target distal dendrites (Leranth et al., 1990; Maccaferri et al., 2000), SOM+ cells mostly mediate dendritic inhibition. This begs the question why there is a need for a separate neuronal subsystem for dendritic inhibition. The following is an attempt to address this question.

There are a number of voltage-dependent conductances distributed in dendrites of neurons.

1) Hyperpolarization-activated cation channels $\left(\mathrm{I}_{\mathrm{h}}\right)$ expressed in layer 5 neocortical pyramidal dendrites in location-dependent manner generate a "leaky" apical dendrite, which can restrict AP propagation to distal dendrites (Goldberg et al., 2003) and influence the integration of spatially segregated synaptic inputs (Stuart and Spruston, 1998; Golding et al., 2005).

2) Dendritic $\mathrm{Ca}^{2+}$ transients are found in neocortical pyramidal cells (Schiller et al., 1997; Larkum et al., 1999a), spiny stellate cells (Nevian and Sakmann, 2004), neocortical interneurons (Kaiser et al., 2001, 2004; Goldberg et al., 2004), hippocampal pyramidal neurons (Spruston et al., 1995; Magee and Johnston, 1995; Magee et al., 1995; Golding et al., 1999), and hippocampal interneurons (Rozsa et al., 2004). In supragranular SOM+ bitufted interneurons, calcium triggers dendritic GABA release, which causes a retrograde depression in the excitation of presynaptic terminals (Zilberter et al., 1999), in turn facilitating the deinactivation of low threshold calcium channels (T-channels).

3) Dendritic potassium conductances include the transient A-type potassium current $\left(\mathrm{I}_{\mathrm{A}}\right)$ (Hoffman et al., 1997; Johnston et al., 2000), D-type potassium current (Golding et al., 1999; Metz et al., 2007) and calcium-dependent potassium current (Johnston et al., 2000). Density of the $I_{A}$ potassium conductance is higher in the distal apical dendrites in comparison with the soma and proximal dendrites of hippocampal pyramidal cells, which reduces the peak amplitude of back-propagating action potentials (Goldberg et al., 2003). 4) Dendritic sodium channels are also found in pyramidal cells and interneurons (Magee and Johnston, 1995; Jung et al., 1997; Golding and Spruston, 1998; Martina et al., 2000). The backpropagating $\mathrm{Na}+$-dependent APs provide a retrograde signal of a neuronal output to the dendritic tree (Stuart et al., 1997). 
Given the prevalent existence of dendritic conductances and their function, dendritic inhibition may be important in synaptic integration and may participate in preventing hyperexcitation of excitatory cells. For example, because excitatory inputs mostly target dendrites, dendritic inhibition can suppress excitatory inputs by shunting or hyperpolarizing the dendritic membrane, in turn, controlling the excitatory driving force to the cells. Also, because NMDA receptors are distributed in dendrites (Nevian and Sakmann, 2004) and their activation is dependent on removal of magnesium block by depolarizing the cell membrane, dendritic inhibition can suppress activation of NMDA receptors. Moreover, dendritic inhibition also regulates the intradendritic enhancement of cortical excitability. When a subthreshold distal EPSP coincides with a single backpropagating AP in layer 5 pyramidal cells, it can generate distal calcium APs in apical dendrites, and in turn bursts of axonal APs (Larkum et al., 1999b). Dendritic inhibitory terminals can selectively block the generation of calcium APs (Kim et al., 1995; Miles et al., 1996; Larkum et al., 1999b; Mann-Metzer and Yarom, 1999), thereby blocking such bursts of somatic APs.

\section{Electrical coupling / gap junctions}

In the nervous system, inter-neuronal communication can occur via indirect or direct transmission. The former is through chemical synapses, in which neurotransmitters are released into the extracellular space to subsequently bind to the postsynaptic cell membrane. The latter is mediated by electrical synapses whose structural substrate are gap junctions. Both electrical synapses and gap junctions are used interchangeably in following sections. Gap junctions were reported decades ago (Sloper, 1972), but the direct physiological evidence of functional electrical synapses in the adult cerebral cortex came only recently, with paired recordings from specific types of cells. To date, electrical synapses have been found, among other places, in the neocortex (Galarreta and Hestrin, 1999; Gibson et al., 1999), hippocampus (Draguhn et al., 1998; Bartos et al., 2001), thalamus (Landisman et al., 2002), cerebellum (Mann-Metzer and Yarom, 1999) and striatum (Koos and Tepper, 1999), mostly between GABAergic interneurons. Gap junctions permit the direct, intercellular, bidirectional transport of ions (thus electrical signals), metabolites, second messengers and other molecules smaller than about $1 \mathrm{kD}$ 
(Kandler and Katz, 1998). Gap junctions are formed by connexin proteins. Connexins are membrane-spanning proteins, six of which combine to form a hemichannel called connexon. Two connexons that span the apposing plasma membranes of two cells align to form intercellular channels (White and Paul, 1999). Out of more than 20 connexins found in the mouse and human genome, connexin36 (Cx36) is predominantly expressed in the nervous system, including the thalamus (Landisman et al., 2002), the hippocampus (Hormuzdi et al., 2001) and the neocortex (Deans et al., 2001), and is the most prominent connexin in GABAergic interneurons. Single channel conductance of Cx36 is $\sim 15 \mathrm{pS}$ and is only weakly voltage-sensitive (Srinivas et al., 1999; Teubner et al., 2000). However, the existence of other types of connexins such as Cx32 and Cx26 in the neocortex and hippocampus is also reported (Simburger et al., 1997; Venance et al., 2000; Hormuzdi et al., 2001). When injecting dye intracellularly to one cell of a pair of electrically coupled cells, different levels of dye diffusion show in the un-injected cell, suggesting differential Cx expression (Gibson et al., 1999; Mann-Metzer and Yarom, 1999). Recently, a new family of proteins mediating gap junctions, pannexins, has been reported in many neuronal cell populations (Bruzzone et al., 2003).

Electrical synapses behave as a low-pass filter, that is, the coupling coefficient decreases as a function of frequency of delivered signal (Galarreta and Hestrin, 1999; Gibson et al., 1999; Gibson et al., 2005). Higher frequency sine wave injection is accompanied with lower coupling efficacy (Galarreta and Hestrin, 1999). The low-frequency coupling coefficient (defined as the ratio between the steady state voltage deflection of the postjunctional cell and that of the prejunctional cell, when DC current is injected into one cell) is in the range of $0.3 \%-40 \%$, but mostly stays between $2.6 \%$ and $10 \%$, whereas, the coupling coefficient for spikes ranges from 0.5\%-2.5\% (Galarreta and Hestrin, 1999; Gibson et al., 1999; Tamas et al., 2000; Landisman et al., 2002). Electrical synapses exhibit bi-directional or reciprocal coupling, and coupling strength is roughly similar in both directions.

Dynamically, electrically coupled signals have a short latency. Presynaptic spikes transferred through gap junction typically consist of two components: a fast positive phase or "spikelet", which is generated by the prejunctional sodium spike, and a later, slower hyperpolarizing component reflecting the afterhyperpolarization (AHP). Relative 
to the peak of prejunctional spikes, latency to the peak of the postjunctional spikelet is $\sim 0.3 \mathrm{~ms}$; latency to the hyperpolarizing component is $4-10 \mathrm{~ms}$ (Galarreta and Hestrin, 1999, 2001; Tamas et al., 2000; Landisman et al., 2002). Owing to the short latency, action potentials in one cell could induce fast depolarization in the coupled cell, leading to submillisecond spike coordination, which is believed to inducing synchronization (Galarreta and Hestrin, 1999; Mann-Metzer and Yarom, 1999; Beierlein et al., 2000). Additionally, because the AHP is transferred more efficiently due to its lower frequency compared to sodium spikes (Chu et al., 2003), it could substantially time and shape the excitability of the postjunctional partner. The consequent net hyperpolarizing effect between electrically coupled neurons could have important functional implications (Galarreta and Hestrin, 2001).

Gap junctions in the neocortex mostly connect dendrites to dendrites, as well as dendrites to somata (Tamas et al., 2000; Fukuda and Kosaka, 2003). However, gap junctions between somata and somata (Sotelo and Llinas, 1972), or even axons and axons (Schmitz et al., 2001; Traub et al., 2001) have been reported or at least proposed. Gap junctions are localized both proximally (Tamas et al., 2000) and more distally (up to $230 \mu \mathrm{m}$ ) from the somata (Kosaka and Hama, 1985; Fukuda and Kosaka, 2003).

Gap junctions mostly connect same-class GABAergic interneurons, including FS, SOM (LTS), LS, MB, CB1-IS, neurogliaform cells, and RSNP cells (Galarreta and Hestrin, 1999; Gibson et al., 1999; Szabadics et al., 2001; Galarreta and Hestrin, 2002; Blatow et al., 2003; Chu et al., 2003; Fukuda and Kosaka, 2003; Galarreta et al., 2004; Simon et al., 2005). Even within the PV+ group, there are still two subnetworks (MB-MB, FS-FS) with electrical coupling within, not between networks (Blatow et al., 2003). Nevertheless, some studies showed significant interclass electrical coupling. For example, Simon et al. (2005) report that neurogliaform cells in layer $2 / 3$ of the somatosensory cortex establish heterologous electrical connections to basket cells, RSNP cells, an axo-axonic cell, and to various unclassified interneurons. Electrical connections between fusiform interneurons and spiny stellate (excitatory) cells have also been reported (Venance et al., 2000). Further study is required to elucidate the rules governing the selective establishment of electrical synapses. 


\section{Network activity in the neocortex}

Under certain physiological states or pathological conditions, network activities, such as synchronized oscillations, occur over wide areas of the cerebral cortex including the olfactory cortex, hippocampus and neocortex. The frequency of network oscillations covers more than three orders of magnitude, from slower oscillations in the delta (0.5$3 \mathrm{~Hz})$, theta $(3-8 \mathrm{~Hz})$, alpha $(8-12 \mathrm{~Hz})$, beta $(12-30 \mathrm{~Hz})$ to faster oscillation in the gamma $(30-90 \mathrm{~Hz})$ and ultrafast $(90-200 \mathrm{~Hz})$ range. Within this spectrum, gamma oscillations have received particular attention, because their relationship to higher function is most evident. They have been suggested to participate in information coding (Womelsdorf et al., 2006), sensory binding of features into a coherent percept (binding distributed information into a common representation) (Shadlen and Movshon, 1999; Singer, 1999), and storage and recall of information (Singer and Gray, 1995).

Spontaneous slow $(<1 \mathrm{~Hz})$ periodic synaptic network activity has been reported in cortical areas in vitro (Sanchez-Vives and McCormick, 2000; Shu et al., 2003a, 2003b) and in vivo (Steriade et al., 1993; Haider et al., 2006). The periodic oscillations consist of an "UP" state, characteristically with robust synaptic barrages, and a "DOWN" state, the relative quiescent phase. During these periodic network activities, activation of both excitatory and inhibitory conductances is observed (Steriade et al., 1993; Shu et al., 2003a, 2003b).

Intracortical circuitry is considered to be the structural substrate of network activities. Neocortical neurons are activated in identical and precise spatiotemporal patterns during spontaneous and thalamocortical triggered collective events, suggesting temporal modules of cortical activity (Ikegaya et al., 2004; MacLean et al., 2005). Optical probing studies also exhibited precisely organized cortical microcircuits (Kozloski et al., 2001). Other aspects of stereotyped cortical microcircuitry were also described (Silberberg et al., 2002). 
A variety of manipulations are used by investigators to induce network activity, including disinhibition (Castro-Alamancos and Rigas, 2002), cholinergic activation (Buhl et al., 1998; Fisahn et al., 1998), and mGluR activation (Whittington et al., 1995; Beierlein et al., 2000). There are four main underlying mechanisms for synchrony: 1) glutamatergicmediated synchronous activity (Fisahn et al., 2004); 2) GABAergic interneuron-mediated synchrony, through chemical synapses (Cobb et al., 1995), electrical synapses (Beierlein et al., 2000; Hormuzdi et al., 2001) or both (Tamas et al, 2000; Fuchs et al., 2007); 3) glutamatergic and GABAergic together (Fuchs et al., 2001); 4) autonomous collective activity, independent of glutamatergic and GABAergic transmission, but dependent on $\mathrm{I}_{\mathrm{h}}$ and persistent, sodium currents $\left(\mathrm{I}_{\mathrm{Na}, \mathrm{p}}\right)$ (Mao et al., 2001).

In my second project, I elicited network activity by applying $0 \mathrm{Mg}^{2+} \mathrm{ACSF}$ and examined the role of different types of interneurons in this activity. 
This page is intentionally blank. 


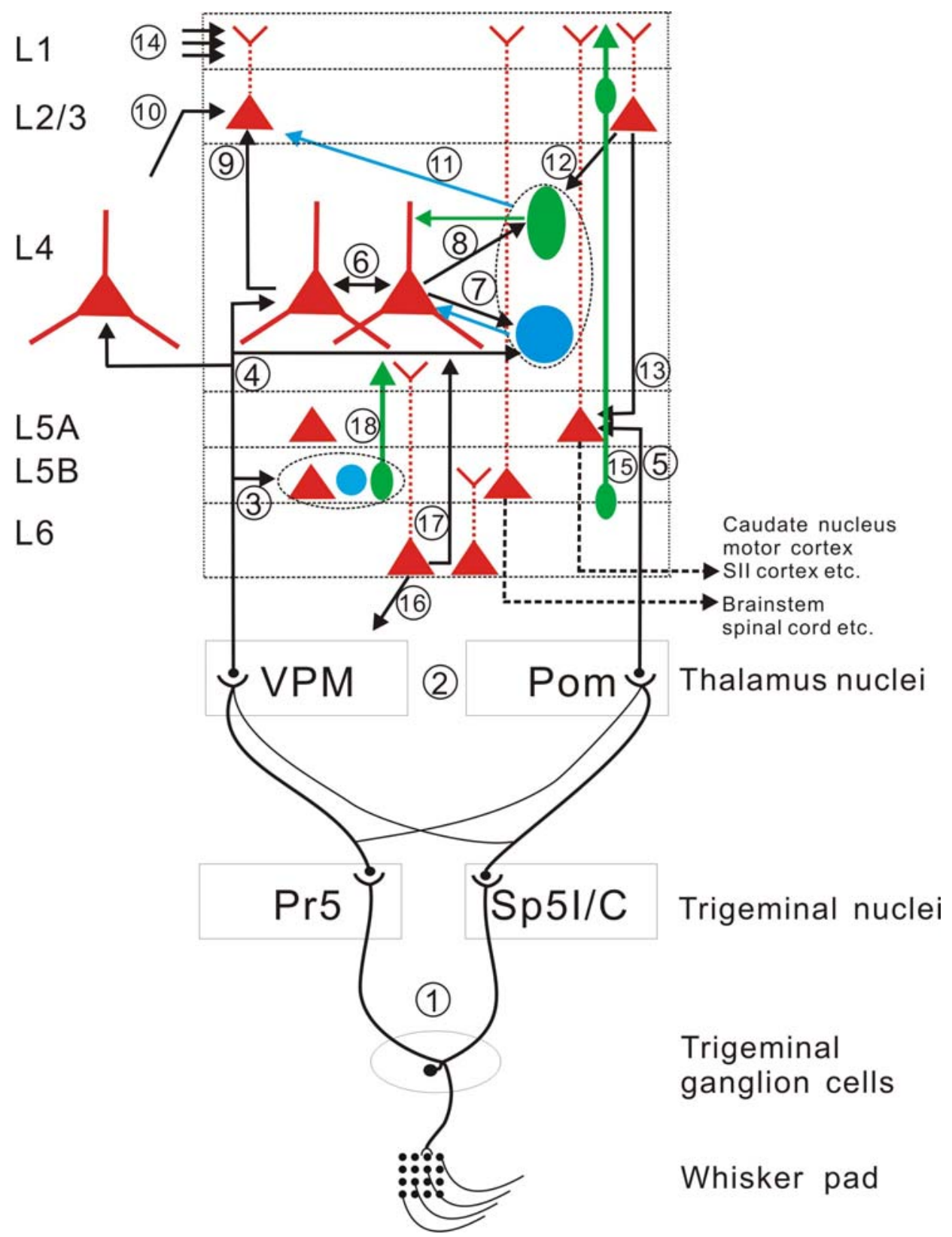

Fig. 1.1. Circuit diagram of the trigeminal pathway and the barrel cortex. Connections are labeled with Arabic numbers. Cells in red, green and blue are RS, SOM+ and FS cells, respectively, in different layers. Dashed red and black lines are apical dendrites / dendritic tufts of pyramidal cells and corticofugal axonal projections, respectively. 


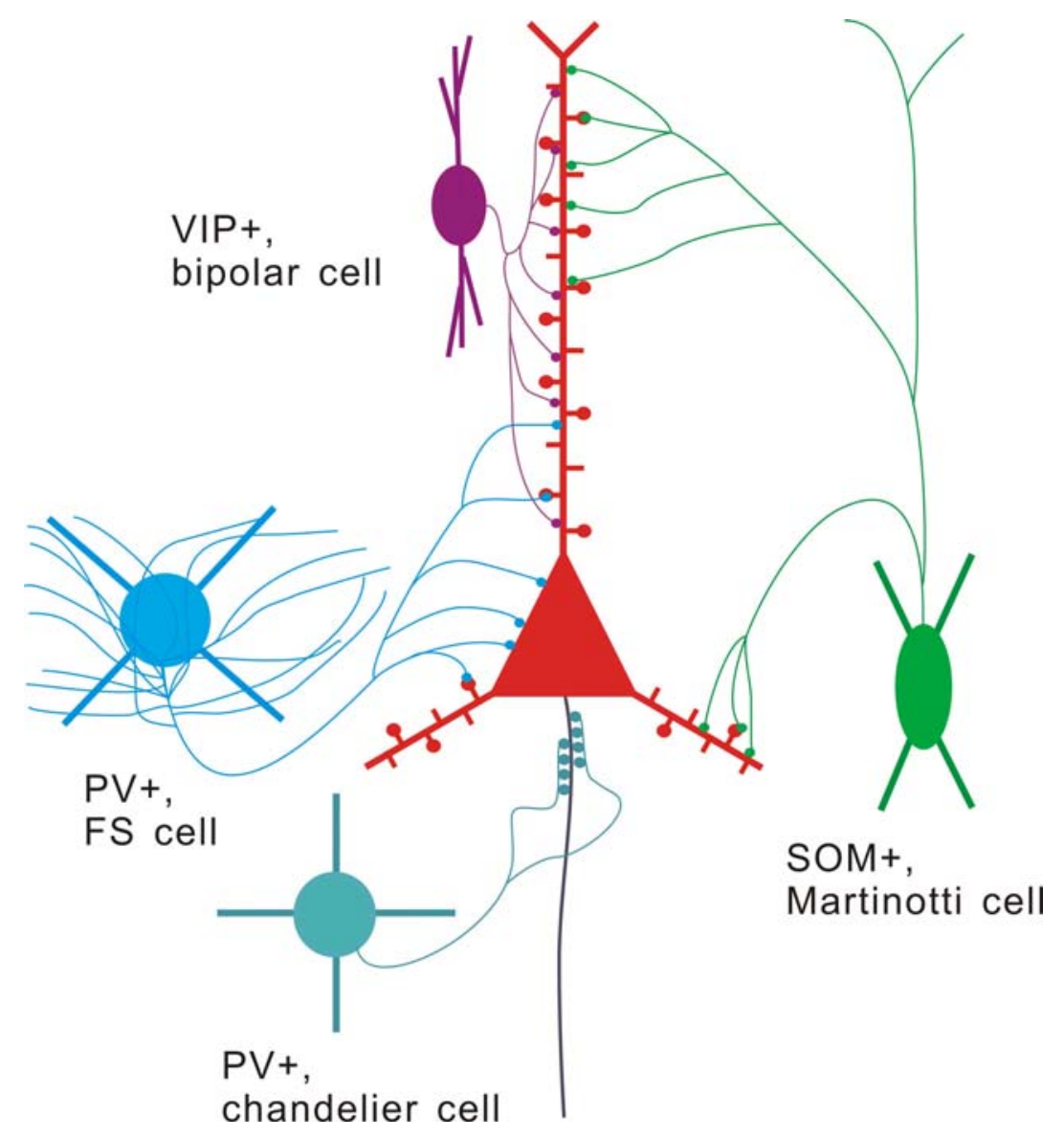

Fig. 1.2. Schematic representation of the three major interneuron subtypes and their preferred postsynaptic targets. Thick and thin lines from the somata indicate dendrites and axons, respectively. A representative pyramidal cell is in the center. 


\section{REFERENCES}

Agmon A, Connors BW (1992) Correlation between intrinsic firing patterns and thalamocortical synaptic responses of neurons in mouse barrel cortex. J Neurosci 12: 319-29.

Agmon A, Yang LT, O’Dowd DK, Jones EG (1993) Organized growth of thalamocortical axons from the deep tier of terminations into layer IV of developing mouse barrel cortex. J Neurosci 13: 5365-82.

Ahissar E, Sosnik R, Haidarliu S (2000) Transformation from temporal to rate coding in a somatosensory thalamocortical pathway. Nature 406: 302-6.

Amitai Y, Gibson JR, Beierlein M, Patrick SL, Ho AM, Connors BW, Golomb D (2002) The spatial dimensions of electrically coupled networks of interneurons in the neocortex. J Neurosci 22: 4142-52.

Bacci A, Huguenard JR, Prince DA (2004) Long-lasting self-inhibition of neocortical interneurons mediated by endocannabinoids. Nature 431: 312-6.

Bacci A, Rudolph U, Huguenard JR, Prince DA (2003) Major differences in inhibitory synaptic transmission onto two neocortical interneuron subclasses. J Neurosci 23: 966474.

Baimbridge KG, Celio MR, Rogers JH (1992) Calcium-binding proteins in the nervous system. Trends Neurosci 15: 303-8.

Baranauskas G, Tkatch T, Nagata K, Yeh JZ, Surmeier DJ (2003) Kv3.4 subunits enhance the repolarizing efficiency of Kv3.1 channels in fast-spiking neurons. Nat Neurosci 6: 258-66.

Bartos M, Vida I, Frotscher M, Geiger JR, Jonas P (2001) Rapid signaling at inhibitory synapses in a dentate gyrus interneuron network. J Neurosci 21: 2687-98.

Bartos M, Vida I, Frotscher M, Meyer A, Monyer H, Geiger JR, Jonas P (2002) Fast synaptic inhibition promotes synchronized gamma oscillations in hippocampal interneuron networks. PNAS 99: 13222-7.

Baulac S, Huberfeld G, Gourfinkel-An I, Mitropoulou G, Beranger A, Prud'homme JF, Baulac M, Brice A, Bruzzone R, LeGuern E (2001) First genetic evidence of GABA(A) receptor dysfunction in epilepsy: a mutation in the gamma2-subunit gene. Nat Genet 28: 46-8.

Beaulieu C (1993) Numerical data on neocortical neurons in adult rat, with special reference to the GABA population. Brain Res 609: 284-92. 
Beierlein M, Gibson JR, Connors BW (2000) A network of electrically coupled interneurons drives synchronized inhibition in neocortex. Nat Neurosci 3: 904-10.

Beierlein M, Gibson JR, Connors BW (2003) Two dynamically distinct inhibitory networks in layer 4 of the neocortex. J Neurophysiol 90: 2987-3000.

Bernardo KL, Woolsey TA (1987) Axonal trajectories between mouse somatosensory thalamus and cortex. J Comp Neurol 258: 542-64.

Blatow M, Rozov A, Katona I, Hormuzdi SG, Meyer AH, Whittington MA, Caputi A, Monyer H (2003) A novel network of multipolar bursting interneurons generates theta frequency oscillations in neocortex. Neuron 38: 805-17.

Bruzzone R, Hormuzdi SG, Barbe MT, Herb A, Monyer H (2003) Pannexins, a family of gap junction proteins expressed in brain. PNAS 100:1 3644-9.

Buhl EH, Han ZS, Lorinczi Z, Stezhka VV, Karnup SV, Somogyi P (1994) Physiological properties of anatomically identified axo-axonic cells in the rat hippocampus. J Neurophysiol 71: 1289-307.

Buhl EH, Tamas G, Fisahn A (1998) Cholinergic activation and tonic excitation induce persistent gamma oscillations in mouse somatosensory cortex in vitro. J Physiol 513: 117-26.

Bureau I, Shepherd GM, Svoboda K (2004) Precise development of functional and anatomical columns in the neocortex. Neuron 42: 789-801.

Buzsaki G, Penttonen M, Nadasdy Z, Bragin A (1996) Pattern and inhibition-dependent invasion of pyramidal cell dendrites by fast spikes in the hippocampus in vivo. PNAS 93: 9921-5.

Caillard O, Moreno H, Schwaller B, Llano I, Celio MR, Marty A (2000) Role of the calcium-binding protein parvalbumin in short-term synaptic plasticity. PNAS 97: 133727.

Castro-Alamancos MA, Rigas P (2002) Synchronized oscillations caused by disinhibition in rodent neocortex are generated by recurrent synaptic activity mediated by AMPA receptors. J Physiol 542: 567-81.

Cauli B, Audinat E, Lambolez B, Angulo MC, Ropert N, Tsuzuki K, Hestrin S, Rossier J (1997) Molecular and physiological diversity of cortical nonpyramidal cells. J Neurosci 17: 3894-906. 
Chard PS, Bleakman D, Christakos S, Fullmer CS, Miller RJ (1993) Calcium buffering properties of calbindin D28k and parvalbumin in rat sensory neurones. J Physiol 472: $341-57$.

Chattopadhyaya B, Di Cristo G, Higashiyama H, Knott GW, Kuhlman SJ, Welker E, Huang ZJ (2004) Experience and activity-dependent maturation of perisomatic GABAergic innervation in primary visual cortex during a postnatal critical period. J Neurosci 24: 9598-611.

Chow A, Erisir A, Farb C, Nadal MS, Ozaita A, Lau D, Welker E, Rudy B (1999) K(+) channel expression distinguishes subpopulations of parvalbumin- and somatostatincontaining neocortical interneurons. J Neurosci 19: 9332-45.

Chu Z, Galarreta M, Hestrin S (2003) Synaptic interactions of late-spiking neocortical neurons in layer 1. J Neurosci 23: 96-102.

Cobb SR, Buhl EH, Halasy K, Paulsen O, Somogyi P (1995) Synchronization of neuronal activity in hippocampus by individual GABAergic interneurons. Nature 378: 75-8.

Cowan AI, Stricker C (2004) Functional connectivity in layer IV local excitatory circuits of rat somatosensory cortex. J Neurophysiol 92: 2137-50.

Daw MI, Ashby MC, Isaac JT (2007) Coordinated developmental recruitment of latent fast spiking interneurons in layer IV barrel cortex. Nat Neurosci 10: 453-61.

Deans MR, Gibson JR, Sellitto C, Connors BW, Paul DL (2001) Synchronous activity of inhibitory networks in neocortex requires electrical synapses containing connexin36. Neuron 31: 477-85.

DeFelipe J, Hendry SH, Hashikawa T, Molinari M, Jones EG (1990) A microcolumnar structure of monkey cerebral cortex revealed by immunocytochemical studies of double bouquet cell axons. Neuroscience 37: 655-73.

Diamond ME, Armstrong-James M, Ebner FF (1992) Somatic sensory responses in the rostral sector of the posterior group (POm) and in the ventral posterior medial nucleus (VPM) of the rat thalamus. J Comp Neurol 318: 462-76.

Diamond ME (1995) Somatosensory thalamus of the rat. In: Jones EG, Diamond IT, editors. The barrel cortex of rodents. New York: Plenum Press. Pp. 189-219.

Douglas RJ, Koch C, Mahowald M, Martin KA, Suarez HH (1991) Recurrent excitation in neocortical circuits. Science 269: 981-5.

Draguhn A, Traub RD, Schmitz D, Jefferys JG (1998) Electrical coupling underlies highfrequency oscillations in the hippocampus in vitro. Nature 394: 189-92. 
Esclapez M, Trottier S (1989) Changes in GABA-immunoreactive cell density during motor focal epilepsy induced by cobalt in the rat. Exp Brain Res 76: 369-85.

Fairen A, DeFelipe J, Regidor J (1984) Nonpyramidal neurons: general account. In: Cerebral cortex, Vol 1, Cellular components of the cerebral cortex (Peters A, Jones EG, eds), pp 201-253. New York: Plenum.

Farrant M, Nusser Z (2005) Variations on an inhibitory theme: phasic and tonic activation of GABA(A) receptors. Nat Rev Neurosci 6: 215-29.

Farrar SJ, Whiting PJ, Bonnert TP, McKernan RM (1999) Stoichiometry of a ligandgated ion channel determined by fluorescence energy transfer. J Biol Chem 274: 10100-4.

Feldmeyer D, Egger V, Lubke J, Sakmann B (1999) Reliable synaptic connections between pairs of excitatory layer 4 neurones within a single 'barrel' of developing rat somatosensory cortex. J Physiol 521: 169-90.

Feldmeyer D, Lubke J, Silver RA, Sakmann B (2002) Synaptic connections between layer 4 spiny neurone-layer $2 / 3$ pyramidal cell pairs in juvenile rat barrel cortex: physiology and anatomy of interlaminar signalling within a cortical column. J Physiol 538: 803-22.

Ferezou I, Cauli B, Hill EL, Rossier J, Hamel E, Lambolez B (2002) 5-HT3 receptors mediate serotonergic fast synaptic excitation of neocortical vasoactive intestinal peptide/cholecystokinin interneurons. J Neurosci 22: 7389-97.

Fisahn A, Pike FG, Buhl EH, Paulsen O (1998) Cholinergic induction of network oscillations at $40 \mathrm{~Hz}$ in the hippocampus in vitro. Nature 394: 186-9.

Fisahn A, Contractor A, Traub RD, Buhl EH, Heinemann SF, McBain CJ (2004) Distinct roles for the kainate receptor subunits GluR5 and GluR6 in kainate-induced hippocampal gamma oscillations. J Neurosci 24: 9658-68.

Flames N, Marin O (2005) Developmental mechanisms underlying the generation of cortical interneuron diversity. Neuron 46: 377-81.

Fuchs EC, Doheny H, Faulkner H, Caputi A, Traub RD, Bibbig A, Kopell N, Whittington MA, Monyer H (2001) Genetically altered AMPA-type glutamate receptor kinetics in interneurons disrupt long-range synchrony of gamma oscillation. PNAS 98: 3571-6.

Fuchs EC, Zivkovic AR, Cunningham MO, Middleton S, Lebeau FE, Bannerman DM, Rozov A, Whittington MA, Traub RD, Rawlins JN, Monyer H (2007) Recruitment of parvalbumin-positive interneurons determines hippocampal function and associated behavior. Neuron 53: 591-604. 
Fukuda T, Kosaka T (2003) Ultrastructural study of gap junctions between dendrites of parvalbumin-containing GABAergic neurons in various neocortical areas of the adult rat. Neuroscience 120: 5-20.

Galarreta M, Erdelyi F, Szabo G, Hestrin S (2004) Electrical coupling among irregularspiking GABAergic interneurons expressing cannabinoid receptors. J Neurosci 24: 97708.

Galarreta M, Hestrin S (1999) A network of fast-spiking cells in the neocortex connected by electrical synapses. Nature 402: 72-5.

Galarreta M, Hestrin S (2002) Electrical and chemical synapses among parvalbumin fastspiking GABAergic interneurons in adult mouse neocortex. PNAS 99: 12438-12443.

Galarreta M, Hestrin S (2001) Spike transmission and synchrony detection in networks of GABAergic interneurons. Science 292: 2295-9.

Gibson JR, Beierlein M, Connors BW (2005) Functional properties of electrical synapses between inhibitory interneurons of neocortical layer 4. J Neurophysiol 93: 467-80.

Gibson JR, Beierlein M, Connors BW (1999) Two networks of electrically coupled inhibitory neurons in neocortex. Nature 402: 75-9.

Goldberg JH, Lacefield CO, Yuste R (2004) Global dendritic calcium spikes in mouse layer 5 low threshold spiking interneurones: implications for control of pyramidal cell bursting. J Physiol 558: 465-78.

Goldberg JH, Tamas G, Yuste R (2003) Ca2+ imaging of mouse neocortical interneurone dendrites: Ia-type $\mathrm{K}+$ channels control action potential backpropagation. J Physiol 551: 49-65.

Golding NL, Jung HY, Mickus T, Spruston N (1999) Dendritic calcium spike initiation and repolarization are controlled by distinct potassium channel subtypes in CA1 pyramidal neurons. J Neurosci 19: 8789-98.

Golding NL, Mickus TJ, Katz Y, Kath WL, Spruston N (2005) Factors mediating powerful voltage attenuation along CA1 pyramidal neuron dendrites. J Physiol 568: 6982.

Golding NL, Spruston N (1998) Dendritic sodium spikes are variable triggers of axonal action potentials in hippocampal CA1 pyramidal neurons. Neuron 21: 1189-200.

Gonchar Y, Burkhalter A (1997) Three distinct families of GABAergic neurons in rat visual cortex. Cereb Cortex 7: 347-58. 
Gulledge AT, Stuart GJ (2003) Excitatory actions of GABA in the cortex. Neuron 37: 299-309.

Gulyas AI, Hajos N, Freund TF (1996) Interneurons containing calretinin are specialized to control other interneurons in the rat hippocampus. J Neurosci 16: 3397-411.

Haeusler S, Maass W (2007) A statistical analysis of information-processing properties of lamina-specific cortical microcircuit models. Cereb Cortex 17: 149-62.

Haider B, Duque A, Hasenstaub AR, McCormick DA (2006) Neocortical network activity in vivo is generated through a dynamic balance of excitation and inhibition. $\mathrm{J}$ Neurosci 26: 4535-45.

Hendry SH, Jones EG, DeFelipe J, Schmechel D, Brandon C, Emson PC (1984) Neuropeptide-containing neurons of the cerebral cortex are also GABAergic. PNAS 81: 6526-30.

Hestrin S (1993) Different glutamate receptor channels mediate fast excitatory synaptic currents in inhibitory and excitatory cortical neurons. Neuron 11: 1083-91.

Hoffman DA, Magee JC, Colbert CM, Johnston D (1997) K+ channel regulation of signal propagation in dendrites of hippocampal pyramidal neurons. Nature 387: 869-75.

Hormuzdi SG, Pais I, LeBeau FE, Towers SK, Rozov A, Buhl EH, Whittington MA, Monyer H (2001) Impaired electrical signaling disrupts gamma frequency oscillations in connexin 36-deficient mice. Neuron 31: 487-95.

Hornung JP, Celio MR (1992) The selective innervation by serotoninergic axons of calbindin-containing interneurons in the neocortex and hippocampus of the marmoset. $\mathrm{J}$ Comp Neurol 320: 457-67.

Hussman JP (2001) Suppressed GABAergic inhibition as a common factor in suspected etiologies of autism. J Autism Dev Disord 31: 247-8.

Ikegaya Y, Aaron G, Cossart R, Aronov D, Lampl I, Ferster D, Yuste R (2004) Synfire chains and cortical songs: temporal modules of cortical activity. Science 304: 559-64.

Jefferys JG, Traub RD, Whittington MA (1996) Neuronal networks for induced '40 Hz' rhythms. Trends Neurosci 19: 202-8.

Jensen KF, Killackey HP (1987) Terminal arbors of axons projecting to the somatosensory cortex of the adult rat. I. The normal morphology of specific thalamocortical afferents. J Neurosci 7: 3529-43. 
Johnston D, Hoffman DA, Magee JC, Poolos NP, Watanabe S, Colbert CM, Migliore M (2000) Dendritic potassium channels in hippocampal pyramidal neurons. J Physiol 525: $75-81$.

Jung HY, Mickus T, Spruston N (1997) Prolonged sodium channel inactivation contributes to dendritic action potential attenuation in hippocampal pyramidal neurons. J Neurosci 17: 6639-46.

Kaiser KM, Lubke J, Zilberter Y, Sakmann B (2004) Postsynaptic calcium influx at single synaptic contacts between pyramidal neurons and bitufted interneurons in layer $2 / 3$ of rat neocortex is enhanced by backpropagating action potentials. J Neurosci 24: 131929.

Kaiser KM, Zilberter Y, Sakmann B (2001) Back-propagating action potentials mediate calcium signalling in dendrites of bitufted interneurons in layer $2 / 3$ of rat somatosensory cortex. J Physiol 535: 17-31.

Kandler K, Katz LC (1998) Coordination of neuronal activity in developing visual cortex by gap junction-mediated biochemical communication. J Neurosci 18: 1419-27.

Katona I, Sperlagh B, Sik A, Kafalvi A, Vizi ES, Mackie K, Freund TF (1999) Presynaptically located CB1 cannabinoid receptors regulate GABA release from axon terminals of specific hippocampal interneurons. J Neurosci 19: 4544-58.

Kawaguchi Y (1995) Physiological subgroups of nonpyramidal cells with specific morphological characteristics in layer II/III of rat frontal cortex. J Neurosci 15: 2638-55.

Kawaguchi Y, Kondo S (2002) Parvalbumin, somatostatin and cholecystokinin as chemical markers for specific GABAergic interneuron types in the rat frontal cortex. J Neurocytol 31:277-87.

Kawaguchi Y, Kubota Y (1997) GABAergic cell subtypes and their synaptic connections in rat frontal cortex. Cereb Cortex 7: 476-86.

Kawaguchi Y, Kubota Y (1996) Physiological and morphological identification of somatostatin- or vasoactive intestinal polypeptide-containing cells among GABAergic cell subtypes in rat frontal cortex. J Neurosci 16: 2701-15.

Kawaguchi Y, Shindou T (1998) Noradrenergic excitation and inhibition of GABAergic cell types in rat frontal cortex. J Neurosci 18: 6963-76.

Kim HG, Beierlein M, Connors BW (1995) Inhibitory control of excitable dendrites in neocortex. J Neurophysiol 74: 1810-4. 
Kim YI, Peacock WJ, Dudek FE (1993) Properties and synaptic mechanisms of bicuculline-induced epileptiform bursts in neocortical slices from children with intractable epilepsy. J Neurophysiol 70: 1759-66.

Kisvarday ZF, Beaulieu C, Eysel UT (1993) Network of GABAergic large basket cells in cat visual cortex (area 18): implication for lateral disinhibition. J Comp Neurol 327: 398415.

Kisvarday ZF, Ferecsko AS, Kovacs K, Buzas P, Budd JM, Eysel UT (2002) One axonmultiple functions: specificity of lateral inhibitory connections by large basket cells. J Neurocytol 31: 255-64.

Kisvarday ZF, Martin KA, Whitteridge D, Somogyi P (1985) Synaptic connections of intracellularly filled clutch cells: a type of small basket cell in the visual cortex of the cat. J Comp Neurol 241: 111-37.

Koos T, Tepper JM (1999) Inhibitory control of neostriatal projection neurons by GABAergic interneurons. Nat Neurosci 2: 467-72.

Kosaka T, Hama K (1985) Gap junctions between non-pyramidal cell dendrites in the rat hippocampus (CA1 and CA3 regions): a combined Golgi-electron microscopy study. J Comp Neurol 231: 150-61.

Kozloski J, Hamzei-Sichani F, Yuste R (2001) Stereotyped position of local synaptic targets in neocortex. Science 293: 868-72.

Kubota Y, Hattori R, Yui Y (1994) Three distinct subpopulations of GABAergic neurons in rat frontal agranular cortex. Brain Res 649: 159-73.

Landisman CE, Long MA, Beierlein M, Deans MR, Paul DL, Connors BW (2002) Electrical synapses in the thalamic reticular nucleus. J Neurosci 22: 1002-9.

Larkum ME, Kaiser KM, Sakmann B (1999a) Calcium electrogenesis in distal apical dendrites of layer 5 pyramidal cells at a critical frequency of back-propagating action potentials. PNAS 96: 14600-4.

Larkum ME, Zhu JJ, Sakmann B (1999b) A new cellular mechanism for coupling inputs arriving at different cortical layers. Nature 398: 338-41.

Le Be JV, Silberberg G, Wang Y, Markram H (2007) Morphological, electrophysiological, and synaptic properties of corticocallosal pyramidal cells in the neonatal rat neocortex. Cereb Cortex 17: 2204-13.

Lee SH, Schwaller B, Neher E (2000) Kinetics of Ca2+ binding to parvalbumin in bovine chromaffin cells: implications for $[\mathrm{Ca} 2+]$ transients of neuronal dendrites. J Physiol 525: 419-32. 
Leranth C, Malcolm AJ, Frotscher M (1990) Afferent and efferent synaptic connections of somatostatin-immunoreactive neurons in the rat fascia dentata. J Comp Neurol 295: 111-22.

Lewis DA, Pierri JN, Volk DW, Melchitzky DS, Woo TU (1999) Altered GABA neurotransmission and prefrontal cortical dysfunction in schizophrenia. Biol Psychiatry 46: 616-26.

Lopez-Bendito G, Sturgess K, Erdelyi F, Szabo G, Molnar Z, Paulsen O (2004) Preferential origin and layer destination of GAD65-GFP cortical interneurons. Cereb Cortex 14: 1122-33.

Lubke J, Egger V, Sakmann B, Feldmeyer D (2000) Columnar organization of dendrites and axons of single and synaptically coupled excitatory spiny neurons in layer 4 of the rat barrel cortex. J Neurosci 20: 5300-11.

Ma Y, Hu H, Berrebi AS, Mathers PH, Agmon A (2006) Distinct subtypes of somatostatin-containing neocortical interneurons revealed in transgenic mice. J Neurosci 26: 5069-82.

Maccaferri G, Roberts JD, Szucs P, Cottingham CA, Somogyi P (2000) Cell surface domain specific postsynaptic currents evoked by identified GABAergic neurones in rat hippocampus in vitro. J Physiol 524: 91-116.

MacLean JN, Watson BO, Aaron GB, Yuste R (2005) Internal dynamics determine the cortical response to thalamic stimulation. Neuron 48: 811-23.

Magee JC, Christofi G, Miyakawa H, Christie B, Lasser-Ross N, Johnston D (1995) Subthreshold synaptic activation of voltage-gated $\mathrm{Ca} 2+$ channels mediates a localized $\mathrm{Ca} 2+$ influx into the dendrites of hippocampal pyramidal neurons. J Neurophysiol 74: 1335-42.

Magee JC, Johnston D (1995) Synaptic activation of voltage-gated channels in the dendrites of hippocampal pyramidal neurons. Science 268: 301-4.

Mann-Metzer P, Yarom Y (1999) Electrotonic coupling interacts with intrinsic properties to generate synchronized activity in cerebellar networks of inhibitory interneurons. $\mathrm{J}$ Neurosci 19: 3298-306.

Mao BQ, Hamzei-Sichani F, Aronov D, Froemke RC, Yuste R (2001) Dynamics of spontaneous activity in neocortical slices. Neuron 32: 883-98.

Markram H, Toledo-Rodriguez M, Wang Y, Gupta A, Silberberg G, Wu C (2004) Interneurons of the neocortical inhibitory system. Nat Rev Neurosci 5: 793-807. 
Marsicano G, Lutz B (1999) Expression of the cannabinoid receptor CB1 in distinct neuronal subpopulations in the adult mouse forebrain. Eur J Neurosci 11: 4213-25.

Martina M, Vida I, Jonas P (2000) Distal initiation and active propagation of action potentials in interneuron dendrites. Science 287: 295-300.

Mason A, Larkman A (1990) Correlations between morphology and electrophysiology of pyramidal neurons in slices of rat visual cortex. II. Electrophysiology. J Neurosci 10: 1415-28.

McBain CJ, Fisahn A (2001) Interneurons unbound. Nat Rev Neurosci 2: 11-23.

McCormick DA, Connors BW, Lighthall JW, Prince DA (1985) Comparative electrophysiology of pyramidal and sparsely spiny stellate neurons of the neocortex. $\mathrm{J}$ Neurophysiol 54: 782-806.

McKernan RM, Whiting PJ (1996) Which GABAA-receptor subtypes really occur in the brain? Trends Neurosci 19: 139-43.

Meskenaite V (1997) Calretinin-immunoreactive local circuit neurons in area 17 of the cynomolgus monkey, Macaca fascicularis. J Comp Neurol 379: 113-32.

Metz AE, Spruston N, Martina M (2007) Dendritic D-type potassium currents inhibit the spike afterdepolarization in rat hippocampal CA1 pyramidal neurons. J Physiol 581: 17587.

Miles R, Toth K, Gulyas AI, Hajos N, Freund TF (1996) Differences between somatic and dendritic inhibition in the hippocampus. Neuron 16: 815-23.

Moll GH, Heinrich H, Trott G, Wirth S, Rothenberger A (2000) Deficient intracortical inhibition in drug-naive children with attention-deficit hyperactivity disorder is enhanced by methylphenidate. Neurosci Lett 284: 121-5.

Morales M, Bloom FE (1997) The 5-HT3 receptor is present in different subpopulations of GABAergic neurons in the rat telencephalon. J Neurosci 17: 3157-67.

Nevian T, Sakmann B (2004) Single spine Ca2+ signals evoked by coincident EPSPs and backpropagating action potentials in spiny stellate cells of layer 4 in the juvenile rat somatosensory barrel cortex. J Neurosci 24: 1689-99.

Ohliger-Frerking P, Wiebe SP, Staubli U, Frerking M (2003) GABA(B) receptormediated presynaptic inhibition has history-dependent effects on synaptic transmission during physiologically relevant spike trains. J Neurosci 23: 4809-14. 
Oliva AA Jr, Jiang M, Lam T, Smith KL, Swann JW (2000) Novel hippocampal interneuronal subtypes identified using transgenic mice that express green fluorescent protein in GABAergic interneurons. J Neurosci 20: 3354-68.

Peters A (1990) The axon terminals of vasoactive intestinal polypeptide (VIP)-containing bipolar cells in rat visual cortex. J Neurocytol 19: 672-85.

Petersen CC, Sakmann B (2001) Functionally independent columns of rat somatosensory barrel cortex revealed with voltage-sensitive dye imaging. J Neurosci 21: 8435-46.

Porter JT, Cauli B, Staiger JF, Lambolez B, Rossier J, Audinat E (1998) Properties of bipolar VIPergic interneurons and their excitation by pyramidal neurons in the rat neocortex. Eur J Neurosci 10: 3617-28.

Porter JT, Cauli B, Tsuzuki K, Lambolez B, Rossier J, Audinat E (1999) Selective excitation of subtypes of neocortical interneurons by nicotinic receptors. J Neurosci 19: 5228-35.

Porter JT, Johnson CK, Agmon A (2001) Diverse types of interneurons generate thalamus-evoked feedforward inhibition in the mouse barrel cortex. J Neurosci 21: 2699710 .

Pouille F, Scanziani M (2001) Enforcement of temporal fidelity in pyramidal cells by somatic feed-forward inhibition. Science 293: 1159-63.

Pouille F, Scanziani M (2004) Routing of spike series by dynamic circuits in the hippocampus. Nature 429: 717-23.

Ren JQ, Aika Y, Heizmann CW, Kosaka T (1992) Quantitative analysis of neurons and glial cells in the rat somatosensory cortex, with special reference to GABAergic neurons and parvalbumin-containing neurons. Exp Brain Res 92: 1-14.

Ribak CE, Harris AB, Vaughn JE, Roberts E (1979) Inhibitory, GABAergic nerve terminals decrease at sites of focal epilepsy. Science 205: 211-4.

Richter MM, Ehlis AC, Jacob CP, Fallgatter AJ (2007) Cortical excitability in adult patients with attention-deficit/hyperactivity disorder (ADHD). Neurosci Lett 419: 137-41.

Rozov A, Jerecic J, Sakmann B, Burnashev N (2001) AMPA receptor channels with long-lasting desensitization in bipolar interneurons contribute to synaptic depression in a novel feedback circuit in layer 2/3 of rat neocortex. J Neurosci 21: 8062-71.

Rozsa B, Zelles T, Vizi ES, Lendvai B (2004) Distance-dependent scaling of calcium transients evoked by backpropagating spikes and synaptic activity in dendrites of hippocampal interneurons. J Neurosci 24: 661-70. 
Rudy B, McBain CJ (2001) Kv3 channels: voltage-gated K+ channels designed for highfrequency repetitive firing. Trends Neurosci 24: 517-26.

Sanchez-Vives MV, McCormick DA (2000) Cellular and network mechanisms of rhythmic recurrent activity in neocortex. Nat Neurosci 3: 1027-34.

Schiller J, Schiller Y, Stuart G, Sakmann B (1997) Calcium action potentials restricted to distal apical dendrites of rat neocortical pyramidal neurons. J Physiol 505: 605-16.

Schmitz D, Schuchmann S, Fisahn A, Draguhn A, Buhl EH, Petrasch-Parwez E, Dermietzel R, Heinemann U, Traub RD (2001) Axo-axonal coupling. A novel mechanism for ultrafast neuronal communication. Neuron 31: 831-40.

Semyanov A, Walker MC, Kullmann DM, Silver RA (2004) Tonically active GABA A receptors: modulating gain and maintaining the tone. Trends Neurosci 27: 262-9.

Shadlen MN, Movshon JA (1999) Synchrony unbound: a critical evaluation of the temporal binding hypothesis. Neuron 24: 67-77.

Shepherd GM, Svoboda K (2005) Laminar and columnar organization of ascending excitatory projections to layer $2 / 3$ pyramidal neurons in rat barrel cortex. J Neurosci 25 : $5670-9$.

Shu Y, Hasenstaub A, Badoual M, Bal T, McCormick DA (2003a) Barrages of synaptic activity control the gain and sensitivity of cortical neurons. J Neurosci 23: 10388-401.

Shu Y, Hasenstaub A, McCormick DA (2003b) Turning on and off recurrent balanced cortical activity. Nature 423: 288-93.

Silberberg G, Gupta A, Markram H (2002) Stereotypy in neocortical microcircuits. Trends Neurosci 25: 227-30.

Silberberg G, Markram H (2007) Disynaptic inhibition between neocortical pyramidal cells mediated by Martinotti cells. Neuron 53: 735-46.

Simburger E, Stang A, Kremer M, Dermietzel R (1997) Expression of connexin43 mRNA in adult rodent brain. Histochem Cell Biol 107: 127-37.

Simon A, Olah S, Molnar G, Szabadics J, Tamas G (2005) Gap-junctional coupling between neurogliaform cells and various interneuron types in the neocortex. J Neurosci 25: 6278-85.

Singer W (1999) Time as coding space? Curr Opin Neurobiol 9: 189-94.

Singer W, Gray CM (1995) Visual feature integration and the temporal correlation hypothesis. Annu Rev Neurosci 18: 555-86. 
Sloper JJ (1972) Gap junctions between dendrites in the primate neocortex. Brain Res 44 : 641-6.

Soltesz I (2005) Diversity in the neuronal machine. New York: Oxford UP.

Somogyi P, Freund TF, Cowey A (1982) The axo-axonic interneuron in the cerebral cortex of the rat, cat and monkey. Neuroscience 7: 2577-607.

Sotelo C, Llinas R (1972) Specialized membrane junctions between neurons in the vertebrate cerebellar cortex. J Cell Biol 53: 271-89.

Srinivas M, Rozental R, Kojima T, Dermietzel R, Mehler M, Condorelli DF, Kessler JA, Spray DC (1999) Functional properties of channels formed by the neuronal gap junction protein connexin36. J Neurosci 19: 9848-55.

Spruston N, Schiller Y, Stuart G, Sakmann B (1995) Activity-dependent action potential invasion and calcium influx into hippocampal CA1 dendrites. Science 268: 297-300.

Steriade M, Nunez A, Amzica F (1993) A novel slow ( $<1 \mathrm{~Hz})$ oscillation of neocortical neurons in vivo: depolarizing and hyperpolarizing components. J Neurosci 13: 3252-65.

Stinehelfer S, Vruwink M, Burette A (2000) Immunolocalization of mGluR1alpha in specific populations of local circuit neurons in the cerebral cortex. Brain Res 861: 37-44.

Stuart G, Spruston N (1998) Determinants of voltage attenuation in neocortical pyramidal neuron dendrites. J Neurosci 18: 3501-10.

Stuart G, Spruston N, Sakmann B, Hausser M (1997) Action potential initiation and backpropagation in neurons of the mammalian CNS. Trends Neurosci 20: 125-31.

Szabadics J, Lorincz A, Tamas G (2001) Beta and gamma frequency synchronization by dendritic gabaergic synapses and gap junctions in a network of cortical interneurons. J Neurosci 21: 5824-31.

Tamas G, Buhl EH, Lorincz A, Somogyi P (2000) Proximally targeted GABAergic synapses and gap junctions synchronize cortical interneurons. Nat Neurosci 3: 366-71.

Tamas G, Lorincz A, Simon A, Szabadics J (2003) Identified sources and targets of slow inhibition in the neocortex. Science 299: 1902-5.

Tan Z, Hu H, Huang ZJ, Agmon A (in press) Robust but Delayed Thalamocortical Activation of Dendritic-Targeting Inhibitory Interneurons. PNAS.

Teubner B, Degen J, Sohl G, Guldenagel M, Bukauskas FF, Trexler EB, Verselis VK, De Zeeuw CI, Lee CG, Kozak CA, Petrasch-Parwez E, Dermietzel R, Willecke K (2000) 
Functional expression of the murine connexin 36 gene coding for a neuron-specific gap junctional protein. J Membr Biol 176: 249-62.

Thomson AM, Bannister AP (2003) Interlaminar connections in the neocortex. Cereb Cortex 13: 5-14.

Thomson AM, Bannister AP, Mercer A, Morris OT (2002a) Target and temporal pattern selection at neocortical synapses. Philos Trans R Soc Lond B Biol Sci 357: 1781-91.

Thomson AM, Deuchars J (1997) Synaptic interactions in neocortical local circuits: dual intracellular recording in vitro. Cereb Cortx 7: 510-22.

Thomson AM, West DC, Wang Y, Bannister AP (2002b) Synaptic connections and small circuits involving excitatory and inhibitory neurons in layers 2-5 of adult rat and cat neocortex: triple intracellular recordings and biocytin labelling in vitro. Cereb Cortex 12: 936-53.

Toledo-Rodriguez M, Blumenfeld B, Wu C, Luo J, Attali B, Goodman P, Markram H (2004) Correlation maps allow neuronal electrical properties to be predicted from singlecell gene expression profiles in rat neocortex. Cereb Cortex 14: 1310-27.

Toledo-Rodriguez M, Goodman P, Illic M, Wu C, Markram H (2005) Neuropeptide and calcium-binding protein gene expression profiles predict neuronal anatomical type in the juvenile rat. J Physiol 567: 401-13.

Traub RD, Bibbig R, Piechotta A, Draguhn R, Schmitz D (2001) Synaptic and nonsynaptic contributions to giant ipsps and ectopic spikes induced by 4-aminopyridine in the hippocampus in vitro. J Neurophysiol 85: 1246-56.

Tsou K, Brown S, Sanudo-Pena MC, Mackie K, Walker JM (1998) Immunohistochemical distribution of cannabinoid CB1 receptors in the rat central nervous system. Neuroscience 83: 393-411.

Tsubokawa H, Ross WN (1996) IPSPs modulate spike backpropagation and associated $[\mathrm{Ca} 2+] \mathrm{i}$ changes in the dendrites of hippocampal CA1 pyramidal neurons. J Neurophysiol 76: 2896-906.

Ulrich D (2003) Differential arithmetic of shunting inhibition for voltage and spike rate in neocortical pyramidal cells. Eur J Neurosci 18: 2159-65.

Van der Loos H (1976) Barreloids in mouse somatosensory thalamus. Neuroscience Letters 2: 1-6.

Venance L, Rozov A, Blatow M, Burnashev N, Feldmeyer D, Monyer H (2000) Connexin expression in electrically coupled postnatal rat brain neurons. PNAS 97: 10260-5. 
Vida I, Halasy K, Szinyei C, Somogyi P, Buhl EH (1998) Unitary IPSPs evoked by interneurons at the stratum radiatum-stratum lacunosum-moleculare border in the CA1 area of the rat hippocampus in vitro. J Physiol 506: 755-73.

Vidal C, Zieglgansberger W (1989) Actions of Somatostatin on Rat Neocortical Neurons in vitro. Eur J Neurosci 1: 489-493.

Wahle P (1993) Differential regulation of substance P and somatostatin in Martinotti cells of the developing cat visual cortex. J Comp Neurol 329: 519-38.

Wang Y, Gupta A, Toledo-Rodriguez M, Wu CZ, Markram H (2002) Anatomical, physiological, molecular and circuit properties of nest basket cells in the developing somatosensory cortex. Cereb Cortex 12: 395-410.

Wang Y, Markram H, Goodman PH, Berger TK, Ma J, Goldman-Rakic PS (2006) Heterogeneity in the pyramidal network of the medial prefrontal cortex. Nat Neurosci 9: 534-42.

Wang Y, Toledo-Rodriguez M, Gupta A, Wu C, Silberberg G, Luo J, Markram H (2004) Anatomical, physiological and molecular properties of Martinotti cells in the somatosensory cortex of the juvenile rat. J Physiol 561: 65-90.

Watts J, Thomson AM (2005) Excitatory and inhibitory connections show selectivity in the neocortex. J Physiol 562: 89-97.

Wells JE, Porter JT, Agmon A (2000) GABAergic inhibition suppresses paroxysmal network activity in the neonatal rodent hippocampus and neocortex. J Neurosci 20: 882230 .

White TW, Paul DL (1999) Genetic diseases and gene knockouts reveal diverse connexin functions. Annu Rev Physiol 61: 283-310.

Whittington MA, Traub RD, Jefferys JG (1995) Synchronized oscillations in interneuron networks driven by metabotropic glutamate receptor activation. Nature 373: 612-5.

Wirth C, Luscher HR (2004) Spatiotemporal evolution of excitation and inhibition in the rat barrel cortex investigated with multielectrode arrays. J Neurophysiol 91: 1635-47.

Wisden W, Laurie DJ, Monyer H, Seeburg PH (1992) The distribution of 13 GABAA receptor subunit mRNAs in the rat brain. I. Telencephalon, diencephalon, mesencephalon. J Neurosci 12: 1040-62.

Womelsdorf T, Fries P, Mitra PP, Desimone R (2006) Gamma-band synchronization in visual cortex predicts speed of change detection. Nature 439: 733-6. 
Wonders CP, Anderson SA (2006) The origin and specification of cortical interneurons. Nat Rev Neurosci 7: 687-96.

Wong CG, Bottiglieri T, Snead OC $3^{\text {rd }}$ (2003) GABA, gamma-hydroxybutyric acid, and neurological disease. Ann Neurol 54 Suppl 6: S3-12.

Woolsey TA, Van der Loos H (1970) The structural organization of layer IV in the somatosensory region (SI) of mouse cerebral cortex. The description of a cortical field composed of discrete cytoarchitectonic units. Brain Res 17: 205-42.

Zhang ZW, Deschenes M (1998) Projections to layer VI of the posteromedial barrel field in the rat: a reappraisal of the role of corticothalamic pathway. Cereb Cortex 8: 428-36.

Zhu Y, Stornetta RL, Zhu JJ (2004) Chandelier cells control excessive cortical excitation: characteristics of whisker-evoked synaptic responses of layer $2 / 3$ nonpyramidal and pyramidal neurons. J Neurosci 24: 5101-8.

Zeki S, Shipp S (1988) The functional logic of cortical connections. Nature 353: 311-17.

Zilberter Y, Kaiser KM, Sakmann B (1999) Dendritic GABA release depresses excitatory transmission between layer $2 / 3$ pyramidal and bitufted neurons in rat neocortex. Neuron 24: $979-88$. 


\section{Chapter Two}

\section{Distinct Subtypes of Somatostatin-Containing Neocortical Interneurons Revealed in Transgenic Mice}

This chapter is identical to a manuscript, published in the Journal of Neuroscience 26: 5069-5082 (2006).

In this project, I performed all the electrophysiological experiments, histochemical reactions, most of the computerized morphological reconstructions and the analysis of cellular properties. Dr. Hang $\mathrm{Hu}$ conducted the immunocytochemical experiments, confocal imaging, cell counts and some of the morphological reconstructions. Dr. Albert Berrebi helped with immunocytochemical staining and cell counts. Dr. Peter Mathers made the GAD67-GFP construct used to generate the transgenic mice. Dr. Ariel Agmon conducted the multivariate statistical analysis and most of the manuscript writing. 


\begin{abstract}
GABA-releasing inhibitory interneurons in the cerebral cortex can be classified by their neurochemical content, firing patterns, or axonal targets, to name the most common criteria, but whether classifications using different criteria converge on the same neuronal subtypes, and how many such subtypes exist, is a matter of much current interest and considerable debate. To address these issues, we generated transgenic mice expressing green fluorescent protein (GFP) under control of the GAD67 promoter. In two of these lines, named X94 and X98, GFP expression in the barrel cortex was restricted to subsets of somatostatin-containing (SOM+) GABAergic interneurons, similarly to the previously reported "GIN" line (Oliva et al., 2000), but the laminar distributions of GFP-expressing $(\mathrm{GFP}+)$ cell bodies in the X94, X98 and GIN lines were distinct and nearly complementary. We compared neurochemical content and axonal distribution patterns of GFP+ neurons between the three lines, and analyzed in detail electrophysiological properties in a dataset of 150 neurons recorded in whole-cell, current clamp mode. By all criteria, there was nearly perfect segregation of X94 and X98 GFP+ neurons, while GIN GFP+ neurons exhibited intermediate properties. In the X98 line, GFP expression was found in infragranular, calbindin-containing, layer 1-targeting ("Martinotti") cells that had a propensity to fire low-threshold calcium spikes, while X94 GFP+ cells were stuttering interneurons with quasi fast-spiking properties, residing in and targeting the thalamo-recipient neocortical layers. We conclude that much of the variability previously attributed to neocortical SOM+ interneurons can be accounted for by their natural grouping into distinct subtypes.
\end{abstract}




\section{INTRODUCTION}

Inhibitory, GABA-releasing interneurons are a minority of all cortical neurons, but are crucially important for damping cortical excitability, imposing temporal precision on cortical firing, enhancing the saliency of sensory inputs and promoting long-range synchrony (McBain and Fisahn, 2001; Whittington and Traub, 2003). Moreover, abnormalities in GABAergic neurons are implicated as a major factor in brain disorders ranging from epilepsy to autism and schizophrenia (DeFelipe, 1999; Levitt et al., 2004; Lewis et al., 2005). Such diverse functions are unlikely to be carried out by a homogeneous population of neurons. Indeed, as studies during the last two decades have amply revealed, cortical interneurons display highly diverse anatomical, electrophysiological and molecular properties (Freund and Buzsaki, 1996; Kawaguchi and Kubota, 1997; Markram et al., 2004). Electrophysiologically, interneurons can be described by their firing patterns as fast-spiking (FS), regular-spiking non-pyramidal (RSNP), low-threshold spiking (LTS), irregular spiking (IS), or stuttering. Based on their axonal targets, soma-preferring (basket), axon-preferring (chandelier) or dendritepreferring interneurons are recognized. Neurochemically, interneurons may express either parvalbumin (PV), somatostatin (SOM), cholecystokinin (CCK) or calretinin (CR). Unfortunately, classification schemes based on any individual criterion do not correlate with each other in a simple way, and different categories of properties appear at times to vary independently, leading some researchers to conclude that the number of potential GABAergic subtypes is very high (Gupta et al., 2000), or even that each interneuron is unique (Mott et al., 1997; Parra et al., 1998). This lack of consensus on the classification - indeed, the classifiability - of interneurons has greatly hindered progress on deciphering their role in cortical circuitry (Yuste, 2005).

At the heart of the problem is the uncertainty in identifying the same subsets of neurons in different studies using different techniques. Recently, transgenic mice have been generated in which specific subsets of interneurons belonging to a single neurochemical class express GFP (Oliva et al., 2000; Meyer et al., 2002; Chattopadhyaya et al., 2004). In a few cases, their detailed analysis revealed novel subtypes within this class. A good 
example is the $\mathrm{PV}+$ subset, which is probably the best studied neurochemical class of interneurons: initially all $\mathrm{PV}+$ interneurons were considered fast spiking, but studies using transgenic mice revealed a novel electrophysiological phenotype of bursting PV+ cells (Meyer et al., 2002).

Neocortical $\mathrm{SOM}+$ interneurons appear considerably more variable than $\mathrm{PV}+$ interneurons in their neurochemical, morphological and electrophysiological phenotypes (Kawaguchi and Shindou, 1998; Wang et al., 2004), but so far no distinct SOM+ subtypes have been described based on a combination of multiple criteria. To use a recently proposed nomenclature, (Soltesz, 2005), it is not known whether SOM+ interneuron heterogeneity reflects variability (within-group differences) or diversity (the existence of multiple subtypes). Here we used novel lines of transgenic mice, with GFPtagged $\mathrm{SOM}+$ interneurons, to show that neocortical $\mathrm{SOM}+$ interneurons belong to (at least) two morphologically, neurochemically and electrophysiologically distinct "species", suggesting that $\mathrm{SOM}+$ interneurons may be less variable, but more diverse, than previously recognized. 


\section{MATERIALS AND METHODS}

\section{Generation of GAD67-GFP transgenic mice}

The DNA construct used for pronuclear injection was derived from our previously described GAD67-GFP vector (Jin et al., 2001; Jin et al., 2003). The vector contained $10.3 \mathrm{~kb}$ of the mouse GAD67 promoter (Szabo et al., 1996; Katarova et al., 1998), including exon 1, intron 1, and a small portion of exon 2, fused in frame at the BamHI site to the enhanced GFP (EGFP) coding region in the pEGFP-1 vector (Clontech, Palo Alto, CA). In order to isolate the fragment for injection using the upstream HindIII site and an AfIII site present in the pEGFP-1 vector, we first removed the AflII site present in the GAD67 promoter by end-filling and re-ligating the plasmid. The linearized fragment was injected into fertilized C57BL/6 x SJL hybrid eggs under contract with DNX (now Xenogen Biosciences, Cranbury, NJ). Out of 11 founder animals positive by PCR, five lines were found to express GFP in the brain, and maintained as hemizygotes by breeding transgenic males with wildtype CD-1 females. Weaned pups were genotyped with GFP primers using standard tail biopsy protocols. GIN mice (strain FVB$\operatorname{Tg}(\mathrm{GadGFP}) 45704 \mathrm{Swn} / \mathrm{J})$ were purchased from Jackson Labs (Bar Harbor, Me); to breed pups for electrophysiological experiments, homozygous GIN males were mated with wildtype CD-1 females.

\section{Immunohistochemistry}

For visualization of GFP+ neurons, adult mice (2-3 months old) were deeply anesthetized with $4 \%$ chloral hydrate $(0.02 \mathrm{ml} / \mathrm{g}$ i.p.) and perfused through the ascending aorta with 10 $\mathrm{ml}$ of saline, followed by $35 \mathrm{ml}$ of $4 \%$ paraformaldehyde in $0.12 \mathrm{M}$ sodium phosphate

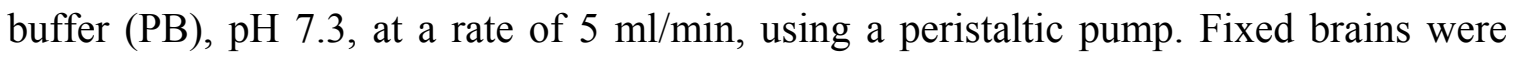
dissected and post-fixed for $4 \mathrm{hrs}$ at $4^{\circ} \mathrm{C}$, then placed overnight in $30 \%$ sucrose in $0.075 \mathrm{M}$ PB at $4^{\circ} \mathrm{C}$ for cryoprotection. Equilibrated brains were sectioned on a freezing microtome (Micron) into $40 \mu \mathrm{m}$ thick sections, in either coronal or parasagittal planes, and sections rinsed three times in $0.5 \mathrm{M}$ Tris buffer (Tris), $\mathrm{pH} 7.6$, at room temperature. To quench endogenous peroxidases, sections were washed for $20 \mathrm{~min}$ in $3 \% \mathrm{H}_{2} \mathrm{O}_{2}$ in 10\% Methanol (Sigma), then rinsed three times in Tris and transferred into blocking 
solution ( $5 \%$ normal goat serum (NGS) $+0.5 \%$ Triton-X100 (TX) in Tris). Sections were transferred directly from blocking solution into diluted primary antibody (1:1000 rabbit anti-GFP, Molecular Probes) in vehicle ( $1 \%$ NGS $+0.1 \%$ TX in Tris), and gently agitated for $36 \mathrm{hrs}$ at $4^{\circ} \mathrm{C}$. After three rinses in Tris, sections were transferred into diluted secondary antibody (1:200 biotinylated goat anti rabbit, Vector) in vehicle, and rotated for $2 \mathrm{hrs}$ at room temperature. After three washes in Tris, sections were incubated in $\mathrm{ABC}$ solution (Vector) for $1 \mathrm{hr}$ at room temperature, rinsed three times in Tris, and placed for 3-5 min into 0.05\% 3,3'-diaminobenzidine tetrahydrochloride (DAB, Aldrich) with $0.01 \% \mathrm{H}_{2} \mathrm{O}_{2}$ in Tris. Reaction was stopped with cold buffer, and sections rinsed three times and mounted from $40 \%$ gelatin-alcohol onto glass slides, air-dried overnight, and coverslipped in a drop of Cytoseal (Richard-Allan Scientific). DAB-labeled sections were imaged on an Olympus Provis AX70 microscope equipped with a Magnafire camera (Optronics).

\section{Immunofluorescence}

For identification of neurochemical markers, perfusion and sectioning were done as above. Sections were then rinsed three times in phosphate buffer saline (PBS), placed in blocking solution (5\% NGS $+0.5 \%$ TX in PBS) and rotated for $2 \mathrm{hrs}$ at room temperature. Sections were transferred directly from the blocking solution into primary antibody (1:800 rabbit anti-SOM14, Bachem (Peninsula Scientific) T-4103; 1:1000 mouse monoclonal anti-PV, Swant; 1:1000 mouse monoclonal anti-CB, Swant; 1:800 rabbit anti-NPY, Bachem T-4070) diluted in vehicle solution (1\% NGS $+0.1 \%$ TX in PBS), and rotated for $48 \mathrm{hrs}$ at $4^{\circ} \mathrm{C}$. Following 3 rinses in PBS, sections were transferred into vehicle with diluted secondary antibody (1:1000 Alexa 546 goat anti-rabbit or antimouse, Molecular Probes), rotated for $2 \mathrm{hrs}$ at room temperature, rinsed three times, mounted in hard-set Vectashield (Vector Laboratories, Burlingame, CA) on glass slides and coverslipped. Sections were imaged with a Zeiss LSM510 confocal microscope, using non-simultaneous excitation of GFP with the $488 \mathrm{~nm}$ line of the Argon laser, and of Alexa 546 with the $543 \mathrm{~nm}$ line of the HeNe laser. 


\section{Cell counts}

To quantify laminar distributions of GFP+ neurons, 6 coronal sections, from two different rostrocaudal levels through the barrel cortex, were selected for each line. Strips delineating the barrel region were outlined, and all DAB-labeled somatic profiles within each strip were marked under a $10 \mathrm{X}$ objective. Neuroexplorer software (MicroBrightfield) was then used to determine the orthogonal distance between each marked neuron and the pial surface. The fraction of SOM+ interneurons expressing GFP, and vice versa, was estimated from confocal projections of double-labeled sections from barrel cortex.

\section{Electrophysiological recordings}

Whole-cell recordings and intracellular staining were performed in juvenile animals (Postnatal day (P)16-24), an age range easily amenable to patch-clamp recordings and comparable to the age used in many previous studies of cortical interneurons in vitro. Cortical inhibitory neurons have acquired many of their adult electrophysiological, morphological and molecular characteristics by the beginning of the third postnatal week (McDonald et al., 1982; Miller, 1986b; Eadie et al., 1987; Minelli et al., 2003; Long et al., 2005). For preparation of brain slices, mice were deeply anesthetized with Isoflurane (North Chicago, IL) and decapitated. The brains were removed and submerged in icecold artificial cerebrospinal fluid (ACSF). Using a Vibroslicer (WPI, Sarasota, FL), 300 $\mu \mathrm{m}$-thick slices were cut and transferred into a holding chamber filled with recirculated $\mathrm{ACSF}$ at room temperature, incubated for at least 1 hour, and then transferred to the recording chamber and continuously superfused with $32^{\circ} \mathrm{C} \mathrm{ACSF}$ at a rate of $2-3 \mathrm{ml} / \mathrm{min}$. ACSF was saturated with $95 \% \mathrm{O}_{2} / 5 \% \mathrm{CO}_{2}$, and contained (in $\mathrm{mM}$ ): $126 \mathrm{NaCl}, 3 \mathrm{KCl}$, $1.25 \mathrm{NaH}_{2} \mathrm{PO}_{4}, 2 \mathrm{CaCl}_{2}, 1.3 \mathrm{MgSO}_{4}, 26 \mathrm{NaHCO}_{3}$, and 20 D-glucose.

For recording, barrel cortex GFP+ neurons were selected under fluorescence illumination using an Olympus BX50WI microscope (Melville, NY) equipped with a 40X water immersion objective and a Hamamatsu Orca (Hamamatsu-City, Japan) CCD camera controlled by SimplePCI software (Compix Inc. Imaging Systems, Cranberry Township, PA). The selected cells were then visualized with differential interference contrast (DIC) 
optics and targeted by patch pipettes for recordings. Just before seal formation, GFP expression in the targeted cell was re-verified by fluorescence. Whole-cell responses were recorded in true current-clamp mode with a patch-clamp amplifier (Axoclamp 2B; Axon Instruments, Inc., Foster city, $\mathrm{CA}$ ). Patch pipettes (5-7 M $\Omega$ resistance) were pulled from high lead content glass capillaries (PG52165, WPI) and filled with intracellular solution containing (in $\mathrm{mM}$ ): $122 \mathrm{KMeSO} 4,10 \mathrm{KCl}, 2 \mathrm{MgCl}_{2}, 0.1 \mathrm{CaCl}_{2}, 1.1$ EGTA, 10 HEPES, 4 ATP-Mg, 0.3 GTP-Na, and 8 Phosphocreatine-Tris (pH 7.25, 285-295mOsm); $2 \mathrm{mg} / \mathrm{ml}$ biocytin (Sigma) was routinely included in the pipette solution. Current pulse protocols were created with the Master-8 pulse generator (AMPI, Jerusalem, Israel); injected current pulses were routinely $600 \mathrm{~ms}$ long. The recorded signals were filtered at $3 \mathrm{kHz}$ and digitized at $10 \mathrm{kHz}$ with a National Instruments ADC board. All reported membrane potentials are positively biased by $8 \mathrm{mV}$, which was the measured liquid junction potential in our experiments.

\section{Electrophysiological parameter definitions (in alphabetical order)}

AHP ( $\mathrm{mV}$ ): Spike after-hyperpolarization, the difference between threshold and the most negative membrane potential following the spike, measured on the response to the smallest current step evoking an action potential.

Adaptation ratio (dimensionless): The ratio of $\boldsymbol{F}_{\max }$ steady state to $\boldsymbol{F}_{\max }$ initial.

F-I slope ( $\mathrm{Hz} / \mathrm{pA})$ : Frequency-current slope, the slope of the regression line fitted to the initial, steeper portion of the F-I plot. Frequency was defined as the reciprocal of the first inter-spike interval (ISI).

$\boldsymbol{F}_{\max }$ initial $(\mathrm{Hz})$ : The reciprocal of the first ISI, measured at the maximal current step applied before spike inactivation became evident.

$\boldsymbol{F}_{\boldsymbol{m a x}}$ steady state $(\mathrm{Hz})$ : The reciprocal of the average of the last 4 ISIs, measured at the maximal current step applied before spike inactivation became evident.

$\boldsymbol{F}_{\max }$ stuttering $(\mathrm{Hz})$ : For stuttering cells, the steady-state firing rate at the highest current level at which stuttering was evident (measured as the reciprocal of the average of the last 4 ISIs during the last firing epoch). For non-stuttering cells, the value of this parameter was defined as zero.

Rate of rise (V/s): maximal voltage slope (dV/dt) during action potential upswing. 
Rate of fall (V/s): Absolute value of maximal voltage slope (dV/dt) during action potential downswing.

Rheobase ( $p A$ ): The intercept of the extrapolated F-I curve with the current axis.

$\boldsymbol{R}_{\text {in }}(M \Omega)$ : Input resistance, the slope of the regression line fitted to the V-I curve, measured from the response to small current steps resulting in deflections of $\leq 10 \mathrm{mV}$ on both sides of resting potential.

Sag-V slope (dimensionless): The slope of the regression line fitted to the plot of sag $v s$ membrane potential, sag being the difference between the most negative membrane potential during a $600 \mathrm{~ms}$ hyperpolarizing current step and the membrane potential at the end of the step.

Spike height $(\mathrm{mV})$ : The difference between threshold and voltage at peak of action potential.

Spike width (ms): Measured at half height between threshold and peak action potential. Stuttering range (dimensionless): ratio of $\boldsymbol{F}_{\max }$, stuttering to $\boldsymbol{F}_{\max }$, steady state.

$\boldsymbol{T a u}_{\boldsymbol{m}}(\mathrm{ms})$ : Membrane time constant, determined from the monoexponential curve best fitting the rising or falling phase of the response to a small hyperpolarizing current step ( $\leq 10 \mathrm{mV}$ from resting potential).

Threshold $(\mathrm{mV})$ : The membrane potential at the point where the interpolated rate of rise $(\mathrm{dV} / \mathrm{dt})$ of the action potential equaled $5 \mathrm{~V} / \mathrm{s}$, measured on the response to the smallest current step evoking an action potential.

$V_{\text {rest }}(\mathrm{mV})$ : Resting potential, the stable membrane potential reached a few minutes after breaking the seal, with no current applied.

\section{Morphological reconstruction of recorded neurons}

For morphological reconstruction, slices were fixed overnight in $4 \%$ paraformaldehyde in $0.1 \mathrm{M}$ PBS, rinsed with $0.1 \mathrm{M}$ PBS and permeabilized for $3 \mathrm{hr}$ in $0.6 \%$ Triton X-100 in PBS. To neutralize endogenous peroxidases, slices were pretreated in $1 \% \mathrm{H}_{2} \mathrm{O}_{2}$ in PBS for $30 \mathrm{~min}$. After three additional rinses in 0.1M PBS, slices were incubated overnight at $4^{\circ} \mathrm{C}$ in $\mathrm{ABC}$ solution in $0.1 \mathrm{M}$ PBS with $0.6 \% \mathrm{TX}$. After three additional rinses in PBS, slices were rinsed for $10 \mathrm{~min}$ in $0.05 \mathrm{M}$ Tris buffer $(\mathrm{pH} 7.6)$, incubated in $0.06 \% \mathrm{DAB}$ in Tris for an additional $15 \mathrm{~min}$, and then the reaction was initiated by adding $0.006 \% \mathrm{H}_{2} \mathrm{O}_{2}$. 
When the cell body and dendritic processes were clearly visible, the DAB reaction was stopped with cold PBS solution. Slices were mounted in PBS-glycerol, coverslipped, and sealed with nail polish. Biocytin-filled neurons were visualized, traced and digitally reconstructed using the Neurolucida system (Microbrightfield Inc., Williston, VT) with a 60x water-immersion objective (Olympus) with a working distance of $\sim 130 \mu \mathrm{m}$.

\section{Multivariate analysis}

Multivariate analysis followed Manly (Manly, 2005). Each cell was represented as a vector in a multi- dimensional parameter space of $\mathbf{p}$ dimensions ( $\mathbf{p}$ was 9 for principal component analysis (PCA), and 11 for discriminant function analysis (DFA)). The full dataset was represented by a "Total" matrix $\mathbf{T}$ of $\mathbf{r}=150$ rows (cells) and $\mathbf{p}$ columns (parameters), with values in each column shifted by the grand average of the corresponding parameter so as to have a mean of 0 , and by a similarly sized "Within" matrix, $\mathbf{W}$, in which the values in each column were shifted independently for each group by the group average of the corresponding parameter. A "Between" matrix was defined as $\mathbf{B}=\mathbf{T}$-W. From $\mathbf{T}$, a "Normalized Total" matrix NT was constructed by scaling each column to have a standard deviation (SD) of 1, and from W a "Normalized Within" matrix NW was constructed by scaling each group independently to have an SD of 1 .

From $\mathbf{T}, \mathbf{W}$ and $\mathbf{B}$, three $\mathbf{p x p}$ variance-covariance (VCV) matrices were computed (the symbol $*$ denotes matrix multiplication, and the superscript ${ }^{\mathrm{T}}$ denotes a transposed matrix):

"Total" VCV matrix: $\quad \mathbf{T V}=1 / \mathbf{r}\left(\mathbf{T}^{\mathrm{T}} * \mathbf{T}\right)$

"Within" (pooled) VCV matrix: $\quad \mathbf{W V}=1 / \mathbf{r}\left(\mathbf{W}^{\mathrm{T} *} \mathbf{W}\right)$

"Between" VCV matrix: $\quad \mathbf{B V}=1 / \mathbf{r}\left(\mathbf{B}^{\mathrm{T}} * \mathbf{B}\right)$

The "Within" VCV matrix was the average of the 3 groupwise VCV matrices, weighted by the number of cases in each group. The diagonal elements of TV, WV and BV represented the total, within-group and between-group variance in each parameter. The fraction of between-group variance $\left(e t a^{2}\right)$ for parameter $i$ was therefore $e t a^{2}=\mathbf{B V}_{\mathrm{i}, i} \mathbf{T V}_{\mathrm{i}, \mathrm{i}}$

From NT and NW, two pxp correlation matrices were computed:

"Total" correlation matrix: $\quad \mathbf{T C}=1 / \mathbf{r}\left(\mathbf{N} \mathbf{T}^{\mathrm{T} * \mathbf{N T}}\right)$

"Within" (pooled) correlation matrix:WC=1/r(NW $\mathbf{N W}^{\mathrm{T} * \mathbf{N W})}$ 
The "Within" correlation matrix was the average of the 3 groupwise correlation matrices, weighted by the number of cases in each group. Matrices TC and WC are shown graphically in Fig. 2.7E and 2.7F, respectively. The average correlation within each matrix was defined as the cosine of the average arccosine of the absolute values of the correlation coefficients, calculated over the lower triangle of the matrix.

For PCA, the eigenvalues of WC were calculated, and the two eigenvectors corresponding to the two largest eigenvalues, EVEC1 and EVEC2, used to define the two principal components, by

$\mathrm{PC} 1=\mathbf{N T} *$ EVEC 1

$\mathrm{PC} 2=\mathbf{N T} * \mathrm{EVEC} 2$

For DFA, the eigenvalues of $\mathbf{W V}^{-1} * \mathbf{B V}$ were calculated, and the two eigenvectors corresponding to the two largest eigenvalues, EVEC1 and EVEC2 (not to be confused with the eigenvectors of WC above), used to define the two canonical discriminant functions, by

$\mathrm{CDF} 1=\mathbf{T} * \mathrm{EVEC} 1$

$\mathrm{CDF} 2=\mathbf{T}^{*} \mathrm{EVEC} 2$

\section{Statistics}

Unless noted otherwise, statistical significance values (p-values) were computed numerically, by performing 10,000 random permutations of the dataset and computing the probability for occurrence of values as or more extreme than the experimental result (Good, 1999). Where 10,000 permutations yielded no more extreme values, this is indicated as $\mathrm{p}<<10^{-4}$. All tests were two-tailed unless noted otherwise. Some data are presented as mean $\pm \mathrm{SD}$.

\section{Software}

Data acquisition and processing were done with home-made software written in the LabView environment (National Instruments, Austin, TX). Data were tabulated in Excel (Microsoft), which was also used to generate scatterplots. Multivariate analysis, correlation matrices, density plots and permutation tests were programmed in MathCad (MathSoft). Final graphics were prepared with CorelDraw. 


\section{RESULTS}

We generated 5 transgenic mouse lines with GFP expression under control of the GAD67 promoter. Even though all 5 lines were generated by in-ovo injection of the same GAD67-GFP DNA construct (see Methods), the spatial distribution of GFP+ neurons in the brain was distinct in each line. The present study is based on two of these novel transgenic lines, named X94 and X98, in which GFP expression in the cerebral cortex was clearly restricted to non-pyramidal cells, and on the previously published transgenic mouse line GIN in which GFP expression is also driven by the GAD67 promoter, albeit by a shorter segment of the promoter than used by us (Oliva et al., 2000). For convenience, we refer to GFP+ neurons in the X94, X98 and GIN lines as "X94 neurons", "X98 neurons" and "GIN neurons", respectively. It should be understood, though, that we consider GFP + neurons in these mice to be representative of homologous subsets of neurons which are presumed to exist in wildtype animals and, except for GFP expression, to display the same properties.

\section{Laminar distribution of GFP+ neurons}

In the neocortex of adult X94, X98 and GIN mice, GFP was expressed only in nonpyramidal, putative GABAergic neurons (Fig. 2.1). Since there were some inter-areal variations in the detailed cortical expression patterns within each line, we focused on the somatosensory "barrel" cortex, which provided an easily identifiable cortical region for inter-line comparisons, and for which the composition and properties of GABAergic interneurons are already known in some detail (Staiger et al., 1996; Porter et al., 2001; Wang et al., 2002; Beierlein et al., 2003; Wang et al., 2004). Qualitative examination of the barrel cortex of adult (2-3 months old) X94, X98 and GIN mice revealed a distinct laminar distribution pattern of GFP+ neurons in each line. X94 neurons were found mostly in layers 4 and 5B, with a small number in layers 2/3, 5A and upper 6 (Fig. 2.1A,D). X98 neurons resided mostly in layers 5B and 6 (Fig. 1B,E), with a minor population in layers $2 / 3$ (see Fig. 2.3B). In the X98 line, low-level expression of GFP was also found in many small cells with glial morphology (faintly visible in Fig. 2.1B,E) which formed a remarkably regular lattice, and which will not be considered here further. 
GIN neurons were found mainly in layers $2 / 3$ and $5 \mathrm{~A}$, with a smaller number of cells within layer 4 (Fig. 2.1C,F), consistent with their original description (Oliva et al., 2000). Thus, the laminar distributions of GFP + neurons in the three lines were nearly complementary.

The qualitative impression of complementary distribution patterns was substantiated by counting cells in radial strips through the barrel cortex of the three lines (Fig. 2.1A-C, histograms at the left end of each panel). The inter-line differences were most striking in layer 4. In the X94 line, layer 4 contained a high density of GFP-containing neuropil, often segregated into clusters suggestive of barrel boundaries (Fig. 2.1A,D). Many labeled cell bodies were located at the lower border of layer 4 , or within layer $5 \mathrm{~A}$ immediately below this border; layer 5A was otherwise very lightly labeled. A second, lower tier of GFP+ cell bodies was found in layers 5B (with a small number in upper layer 6). Thus, GFP expression in the X94 cortex closely followed the laminar distribution pattern of thalamocortical afferents (Agmon et al., 1993). In the X98 line, in contrast, GFP expression in layer 4 was totally absent (Fig. 2.1B). In the GIN line there was a dense expression of GFP in cell bodies and neuropil immediately above and below layer 4 , but in layer 4 there were only a small number of GFP-containing cell bodies and very little labeled neuropil (Fig. 2.1C).

Since electrophysiological recordings are often done in brain slices from juvenile mice (as were our recordings), we also examined GFP expression patterns in tissue from 2-3 week old mice (data not shown). GFP expression levels were somewhat lower in juveniles, but expression patterns were overall similar to the adult ones, with a few noteworthy exceptions. In juvenile X98 cortex, strongly labeled GFP+ neurons in the supragranular layers were considerably more numerous than in adults. In juvenile GIN mice, there was an apparently ectopic expression of GFP in a subset of pyramidal neurons in the deep cortical layers. GFP expression in 2-3 week old X94 mice was qualitatively very similar to the adult pattern, but in X94 pups younger than 2 weeks expression was very weak. 


\section{Neurochemical characterization of GFP+ neurons}

Being non-pyramidal, GFP+ neurons in our transgenic lines were, most likely, GABAergic interneurons. Cortical interneurons fall into several distinct neurochemical classes (Kubota et al., 1994; Kawaguchi and Kondo, 2002). To determine whether GFP+ neurons in our lines belonged to a specific neurochemical class, we stained sections from adult brains (2 animals/line) with antibodies to PV and to SOM (Fig. 2.2A-D), and quantified the fraction of GFP+ cells which were also immunopositive for each marker, and the fraction of marker immunopositive cells which were also GFP+ (Table 2.1). Virtually all GFP+ neurons in both X94 and X98 lines (95\% and 96\%, respectively) were $\mathrm{SOM}+$ (Fig. 2.2, A-B), and all GFP + neurons in both lines were PV immunonegative (Fig. 2.2, C-D; note that yellow regions in Fig. 2.2C are the result of overlap of red cell bodies and green neuropil, not co-localization of the labels). We also confirmed that nearly all GIN neurons (97\%) were SOM-immunopositive (data not shown), as previously reported (Oliva et al., 2000). GFP+ neurons were clearly only a partial subset of all SOM+ interneurons in their vicinity (Table 2.1). Even in the layers in which they were most numerous, layers $4,5 / 6$ and 2/3 for X94, X98 and GIN, respectively, GFP+ neurons accounted for only $41 \%, 20 \%$ and $35 \%$ of all SOM+ neurons, respectively. In total, and assuming that X94, X98 and GIN neurons consist of non-overlapping populations, GFP + neurons in the three lines accounted for slightly more than half of all $\mathrm{SOM}+$ neurons.

Several neurochemicals are known to be expressed in subsets of SOM+ interneurons, and could potentially be used as markers for subtypes within the SOM+ population. We tested GFP+ interneurons in our mice for expression of two of these molecules calbindin (CB) and neuropeptide Y (NPY) (2 animals/line). X94 neurons never stained for either marker (Fig. 2.2E,G). In contrast, virtually all X98 cells (96\%), and about one third of all GIN cells, were immunopositive for CB; about $40 \%$ of all X98 neurons, and $27 \%$ of all supragranular GIN cells, were immunopositive for NPY (Fig. 2.2F,H; Table 2.1). Thus, $X 94, X 98$ and GIN neurons had distinct neurochemical profiles. Moreover, these results indicate that even where they overlap in laminar position, e.g. in layer 5B, X94 and X98 neurons belong to distinct populations. 


\section{Axonal morphologies of GFP+ neurons}

Confocal imaging of fixed brain sections from the three lines revealed strong GFP fluorescence in cortical layer 1 of X98 and GIN mice, seemingly emanating from GFPcontaining axonal bundles running below the pial surface (Fig. 2.3B,C); in contrast, layer 1 in X94 cortex was nearly devoid of fluorescence (Fig. 2.3A). An axonal projection to layer 1 is the defining feature of Martinotti cells (DeFelipe and Jones, 1988), a morphological class of neocortical interneurons known to express SOM (Wahle, 1993; Kawaguchi and Kubota, 1996; Shlosberg et al., 2003); but it is not known if all SOM+ cortical interneurons are Martinotti cells. To further examine this question at a single-cell resolution, we filled GFP + neurons in the three lines with biocytin during electrophysiological recordings, and reconstructed their dendritic and axonal trees using the Neurolucida system. From 230 recorded and filled cells, 69 neurons (35 X94, 19 X98 and 15 GIN cells) retained a sufficiently extensive axonal tree within the slice to warrant a detailed computer-assisted reconstruction; twelve representative reconstructions are illustrated in Fig. 2.4.

In all three lines, the axon (labeled red in Fig. 2.4) almost always emerged from the upper aspect of the cell body or from an ascending dendritic trunk and, at least initially, extended towards the pial surface. Layer 4 X94 neurons (N=27; Fig. 2.4A-D) had compact axonal trees which remained within layer 4 or (in a few cases) extended into layer 3, and formed a tight cluster which appeared restricted to a single barrel or barrel column. Following the "blueprint" of the barrel cortex (Woolsey et al., 1975; Lorente de No, 1992), X94 cells often extended highly asymmetric dendritic and axonal trees towards the presumed center of their barrel (Fig. 2.4A-C). In six reconstructed cells, the main axon extended to upper layer $2 / 3$ or even lower layer 1 , where it made a sharp loop and descended back toward layer 4, in which it made its terminal arbor (Fig. 2.4B-D, turning point indicated by arrows). Only one X94 neuron had an axon that branched within layer 1 (not shown). Infragranular X94 neurons (N=8; Fig. 2.4E,F) emitted a local axonal arbor in the vicinity of the cell body, but in all cases one or more axonal

branches entered layer 4 (and in some cases also layer 3) and formed a second arbor there, usually restricted to the same radial column, but in one case (not shown) extending within layer 4 into adjacent columns. In all cases, by far the most extensive target of X94 
neurons was layer 4, never layer 1, confirming the observations from GFP fluorescence (Fig. 2.3A). Therefore, X94 neurons cannot be considered to be Martinotti cells; rather, they appear to constitute a separate morphological subtype within the SOM+GABAergic subclass.

X98 axons always ramified immediately above the cell body, usually in upper layer 6 and layer 5. Invariably, however, the main axon continued upwards. This ascending trunk was unfortunately truncated in many cells at the cut surface of the slice, but in the cases in which it was retained within the slice $(\mathrm{N}=11)$ it always reached layer 1 . In 7 of these cases (examples shown in Fig. 2.4J-L) the axon ascended as multiple parallel branches through layers 4 and 2/3 before entering layer 1, where at least some of the branches made a $90^{\circ}$ turn and coursed for some distance parallel to the pial surface, occasionally sending out short terminal side branches. By this pattern of axonal arborizations, which is consistent with the observations of GFP fluorescence in layer 1 (Fig. 2.3B), X98 cells fit the classical definition of Martinotti cells (DeFelipe and Jones, 1988). None of the reconstructed X98 cells in our sample was found to branch within layer 4 to any noticeable degree. Finally, all supragranular GIN cells (examples in Fig. 2.4G,H), and the one reconstructed layer 5A GIN cell (Fig. 2.4I), had multiple ascending axonal branches which branched extensively within layer 1, consistent with our confocal images (Fig. 2.3C); GIN neurons were therefore supragranular Martinotti cells.

\section{Firing patterns of GFP+ interneurons}

Previous studies reported considerable heterogeneity in the electrophysiological and morphological properties of SOM+ cortical interneurons (Wang et al., 2004), but it remains unclear whether they comprise several distinct subtypes. To address this question, we recorded from GFP+ neurons in the current-clamp, whole-cell mode, and compared intracellularly elicited voltage responses between the three lines. This analysis was carried out on a dataset of 150 barrel cortex neurons recorded at $32^{\circ} \mathrm{C}$, including 58 X94, 59 X98 and 33 GIN neurons, from 71 juvenile mice (age range P16-P24, average age P18.9, no statistical difference in age between lines). All the cells included in this analysis had stable resting potentials more negative than $-60 \mathrm{mV}$ (uncorrected for 
junction potential) and overshooting action potentials. Although each of the three lines showed some degree of GFP expression in several cortical layers (Fig. 2.1), we selected our sample from the major concentration of GFP+ neurons in each line: layers $4(\mathrm{~N}=32)$ and 5B $(\mathrm{N}=26) \mathrm{X} 94$ neurons, infragranular X98 neurons and supragranular GIN neurons. When injected with sufficiently large depolarizing current steps, all three lines fired trains of action potentials that exhibited frequency adaptation. This adaptation was usually most pronounced at the highest current levels, with firing rates at the end of a $600 \mathrm{~ms}$ long maximal current step falling to $<60 \%$ of the initial rate (Fig. 2.5Aa-c). Compared to the other two groups, X94 neurons required much larger current steps to achieve similar voltage deflections (compare current levels in Fig. 2.5Aj and 2.5Bd to those in Fig. 2.5Ak,l and 2.5Be,f), indicative of a much lower input resistance (Table 2.2; see below). X94 spikes were pronouncedly narrower than those of X98 and GIN neurons (Fig. 2.5Ag-i, insets; Table 2.2; see below). At the lowest firing frequencies, action potentials in $42 \%$ of X98 and $82 \%$ of GIN cells were followed by a sequence of an early "fast" after-hyperpolarization (AHP) followed by a delayed "slow" AHP (Zhang and McBain, 1995), which together formed a characteristic triphasic waveform (Fig. 2.5Ah,i, arrowheads). Only $14 \%$ of all X94 cells displayed a triphasic AHP; interestingly, all 8 cells who did had input resistances above the median for their group ( $p=0.007$, Fisher's exact test).

X94 neurons were distinctive in another respect - in most cells, spike trains were interrupted at seemingly random intervals for seemingly random periods, often replaced by subthreshold oscillations (Fig. 2.5Ad, asterisks). Most stuttering cells did so only at the lower range of firing frequencies (compare Fig. 2.5Aa to Fig. 2.5Ad); but 11 X94 cells stuttered at all current levels. We quantified the stuttering range of a given cell as the ratio between the highest steady-state firing frequency at which stuttering still occurred to the maximal steady-state firing frequency in the same cell, and defined as "robustly stuttering" cells which stuttered through at least the lower $1 / 3$ of their frequency range (i.e. stuttering range $\geq 0.33$ ). Overall, $58.6 \%$ of X94 cells robustly stuttered, but only $3.3 \%$ of X98 and $12.1 \%$ of GIN neurons did, a highly significant difference between $\mathrm{X} 94$ and the remaining groups ( $\mathrm{p}=2 \cdot 10^{-12}$, Fisher's exact test). Layer 
4 and layer 5 X94 neurons differed in their propensity to stutter: $75 \%$ of all layer 4 X94 cells robustly stuttered, but only $38.5 \%$ of layer 5 cells did, a highly significant difference between layers ( $\mathrm{p}=0.005$, Fisher's exact test). The probability of stuttering was correlated with a low input resistance: $36.7 \%$ of robustly stuttering X94 neurons were in the lower quartile of input resistances for their group, nearly 1.5 times the expected fraction $(\mathrm{p}=0.01$, Fisher's exact test $)$.

In response to hyperpolarizing currents, all 3 cell groups displayed a "sag" (Fig. 2.5Ba-c, asterisks), likely to be mediated by the hyperpolarization-activated cationic current $I_{h}$ (Lupica et al., 2001). All 3 lines also displayed a depolarizing "rebound" upon recovery from the hyperpolarizing step (Fig. 2.5Ba,c, hollow arrowheads). In X94 and GIN neurons, this rebound did not trigger spikes, or rarely (in one X94 cell and 18\% of GIN neurons) triggered one action potential. In contrast, in 37\% of X98 neurons recovery from hyperpolarization evoked at least one action potential; $25 \%$ of all X98 cells fired a burst of 2-3 spikes (Fig. 2.5Bb, right solid arrowhead). The difference in rebound spiking probability between X98 cells and the remaining groups was highly significant $\left(\mathrm{p}=10^{-5}\right.$, Fisher's exact test). Some X98 cells fired a burst also upon depolarization directly from resting potential (Fig. 2.5Bb, left solid arrowhead). The probability of firing a rebound spike or burst was correlated with a high input resistance: $45 \%$ of X98 neurons displaying a rebound spike or burst were in the upper quartile of input resistances for their group, nearly twice the expected fraction ( $\mathrm{p}=0.004$, Fisher's exact test). This correlation held also for the X94 and GIN samples: half the GIN neurons which fired a single rebound spike were in the upper quartile of $\mathrm{R}_{\mathrm{in}}$ for their group, and the one X94 neuron with a rebound spike had the highest input resistance in its group.

The rebound burst in X98 cells was likely to be triggered by a "low-threshold spike" (LTS), mediated by the calcium current $\mathrm{I}_{\mathrm{T}}$ (Goldberg et al., 2004). However, the coexistence of a prominent $I_{h}$ in the same cells raised the possibility that an $\mathrm{I}_{\mathrm{h}}$-mediated rebound could have contributed to the bursting in X98 neurons. Several lines of evidence suggested that this was not the case. First, the amplitude of the $\mathrm{I}_{\mathrm{h}}$-mediated sag, as measured by the slope of the sag-vs-voltage curve, was not significantly different 
between lines (Table 2.2). Also, there was no significant correlation between sag amplitude and the number of rebound spikes fired by X98 cells $\left(r^{2}=0.03\right)$. To further isolate the contributions of $\mathrm{I}_{h}$ and $\mathrm{I}_{\mathrm{T}}$, we used $\mathrm{Cs}^{+}$to block $\mathrm{I}_{\mathrm{h}}$ channels (Maccaferri and McBain, 1996), and mibefradil to block T-type calcium channels (Yunker, 2003). CsCl (3 $\mathrm{mM}$ ) totally or nearly totally blocked the sag and the rebound depolarization in X94 and GIN neurons (Fig. 2.6A,B, hollow arrowheads; $\mathrm{N}=4$ cells from each line), consistent with both being $\mathrm{I}_{\mathrm{h}}$-mediated. $\mathrm{CsCl}$ also strongly blocked the hyperpolarization-induced sag in X98 cells (Fig. 2.6C, hollow arrowhead), but in most (5 of 7) cells it did not block the rebound single spike or burst (Fig. 2.6C, solid arrowhead). In contrast, $10 \mu \mathrm{M}$ mibefradil had no observable effect on the hyperpolarization-induced sag (Fig. 2.6D, hollow arrowhead), but totally blocked the rebound burst in 2 of 3 cells, even when the hyperpolarizing step was increased (Fig. 2.6D, solid arrowhead), and reduced the burst to a single spike in the third case. We conclude that X98 cells, but not X94 or GIN neurons, have a propensity to fire low-threshold $\mathrm{Ca}^{2+}$ spikes mediated by $\mathrm{I}_{\mathrm{T}}$, and can be classified as "LTS" cells.

\section{Multivariate analysis of electrophysiological parameters}

We used the sub- and suprathreshold voltage responses to calculate 15 basic electrophysiological parameters for each neuron (Table 2.2; see Methods for definitions of parameters). For each parameter we quantified its overall variance in the sample, by calculating the total sample coefficient of variation (CV, i.e. $\mathrm{SD} /$ mean), and its eta ${ }^{2}$ value, i.e. the fraction of the total variance attributable to differences between, rather than within, the 3 groups (see Methods). When eta $^{2}$ was plotted against the CV for each parameter (Fig. 2.7A), there was a clear clustering of parameters into 2 groups. Six parameters (inside dotted half box in Fig. 2.7A) had low between-group variance $\left(\right.$ eta $\left.{ }^{2}<0.1\right)$ and low to intermediate total variance $(0.05<\mathrm{CV}<0.35)$, and 7 parameters (numbered 1-3, 5-8 in Fig. 2.7A) had high between-group variance (eta ${ }^{2}>0.55$, up to 0.72 for spike width) and intermediate to high total variance $(0.25<\mathrm{CV} \leq 1)$. The remaining two parameters (\#4 and \#9) had intermediate values for both $\mathrm{CV}$ and $e t a^{2}$. This correlation between $\mathrm{CV}$ and $e t a^{2}$ suggested that most of the variance in the electrophysiological 
parameters of the neurons in our sample could be accounted for by their natural segregation into three groups.

The six parameters with low eta ${ }^{2}$ values (resting potential, threshold, spike height, sag-V slope, adaptation ratio and F-I slope) were clearly not good indicators of group membership, and were not analyzed further. The remaining 9 parameters had $\operatorname{eta}^{2}>0.1-$ indeed, seven had $e t a^{2} \geq 0.55$ - values which were very significantly different than 0 $(\mathrm{p}<<0.0001$; Table 2.2). Thus, these parameters were very good predictors of group membership. Fig. 2.7B shows by-group density plots for these nine parameters, computed with a Gaussian kernel (Hand et al., 2001, Ch. 9). In nearly all plots, X94 and X98 neurons formed clearly separate peaks with very little overlap, while GIN neurons occupied intermediate positions, overlapping with both other groups. The clear separation between X94 and X98 can also be appreciated from Table 2.2: for the seven parameters with $e t a^{2} \geq 0.55$, the $10^{\text {th }}-90^{\text {th }}$ percentile ranges of the X94 and X98 samples were totally non-overlapping (see also Table 2.3). Some of the pairwise differences between means for X98 and X94 parameters were quite large; for example, the average initial and steady-state $F_{\max }$ values were two-fold smaller, and the average $R_{i n}$ and $t a u_{m}$ values 4 -fold larger, in X98 compared to X94.

Given the differences in stuttering range between layer 4 and layer 5 X94 cells, we also compared their electrophysiological parameters. Compared to layer 4 cells, layer 5 X94 neurons had higher $R_{\text {in }}(163 \pm 62$ vs $109 \pm 41 \mathrm{M} \Omega)$, slower $\operatorname{tau}_{m}(12.3 \pm 4.8$ vs $7.9 \pm 2.1 \mathrm{~ms})$, and lower rheobase (166 \pm 85 vs $231 \pm 95 \mathrm{pA})$; these differences were highly significant $(\mathrm{p}<0.001, \mathrm{p}<0.0001$ and $\mathrm{p}<0.01$, respectively). The remaining parameters were not significantly different between the two X94 subgroups.

Given the strong dependence of parameters 1-8 on group membership (Fig. 2.7B), we expected them to correlate with each other, as was indeed the case (Fig. 2.7C). However, such correlation could also indicate that the parameters in question were not independent - i.e., that they represented different manifestations of the same basic biophysical properties. To identify such intrinsic correlations between parameters, we compared the total sample correlation matrix (Fig. 2.7C) to the pooled within-group correlation matrix 
(Fig. 2.7D; see Methods for definition of the two matrices), reasoning that correlations based on shared biophysical mechanisms should be evident also within each group, whereas correlations based solely on co-segregation into different groups should disappear. Indeed, the average correlation coefficient was reduced from 0.58 in the totalsample matrix to 0.34 in the within-group matrix, suggesting that $\sim 60 \%$ of the total sample correlation reflected shared biophysical mechanisms between parameters. Specifically, the within-group correlation matrix (Fig. 2.7D) suggested that parameters 13 , representing passive membrane properties, were correlated with each other, and that parameters 4-9, representing action potential properties, were correlated with each other, but that these two parameter clusters were not correlated with each other. Since information conveyed by intrinsically correlated parameters is redundant, we conducted principal component analysis (PCA), a method which reduces such redundancy by redistributing the variance in the dataset among the smallest possible number of independent linear combinations of parameters (Manly, 2005). The two principal components with the largest variances ( $\mathrm{PC} 1$ and $\mathrm{PC} 2$ ) accounted for $65 \%$ of the total variance in our sample, and are plotted against each other in Fig. 2.7E. PC1 and PC2 were correlated, respectively, with the active and passive parameter clusters identified above (correlation coefficients of 0.41 and 0.50 , respectively). In the PC1-PC2 plane, X94 and X98 datapoints were almost completely segregated, while GIN datapoints occupied the intermediate region and were intermixed, to some degree, with the other two groups. As expected from the differences in passive parameters between layer 4 and layer 5 X94 cells, the latter (hollow red squares in Fig. 2.7E) had lower values of PC2, and accounted for most of the overlap between X94 and GIN datapoints.

PCA maximizes the overall variance per component, but does not necessarily improve the discriminability between groups. To determine how well the electrophysiological parameters discriminate between the three subsets, we conducted discriminant function analysis (DFA; see Methods). This method maximizes the separation between $\mathrm{N}$ groups (i.e. maximizes $e t a^{2}$ ) along $\mathrm{N}-1$ independent linear combinations of parameters (Manly, 2005). In this analysis we included the parameters 1-9 above, as well as the stuttering range and the number of rebound spikes fired by each neuron upon recovery from a 
maximal hyperpolarizing step. The resulting two canonical discriminant functions (CDF1 and CDF2) are plotted against each other in Fig. 2.7F. Overall, between-group variance accounted for $87 \%$ of the total variance in CDF1, and for $41 \%$ of the variance in CDF2. Clearly, in the CDF1-CDF2 plane there was not only a near-perfect separation of X94 and X98 datapoints along CDF1, but also a very good separation of GIN datapoints from the other two groups along CDF2. The two intersecting lines in Fig. 2.7F divide the CDF plane into three regions, with X94, X98 and GIN datapoints largely segregated into separate regions, indicating that the electrophysiological parameters alone, even without neurochemical or morphological criteria, could be used to classify SOM+ neurons into one of these three groups.

\section{Age-dependent changes in electrophysiological parameters.}

Even though there were no statistically significant differences in age between the three samples, it was still possible that the large between-group differences we observed were related to differential maturation of cells in different cortical layers, and that these differences would disappear by adulthood. This was a-priori unlikely, because maturation of cortical layers proceeds in an inside-out gradient, while electrophysiological properties did not display a pia-to-white matter gradient (e.g. GIN neurons, in the upper layers, had electrophysiological parameters intermediate between X94 cells in the middle layers and X98 cells in the deep layers). Nevertheless, we tested this possibility by performing regression analysis of the two major principal components (PC1 and PC2) against age, by group. PC2 values did not change significantly with age; however PC1 values showed a weak negative correlation with age, although this effect was statistically significant only in X98 and GIN neurons $\left(r^{2}=0.15\right.$ and 0.16 , respectively). The same effect could be seen in the individual "active" parameters which correlated with PC1; for example, spikes of X98 neurons narrowed slightly with age, with the trend line dropping by $0.15 \mathrm{~ms}$ through the age range of our experiments. To test how this small age-dependent change in the active parameters may have affected the estimated degree of difference between groups, we divided our sample into three age ranges, P16-17 (N=43), P18-19 (N=59) and P20-24 ( N=48), and computed the eta ${ }^{2}$ values of PC1 separately for each range. $E t a^{2}$ values were $0.78,0.67$ and 0.66 for the 
three age ranges, respectively, compared with 0.68 for the total sample. We conclude that the contribution of between-group variance to the total variance was somewhat higher at the lower range of ages in our sample, but that it stabilized from P18 onwards, probably reaching its mature value, and that the higher $e t a^{2}$ at the younger ages did not bias our conclusions to any significant degree. 


\section{DISCUSSION}

We compared two novel and one published transgenic mouse lines in which GFP expression is driven by the GAD67 promoter. Although GAD67 is expressed by all GABAergic interneurons (Mugnaini and Oertel, 1985), cortical GFP expression in all three lines was restricted to the SOM+ neurochemical class. Moreover, each line expressed GFP in a strikingly different subset of SOM+ interneurons, distinct in laminar location, neurochemical markers, axonal morphologies and electrophysiological properties. Differences in these properties were most pronounced between X94 and X98 neurons, which segregated almost perfectly by all four criteria (Table 2.3). Although there is no general agreement on what is required to define a neuronal population as a subtype or "species" (Soltesz, 2005), the extent of the differentially expressed properties we observed approaches the requirements of some recently proposed definitions (Migliore and Shepherd, 2005; Somogyi and Klausberger, 2005), and strongly suggests that at least two of the three subsets (i.e. X94 and X98) belonged to distinct, albeit related, subtypes of SOM+ interneurons.

Putative SOM+ interneurons in the rat were previously shown to be electrophysiologically, morphologically and chemically heterogeneous (Wang et al., 2004), but no clear correlations between these different categories of properties were noted. That we observed such correlations is no doubt attributable to our use of transgenic animals, allowing us to target our experiments to well-defined and reproducible subsets of neurons identified by genetically-encoded vital markers. The indentifiability of these subsets means that our results could easily be extended in future studies targeting the same subtypes with additional techniques, e.g. ultrastructural characterization of their synaptic targets (Gulyas et al., 1993; Thomson et al., 1996), or microarray analysis of their gene expression profiles (Lobo et al., 2006; Sugino et al., 2006).

\section{Low-threshold bursts in layer 1-targeting, infragranular SOM+ interneurons}

X98 neurons resided in the infragranular layers, could generate low-threshold calcium spikes, and sent an ascending projection to layer 1. X98 neurons were therefore similar to 
LTS Martinotti cells previously described in rodent infragranular cortex (Kawaguchi, 1993; Deuchars and Thomson, 1995; Kawaguchi, 1995; Goldberg et al., 2004). All X98 cells expressed calbindin, also previously observed in Martinotti neurons (Kawaguchi and Kubota, 1996; Gabbott et al., 1997). As previously noted (Goldberg et al., 2004), $\mathrm{SOM}+$ interneurons in supragranular or granular cortical layers never fired low-threshold bursts, and referring (as is often done) to all putative SOM+ interneurons as "LTS" cells is incorrect.

Low-threshold bursts are thought to be mediated by T-type calcium channels of the $\mathrm{Ca}_{\vee} 3 . \mathrm{X}$ gene family (Perez-Reyes, 2003). We confirmed this pharmacologically by showing that the T-channel preferring blocker mibefradil (Yunker, 2003) blocked the low-threshold bursts. Intriguingly, the occurrence of low-threshold bursts or single rebound spikes, which were observed in $\sim 40 \%$ of all X98 neurons, correlated with high input resistance. This raises the possibility that a sufficiently high input resistance is required for a cell to generate an LTS, and that bursting and non-bursting X98 neurons differed in their input resistance, rather than in the expression of $\mathrm{Ca}_{\mathrm{v}} 3 . \mathrm{X}$ channels.

\section{Stuttering and quasi-fast spiking in layer 4-targeting SOM+ interneurons}

X94 cells appear to be a novel subtype of SOM+ interneurons. They fired in a stuttering pattern and innervated layer 4, not layer 1. The most striking feature of X94 neurons, however, was their electrophysiological parameters, which were within, or very close to, the range of values previously reported for FS interneurons (for example: average spike width of $0.45 \mathrm{~ms}$, compared to $0.31-0.43 \mathrm{~ms}$ for FS cells; average $R_{\text {in }}$ of $132 \mathrm{M} \Omega$, compared to 55-157 MS; (Kawaguchi, 1995; Galarreta and Hestrin, 2002; Beierlein et al., 2003). The major difference between X94 and FS cells was the pronounced firing frequency adaptation in the former (adaptation ratio of $<0.6$, compared to values of 0.8 1.1 in FS cells). Thus, X94 cells could be described as "quasi-FS". Why X94-like neurons have not been previously observed in layer 4 , where they make at least $40 \%$ of all SOM+ interneurons, is perplexing. It is possible that they are less abundant in the rat, where most previous studies were conducted (e.g. (Beierlein et al., 2003; Wang et al., 2004). Alternatively, they could have been encountered but misclassified as FS cells. 
Analysis of gene products amplified from single interneurons shows that ion channel genes tend to be expressed in clusters which are characteristic of each neurochemical class (Toledo-Rodriguez et al., 2004). Differential expression of such gene clusters may also underlie the divergence of a given neurochemical class into different subtypes, such as the subtypes of SOM+ interneurons demonstrated here. For example, to account for the unique electrophysiological properties of X94 neurons, the expression of multiple ion channels would be required. The unusually low input resistance of these cells is likely to be caused by "leak" potassium conductances, such as the two-pore channels formed by the KCNK gene family (Goldstein et al., 2001). Stuttering has been associated with the expression of dendrotoxin-sensitive $\mathrm{K}_{\mathrm{v}} 1.1$ potassium channels (Toledo-Rodriguez et al., 2004), and "fast spiking" properties are thought to depend on the $\mathrm{K}_{\mathrm{V}} 3 . \mathrm{X}$ family of potassium channels (Erisir et al., 1999; Lien and Jonas, 2003). The detailed molecular basis for the unique electrophysiological fingerprint of X94 cells remains to be determined.

\section{Taxonomy of cortical interneurons}

Despite recent efforts (Yuste, 2005), there is no agreement yet on a system for classification of hippocampal and neocortical interneurons, let alone on a multi-level hierarchy of interneuronal taxa, analogous to grouping of organisms into species, genera, etc. That such groupings do exist, however, has received substantial support from several recent studies (Soltesz, 2005, Ch. 7). In molecular systematics, taxonomic distances between organisms are based on the degree of genomic sequence divergence (Sidow and Bowman, 1991); likewise, metrics based on the degree of gene expression similarity could be used for "neuronal systematics". Using such metrics, different neurochemical classes of interneurons in the same cortical region were found to be mutually closer than GABAergic neurons (as a group) were to glutamatergic neurons, but more distant compared to populations of the same neurochemical class in different neocortical regions (Sugino et al., 2006). We expect that subtypes of a single neurochemical class, such as the SOM+ subtypes we described here, would be mutually closer than different neurochemical classes, but further apart than neurons of the same subtype (e.g. X94 neurons) in different cortical areas. 
Just as taxonomical separation between biological species reflects phylogenetic distances from a common ancestor, taxonomical separation between neuronal species should reflect ontogenetic distances from a common precursor (Soltesz, 2005). That different neurochemical classes of GABAergic interneurons diverge relatively early in development follows from the findings that they originate from distinct progenitor zones in the ventral telencephalon (Xu et al., 2003; Xu et al., 2004). How then does intra-class diversity arise? Very recently, a fate-mapping study in vivo (Butt et al., 2005) revealed that late-born $\mathrm{CR}+$ interneurons show more phenotypic diversity than early-born $\mathrm{CR}+$ interneurons, suggesting that intra-class diversity may be generated by temporal, rather than spatial gradients. Similar experiments have not yet been done on $\mathrm{SOM}+$ interneurons; nevertheless, our finding of distinct subtypes of SOM+ interneurons in different cortical layers, together with the pattern of inside-out layering of GABAergic cortical neurons according to age (Miller, 1986a; Valcanis and Tan, 2003), are consistent with a model by which $\mathrm{SOM}+$ interneurons born at different developmental ages are committed to different phenotypes, possibly in response to a changing constellation of transcription factors in the progenitor population (Butt et al., 2005).

The mature phenotype of each interneuron will depend not only on its "genetics", i.e. the genes it expresses, but also on its local cortical environment. For example, X94 axons seem to respond positively to developmental cues emanating from layer 4 and negatively to cues emanating from layer 1, while X98 and GIN axons seem to do the opposite (Katz and Callaway, 1992; Castellani and Bolz, 1997; Castellani et al., 1998). Thus, although the capacity to respond to local molecular cues is likely to be genetically programmed, the detailed morphology of a given neuron is not, accounting for the considerable morphological variability within interneuronal subtypes.

\section{Concluding remarks}

In the past two decades, in-vitro electrophysiological studies, together with immunocytochemistry, electron microscopy, computerized morphological reconstruction and single-cell genomics and proteomics, have greatly expanded the compendium of 
known properties of neocortical interneurons (Markram et al., 2004). That a unified classification scheme has been slow to emerge is largely attributable to the inherent uncertainty in the "identity" of cortical neurons, making it difficult to correlate data acquired by different laboratories using different techniques. What has emerged are parallel systems of technique-specific, or even practitioner-specific classifications, each based on a limited set of features, and which are nearly impossible to reconcile with each other (Soltesz, 2005, Ch. 4). The advent of transgenic animals with genetically-encoded vital markers has made it possible to identify visually the same subsets of neurons in different animals, providing, for the first time, a means to correlate results across techniques, investigators and studies, and integrate them to a holistic portrait of neuronal subtypes, as a necessary step towards the ultimate goal of deciphering the cortical circuit. 


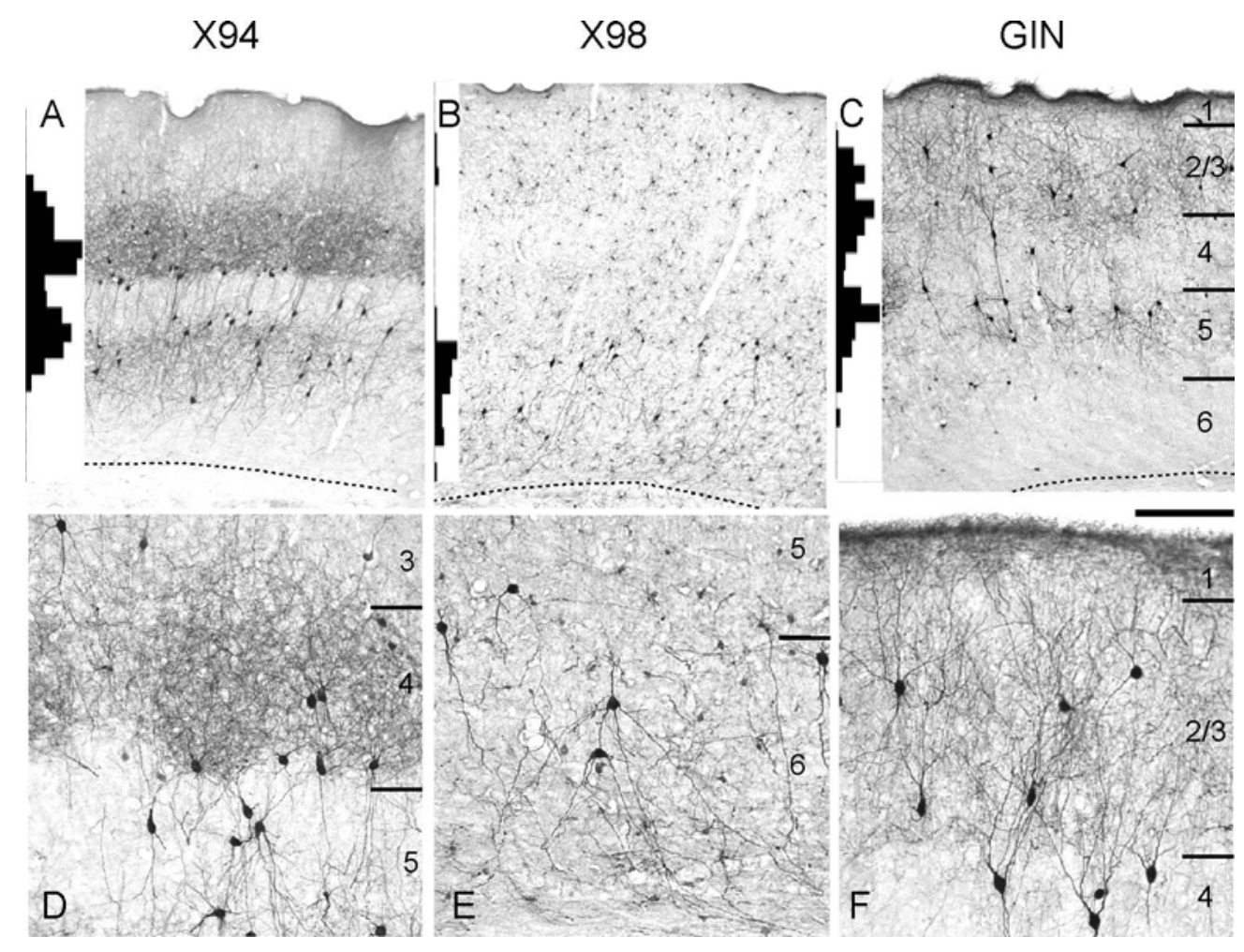

Figure 2.1. Laminar distribution patterns of GFP+ interneurons. GFP expression was visualized by anti-GFP immunocytochemistry in $40 \mu \mathrm{m}$-thick coronal sections from brains of 2-3 months old animals. A-C: low power images. D-F: high power images from different sections of the same brains. Histograms at the left margin of A-C show the laminar distribution of GFP+ neurons, counted in $50 \mu \mathrm{m}$ bins in vertical strips through the barrel cortex. Bin heights in the three panels are to the same scale; the highest bin in panel A represents 30 counts. Note the nearly complementary distribution patterns of the three lines. Laminar boundaries indicated in $\mathbf{C}$ apply also to $\mathbf{A}$ and $\mathbf{B}$; dotted lines indicate the white matter border. Panels D-F are not aligned by layers. Scale bar is 250 $\mu \mathrm{m}$ for A-C, $100 \mu \mathrm{m}$ for $\mathbf{D}-\mathbf{F}$. 

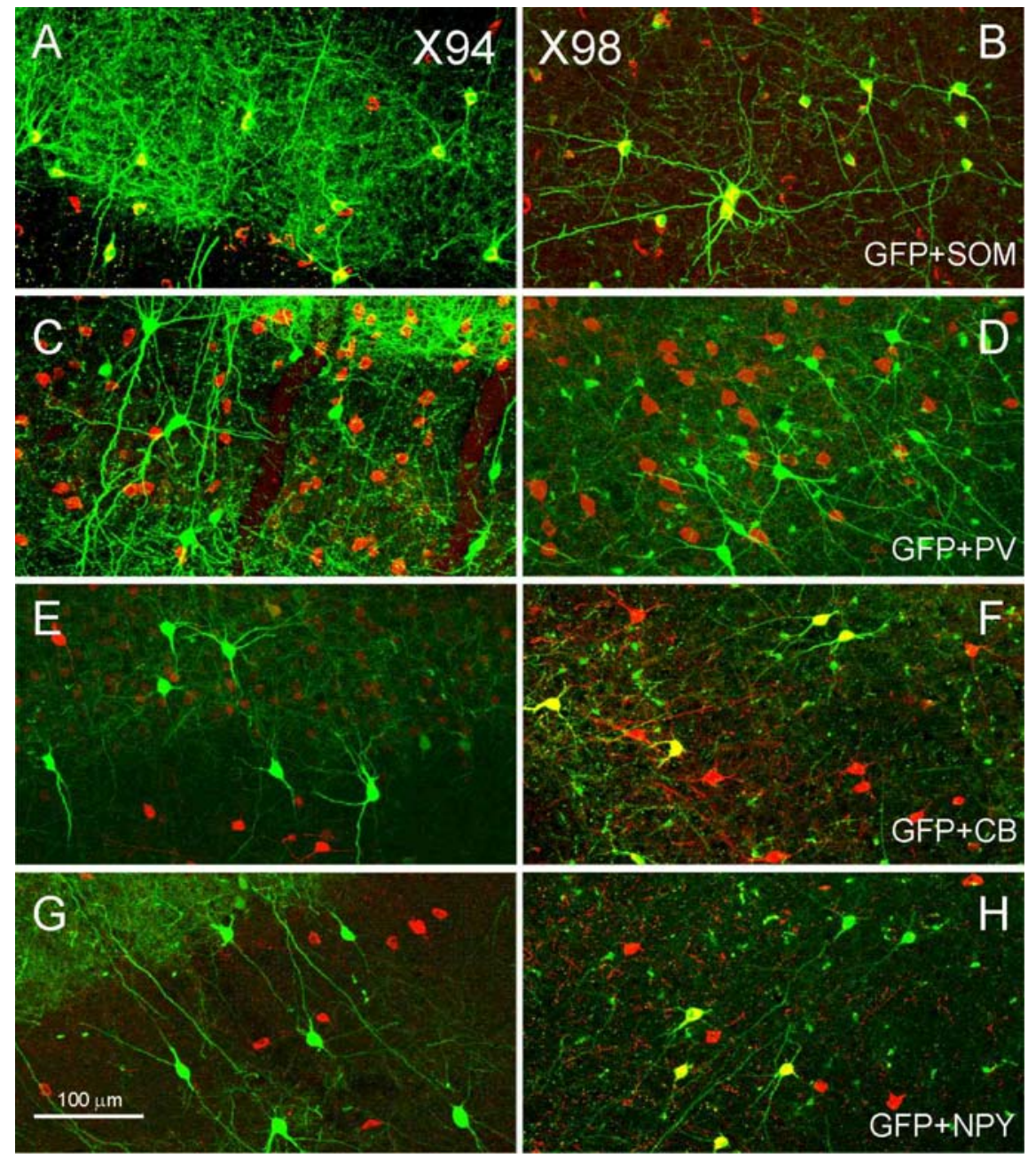

Figure 2.2. Neurochemical identity of GFP+ interneurons. Confocal images of parasagittal sections from X94 (A,C,E,G) and X98 (B,D,F,H) barrel cortex. GFP fluorescence is pseudocolored green, anti-SOM (A,B) anti-PV (C,D), anti-CB (E,F) and anti-NPY $(\mathbf{G}, \mathbf{H})$ immunoreactivity is pseudocolored red. Note that in both lines, all GFP+ neurons were SOM+ and PV-, but only X98 cells were CB+ (all) and NPY+ (some). The yellow seen in panel $\mathrm{C}$ represents overlap in the Z-dimension between redlabeled SOM+ cell bodies and green-labeled GFP+ processes, not colocalization of the two labels. 

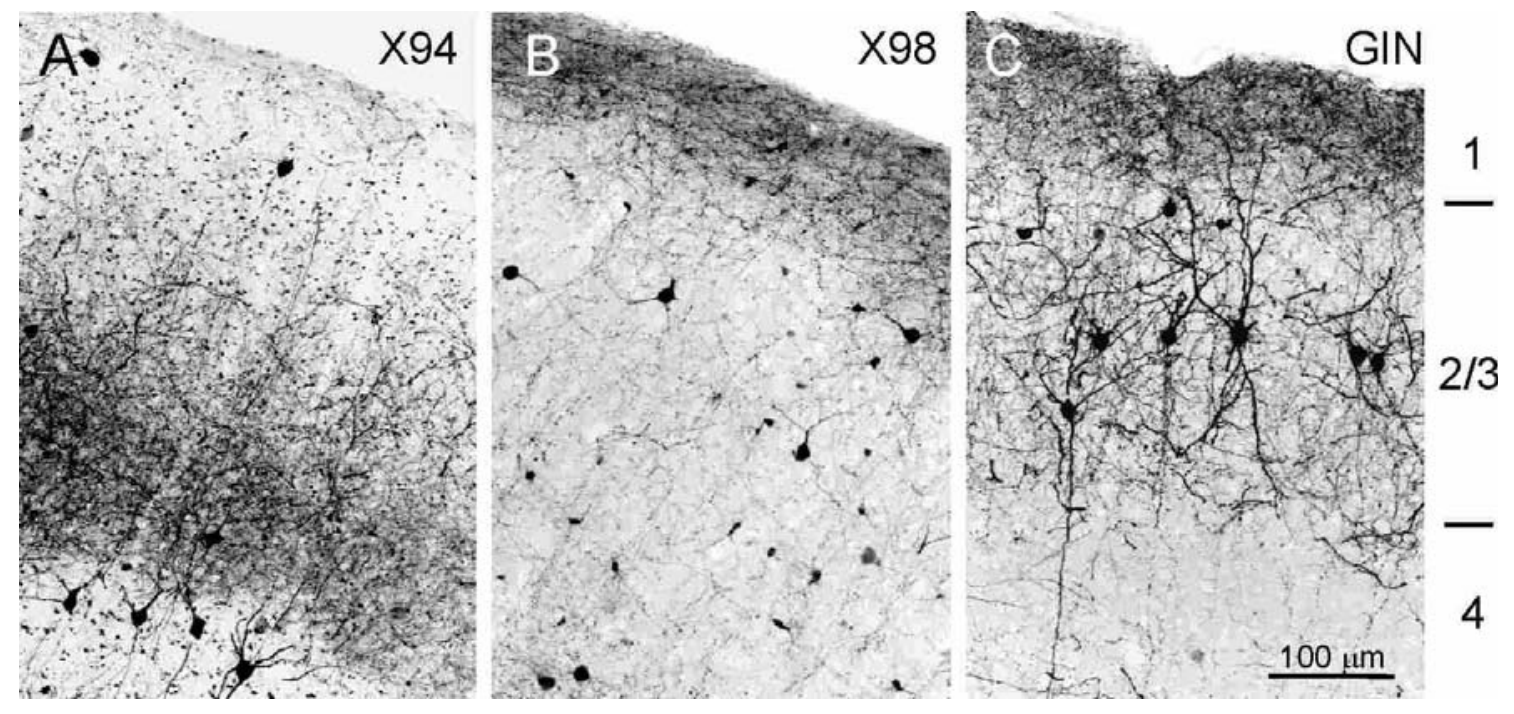

Figure 2.3. Comparison of axonal projections to layer 1. Digitally inverted confocal image stacks showing GFP-containing cell bodies and processes in the upper cortical layers of each line. Note the dense band of fluorescent fibers in layer 1 of X98 and GIN, but not X94 cortex. 


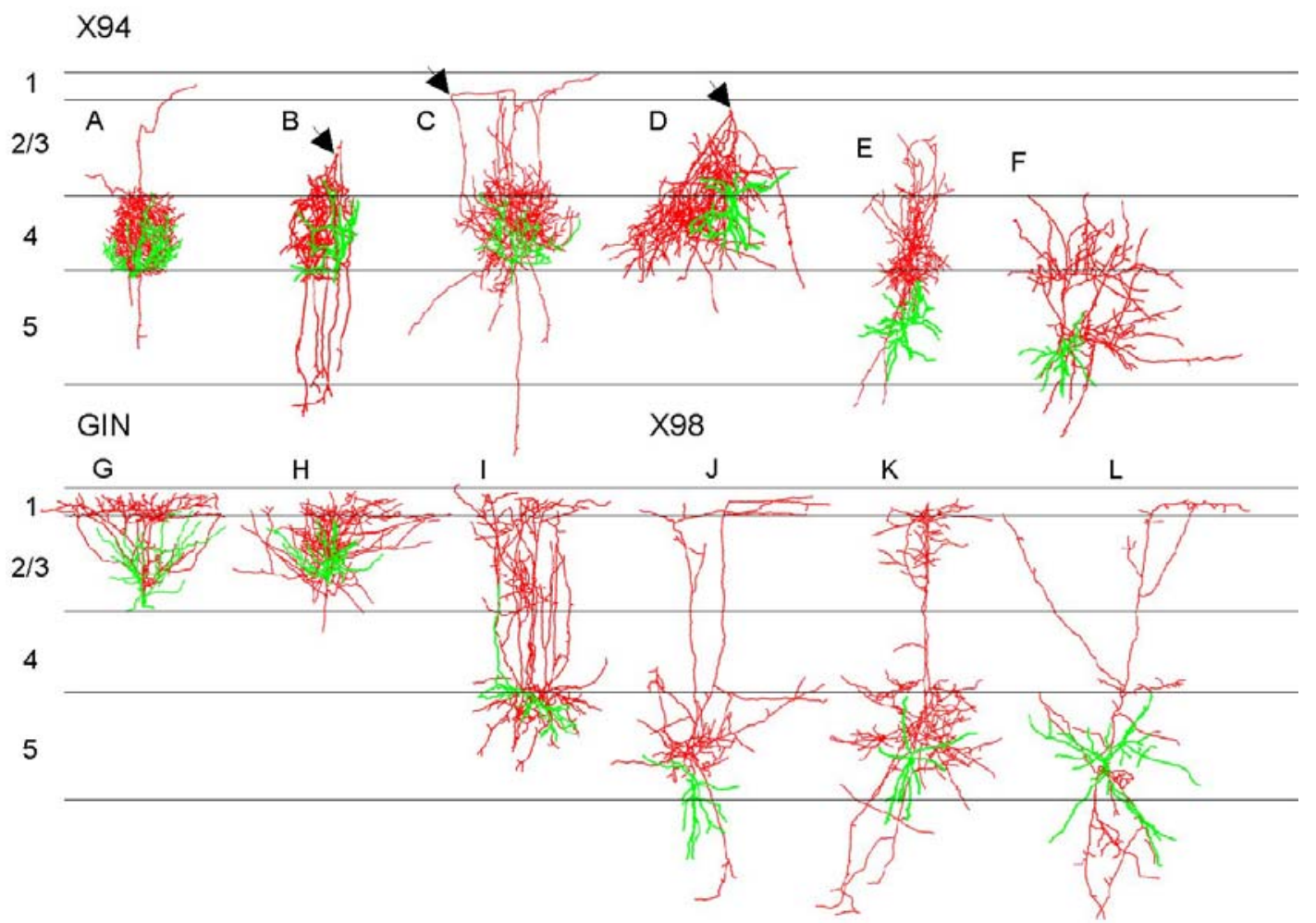

Figure 2.4. Morphological reconstructions of representative GFP+ neurons. Neurons were reconstructed in 3-D using Neurolucida; cell bodies and dendrites are shown in green, axons in red. For ease of comparison, individual drawings were normalized to the same width of layer 4; average width of layer 4 was $240 \pm 7.5 \mu \mathrm{m}$ (mean $\pm \mathrm{SEM})$. Arrowheads in B-D point to a turning point of the axon, from the upper layers back to layer 4 . 

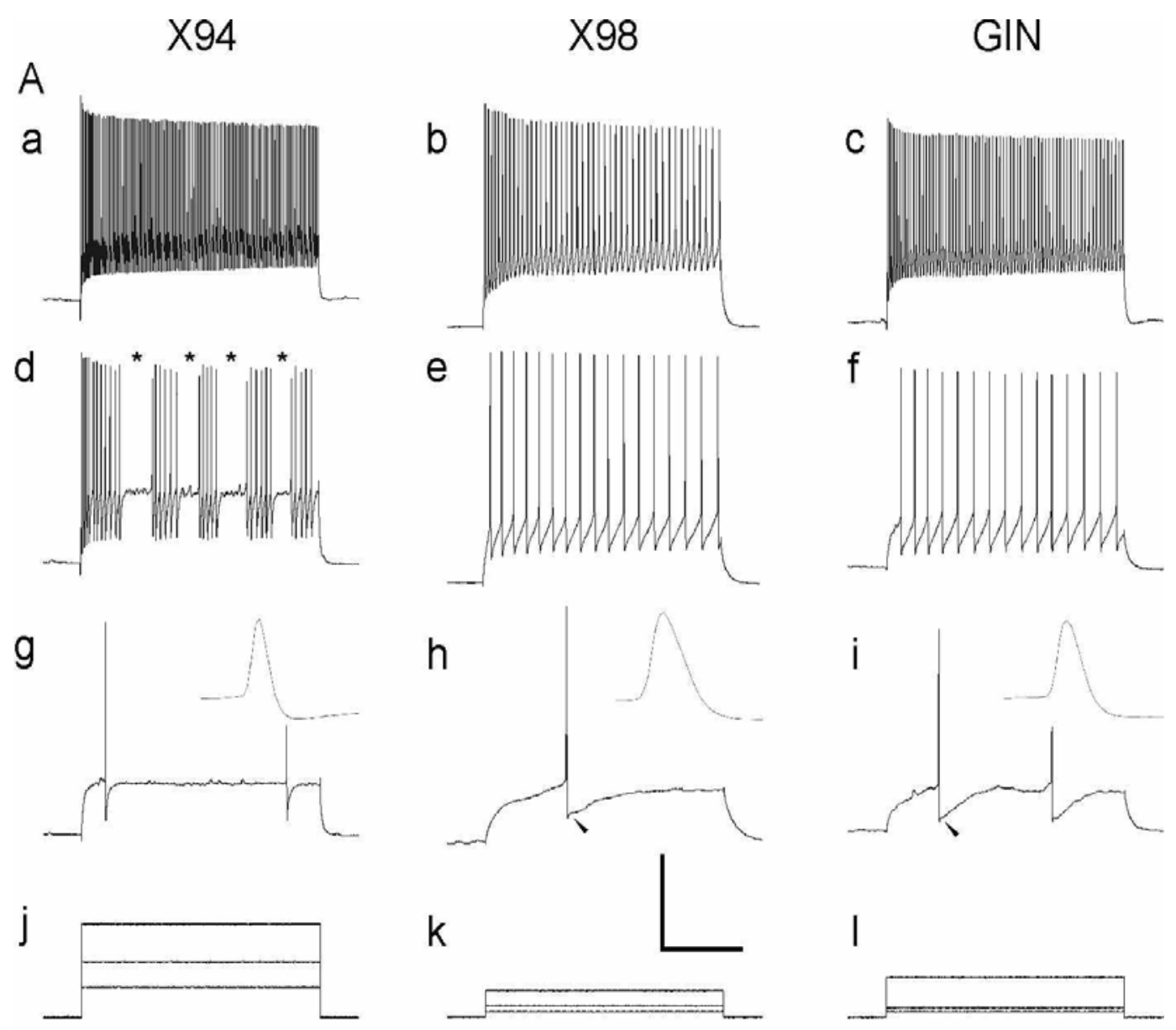

B
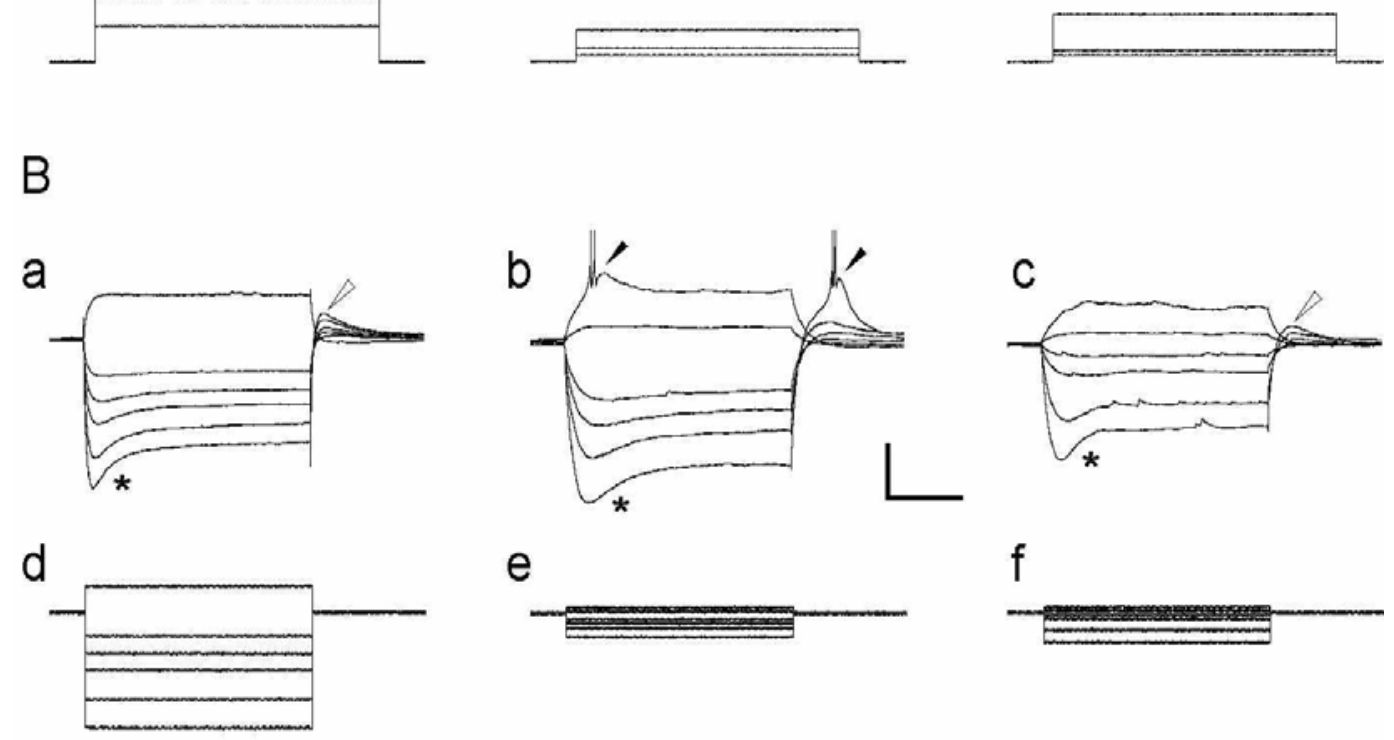
Figure 2.5. Supra- and subthreshold responses of GFP+ neurons. A: Spike trains in response to current steps of increasing amplitudes. Panels a-c, $\mathbf{d - f}$ and $\mathbf{g - i}$ are responses to high, medium and low current levels, respectively; the three current steps for each neuron are shown superimposed in $\mathbf{j}-\mathbf{l}$. Asterisks in $\mathbf{d}$ denote interruptions in firing characteristic of stuttering X94 neurons; some GIN neurons also stuttered, but X98 neurons never did. Insets in g-i are the first action potential from the corresponding trace, shown at half the vertical scale and at a 100-fold expanded horizontal scale; note the pronounced difference in spike widths between lines. Arrowheads in h,i point to the characteristic triphasic AHP in X98 and GIN neurons. Scale bar: $40 \mathrm{mV}$ (a-i), 1000 pA (j-l), $200 \mathrm{~ms}$. B: Superimposed voltage responses (a-c) to the hyperpolarizing and small depolarizing current steps shown in $\mathbf{d - f}$, in three other neurons. Note the very low input resistance of the X94 neuron compared to that of the X98 and GIN neurons (much larger current steps required to elicit similar voltage changes). Asterisks in a-c indicate the "sag" attributable to the hyperpolarization-activated cationic current $\mathrm{I}_{\mathrm{h}}$. Hollow arrowheads in a,c denote a depolarizing rebound, also attributable to $\mathrm{I}_{\mathrm{h}}$. Solid arrowheads in boint to bursts of action potentials riding on low-threshold $\mathrm{Ca}^{2+}$ spikes (LTS). Scale bar: $20 \mathrm{mV}$ (a-c), 300 pA (d-f), $200 \mathrm{~ms}$. 
A $\quad$ X94 $\quad$ B $\quad$ GIN

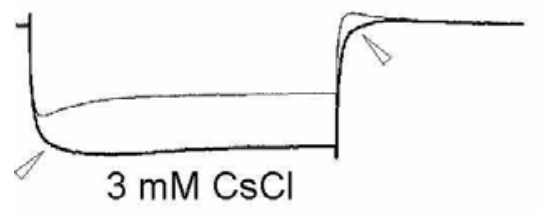

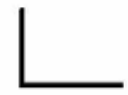

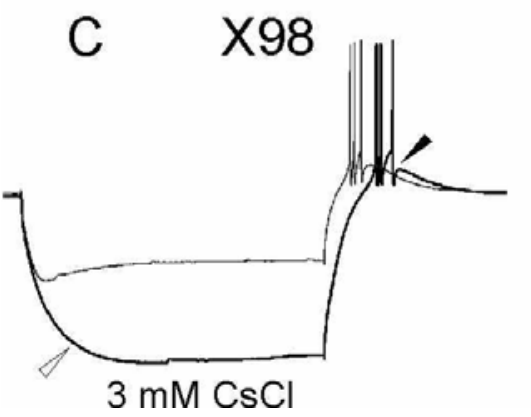

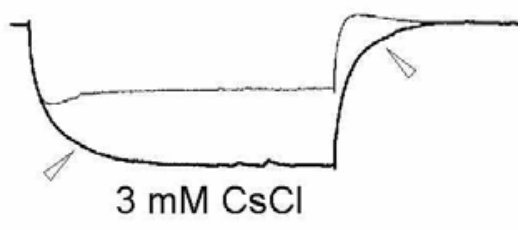

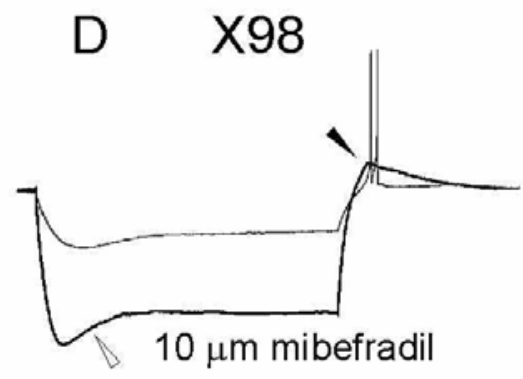

Figure 2.6. The ionic basis of the rebound burst. In all panels, control traces are drawn as thinner lines. $\mathrm{CsCl}(3 \mathrm{mM})$, which blocks the hyperpolarization-activated cationic current $\mathrm{I}_{\mathrm{h}}$, blocked both the sag and the rebound depolarization in X94 and GIN cells (A,B, hollow arrowheads). In bursting $\mathrm{X} 98$ cells, $\mathrm{CsCl}$ blocked the sag (C, hollow arrowhead) but not the burst (solid arrowhead). In contrast, the $\mathrm{I}_{\mathrm{T}}$ channel blocker mibefradil (10 $\mu \mathrm{m})$ did not block the sag (D, hollow arrowhead), but blocked the burst in spite of the large depolarizing rebound (solid arrowhead) evoked by a stronger hyperpolarization ($120 \mathrm{pA}$ in mibefradil, compared to $-40 \mathrm{pA}$ in control). Note that in panels A-C, the superimposed responses in each panel were evoked by the same current step. Scale bar: $40 \mathrm{mV}, 200 \mathrm{~ms}$. 
A

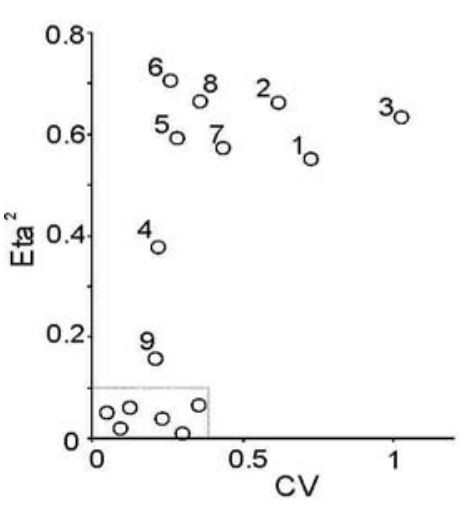

B
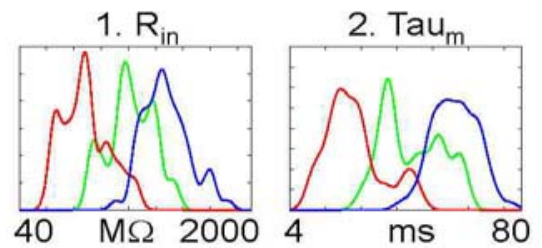

3. Rheobase

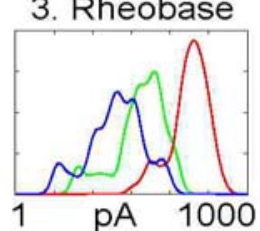

4. Rate of rise

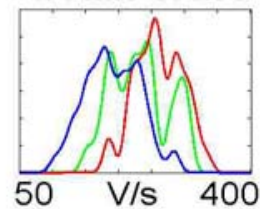

5. Rate of fall

6. Spike width
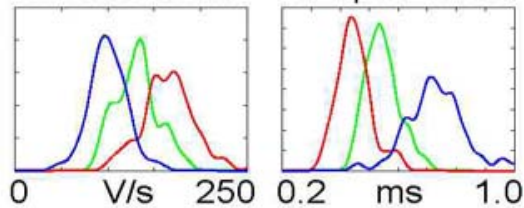

7. $F_{\text {max }}$ :s.s.

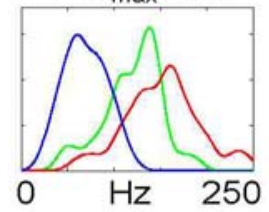

8. $F_{\text {max }}$ : initial
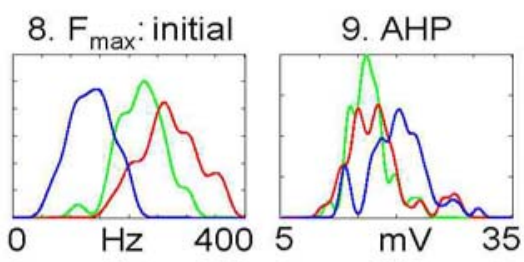

$\mathcal{C}$

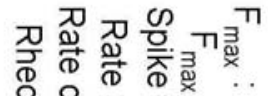

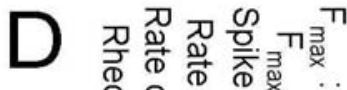

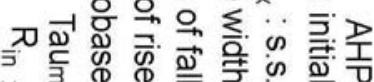

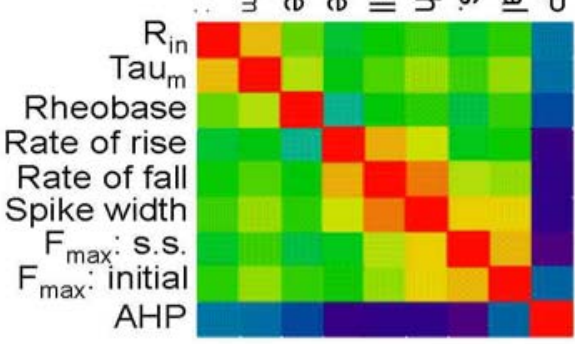

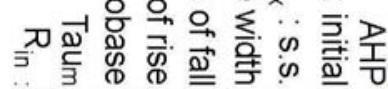
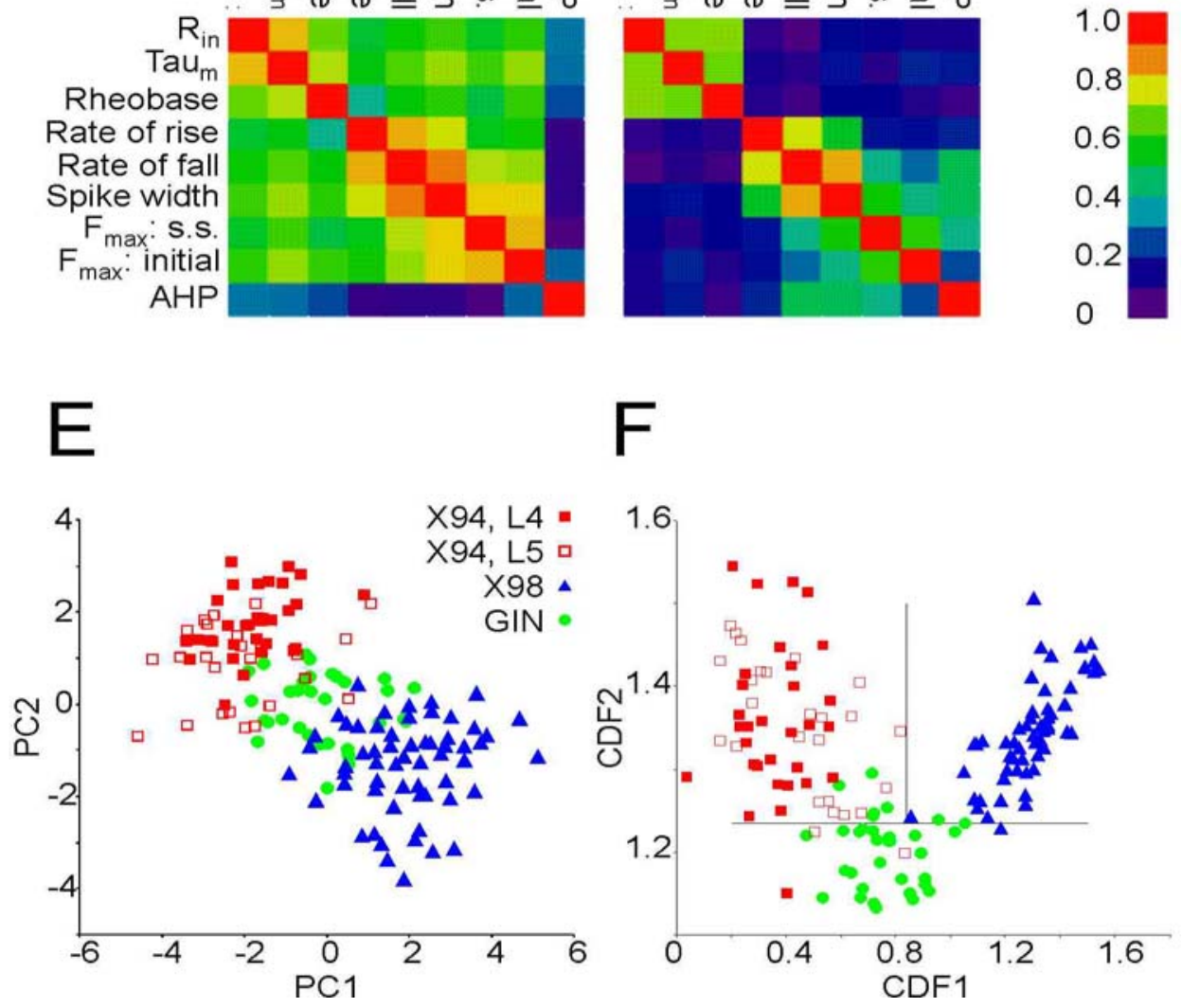
Figure 2.7. Multivariate analysis of electrophysiological parameters. A: Grouping of parameters according to their coefficient of variation (CV) and their fractional betweengroup variance $\left(e t a^{2}\right)$. The nine numbered datapoints correspond, respectively, to the numbered parameters in panel B. The half-box (near the origin of axes) encloses parameters with $e t a^{2}<0.1$ and $\mathrm{CV}<0.35$. B: Density plots (computed with a Gaussian kernel) of the nine parameters with $e t a^{2}>0.1$, separated by transgenic line. Only the two extreme X-values are indicated for each plot. Parameters 1-3 are plotted in a logarithmic scale. C: Total-sample correlation matrix of parameters 1-9; the absolute values of the pairwise Pearson correlation coefficients are coded by color. D: Pooled within-group correlation matrix of the nine parameters. Note the separate clusters of passive (1-3) and active (4-9) parameters; parameters are correlated within, but not between, each cluster. E: Scatterplot of the electrophysiological parameters of the three neuronal subtypes in the principal component plane. Each principal component is a linear combination of the original 9 parameters; PC1 correlates strongly with active parameters, PC2 with passive parameters. X94 datapoints are separated into layer 4 and layer 5B cells. F: scatterplot of the electrophysiological parameters of the three neuronal subsets in the canonical discriminant function plane. Each CDF is a linear combination of 11 electrophysiological parameters. X94 neurons are separated into layer 4 cells and layer 5B cells. The two intersecting lines separate the plane into three regions, with good segregation of the three groups into separate regions. 
This page is intentionally blank. 
Table 2.1. Overlap between GFP and SOM, CB and NPY expression, by line and by laminar position

\begin{tabular}{|c|c|c|c|c|c|c|c|c|c|c|c|c|c|}
\hline \multirow[t]{2}{*}{ Line } & \multirow[t]{2}{*}{ Layer } & \multicolumn{2}{|c|}{ SOM+ } & \multicolumn{2}{|c|}{$\mathrm{GFP}+$} & \multicolumn{2}{|c|}{$\mathrm{CB}+$} & \multicolumn{2}{|c|}{ GFP+ } & \multicolumn{2}{|c|}{$\mathrm{NPY}+$} & \multicolumn{2}{|c|}{$\mathrm{GFP}+$} \\
\hline & & $\mathrm{N}$ & $\% \mathrm{DL}$ & $\mathrm{N}$ & $\% \mathrm{DL}$ & $\mathrm{N}$ & $\% \mathrm{DL}$ & $\mathrm{N}$ & $\% \mathrm{DL}$ & $\mathrm{N}$ & $\% \mathrm{DL}$ & $\mathrm{N}$ & $\% \mathrm{DL}$ \\
\hline \multirow{4}{*}{ X94 } & $2-3$ & 382 & 5.9 & 23 & 100.0 & & & & & & & & \\
\hline & 4 & 408 & 40.9 & 174 & 96.2 & 48 & 0 & 78 & 0 & 48 & 0 & 30 & 0 \\
\hline & $5-6$ & 1079 & 13.0 & 151 & 92.7 & 425 & 0 & 88 & 0 & 177 & 0 & 65 & 0 \\
\hline & All & 1869 & 17.6 & 348 & 94.9 & 473 & 0 & 166 & 0 & 225 & 0 & 95 & 0 \\
\hline \multirow{3}{*}{ X98 } & $2-3$ & 271 & 12.9 & 35 & 100.0 & 173 & 20.2 & 38 & 92.1 & 126 & 1.6 & 13 & 15.4 \\
\hline & $5-6$ & 694 & 20.3 & 148 & 95.2 & 558 & 21.3 & 124 & 96.0 & 456 & 12.3 & 137 & 40.9 \\
\hline & All & 1153 & 15.6 & 186 & 96.2 & 530 & 20.8 & 115 & 95.7 & 582 & 10.0 & 150 & 38.7 \\
\hline \multirow{4}{*}{ GIN } & $2-3$ & 299 & 34.8 & 110 & 95.9 & 172 & 14.0 & 76 & 31.6 & 291 & 6.2 & 80 & 26.9 \\
\hline & 4 & 171 & 26.5 & 45 & 100 & 40 & 0 & 35 & 0 & 114 & 0 & 71 & 0 \\
\hline & $5-6$ & 492 & 10.8 & 56 & 97.4 & 417 & 11.3 & 96 & 49.0 & 159 & 0.6 & 71 & 1.4 \\
\hline & All & 96 & 21.2 & 211 & 97.1 & 629 & 11.3 & 207 & 34.3 & 564 & 3.4 & 222 & 8.6 \\
\hline
\end{tabular}

For each marker, both the percent of marker-immunopositive cells expressing GFP, and the percent of GFP-expressing cells immunopositive for the marker, are indicated. $\mathrm{DL}=$ double labeled cells. 
Table 2.2. Values for 15 electrophysiological parameters analyzed for each neuron

\begin{tabular}{|c|c|c|c|c|c|c|c|c|c|c|}
\hline & & All & X94 & X98 & GIN & & All & X94 & X98 & GIN \\
\hline $\mathrm{N}$ & & 150 & 58 & 59 & 33 & & 150 & 58 & 59 & 33 \\
\hline $\mathrm{Eta}^{2}$ & $V_{\text {rest }}$ & 0.05 & & & & Spike height & 0.06 & & & \\
\hline$p$-value & $(\mathrm{mV})$ & 0.0230 & & & & $(\mathrm{mV})$ & 0.0120 & & & \\
\hline $10 \%$ & & -72.5 & -73.2 & -72.3 & -69.8 & & 51.7 & 51.0 & 53.0 & 48.1 \\
\hline $90 \%$ & & -63.9 & -64.6 & -63.7 & -64.7 & & 71.8 & 70.1 & 73.5 & 69.3 \\
\hline Mean & & -68.3 & -69.1 & -68.2 & -67.1 & & 60.9 & 60.3 & 63.0 & 58.1 \\
\hline $\mathrm{CV}$ & & 0.05 & 0.05 & 0.05 & 0.04 & & 0.13 & 0.12 & 0.12 & 0.13 \\
\hline $\mathrm{Eta}^{2}$ & Sag & 0.01 & & & & Threshold & 0.02 & & & \\
\hline$p$-value & & 0.5240 & & & & $(\mathrm{mV})$ & 0.2420 & & & \\
\hline $10 \%$ & & -0.41 & -0.42 & -0.40 & -0.38 & & -47.5 & -47.4 & -48.4 & -47.2 \\
\hline $90 \%$ & & -0.19 & -0.19 & -0.19 & -0.22 & & -38.3 & -37.9 & -37.4 & -40.5 \\
\hline Mean & & -0.30 & -0.31 & -0.29 & -0.30 & & -43.0 & -42.8 & -42.6 & -44.0 \\
\hline CV & & 0.30 & 0.33 & 0.28 & 0.27 & & 0.10 & 0.11 & 0.10 & 0.06 \\
\hline $\mathrm{Eta}^{2}$ & F-I slope & 0.06 & & & & Adaptation ratio & 0.04 & & & \\
\hline$p$-value & (Hz/pA) & 0.0071 & & & & & 0.0620 & & & \\
\hline $10 \%$ & & 0.47 & 0.53 & 0.40 & 0.55 & & 0.39 & 0.41 & 0.36 & 0.41 \\
\hline $90 \%$ & & 1.12 & 1.26 & 0.98 & 0.81 & & 0.71 & 0.77 & 0.68 & 0.63 \\
\hline Mean & & 0.74 & 0.82 & 0.68 & 0.71 & & 0.54 & 0.57 & 0.51 & 0.54 \\
\hline $\mathrm{CV}$ & & 0.35 & 0.34 & 0.39 & 0.25 & & 0.23 & 0.25 & 0.23 & 0.18 \\
\hline $\mathrm{Eta}^{2}$ & $\mathbf{R}_{\text {in }}$ & 0.55 & & & & $\mathrm{Tau}_{\mathrm{m}}$ & 0.66 & & & \\
\hline$p$-value & (MW) & 0.0000 & & & & (ms) & 0.0000 & & & \\
\hline $10 \%$ & & 92 & 73 & 304 & 149 & & 7.2 & 6.0 & 24.1 & 12.5 \\
\hline $90 \%$ & & 602 & 218 & 796 & 403 & & 41.4 & 17.3 & 47.2 & 33.9 \\
\hline Mean & & 316 & 132 & 514 & 282 & & 22.2 & 9.9 & 35.0 & 20.9 \\
\hline CV & & 0.73 & 0.43 & 0.44 & 0.39 & & 0.62 & 0.42 & 0.29 & 0.41 \\
\hline $\mathrm{Eta}^{2}$ & Rheobase & 0.63 & & & & Rate of rise & 0.38 & & & \\
\hline$p$-value & $(\mathrm{pA})$ & 0.0000 & & & & (V/s) & 0.0000 & & & \\
\hline $10 \%$ & & 11 & 77 & 7 & 13 & & 161 & 217 & 137 & 181 \\
\hline $90 \%$ & & 266 & 331 & 57 & 90 & & 293 & 307 & 241 & 295 \\
\hline Mean & & 100 & 202 & 27 & 51 & & 227 & 261 & 191 & 232 \\
\hline CV & & 1.03 & 0.47 & 0.78 & 0.59 & & 0.22 & 0.14 & 0.22 & 0.19 \\
\hline $\mathrm{Eta}^{2}$ & Rate of fall & 0.59 & & & & Spike width & 0.72 & & & \\
\hline$p$-value & $(\mathrm{V} / \mathrm{s})$ & 0.0000 & & & & $(\mathrm{~ms})$ & 0.0000 & & & \\
\hline $10 \%$ & & -183 & -201 & -122 & -164 & & 0.42 & 0.38 & 0.62 & 0.48 \\
\hline $90 \%$ & & -89 & -130 & -79 & -103 & & 0.79 & 0.50 & 0.86 & 0.63 \\
\hline Mean & & -133 & -166 & -101 & -132 & & 0.58 & 0.45 & 0.74 & 0.55 \\
\hline CV & & 0.28 & 0.17 & 0.20 & 0.17 & & 0.27 & 0.13 & 0.16 & 0.10 \\
\hline $\mathrm{Eta}^{2}$ & Fmax, s.s. & 0.57 & & & & Fmax, initial & 0.67 & & & \\
\hline$p$-value & $(\mathrm{Hz})$ & 0.0000 & & & & $(\mathrm{~Hz})$ & 0.0000 & & & \\
\hline $10 \%$ & & 49 & 106 & 41 & 80 & & 106 & 201 & 86 & 180 \\
\hline $90 \%$ & & 175 & 201 & 103 & 148 & & 304 & 343 & 188 & 265 \\
\hline Mean & & 113 & 152 & 69 & 120 & & 206 & 270 & 135 & 221 \\
\hline CV & & 0.44 & 0.26 & 0.33 & 0.26 & & 0.36 & 0.19 & 0.27 & 0.18 \\
\hline $\mathrm{Eta}^{2}$ & AHP & 0.16 & & & & & & & & \\
\hline$p$-value & $(\mathrm{mV})$ & 0.0000 & & & & & & & & \\
\hline $10 \%$ & & 13.7 & 13.2 & 15.8 & 13.9 & & & & & \\
\hline $90 \%$ & & 23.3 & 23.0 & 24.1 & 19.8 & & & & & \\
\hline Mean & & 18.3 & 17.5 & 20.2 & 16.5 & & & & & \\
\hline CV & & 0.21 & 0.23 & 0.18 & 0.15 & & & & & \\
\hline
\end{tabular}


The $10^{\text {th }}$ and $90^{\text {th }}$ percentiles, mean, and coefficient of variation $(\mathrm{CV})$ are indicated for each parameter. Also indicated for each parameter are its eta ${ }^{2}$ and the p-value of eta ${ }^{2}$. The 9 parameters in bold type had $e t a^{2}>0.1$ and p-values lower than our computational limit of $\mathrm{p}=0.0001$ (probably by several orders of magnitude). All parameters are defined in Methods. 
Table 2.3. Summary of the phenotypic differences between X94 and X98 neurons

\begin{tabular}{|c|c|c|}
\hline Phenotypic property & X94 & X98 \\
\hline Cell body position & Layers 4 and 5B & Layers 5B and 6 \\
\hline $\begin{array}{c}\text { Layer 4 axonal } \\
\text { arborizations } \\
\text { Layer 1 axonal } \\
\text { arborizations }\end{array}$ & Dense & None or sparse \\
\hline Sone or sparse & Dense \\
Somatostatin & All & All \\
Calbindin & None & All \\
Neuropeptide $\mathrm{N}$ & None & $\sim 40 \%$ \\
& & \\
\hline & & \\
Input resistance & $<250 \mathrm{MW}$ & $>300 \mathrm{MW}$ \\
Time constant & $<20 \mathrm{~ms}$ & $>20 \mathrm{~ms}$ \\
Spike width & $\leq 0.5 \mathrm{~ms}$ & $<0.6 \mathrm{~ms}$ \\
$\mathrm{~F}_{\text {max }}$ initial & $>200 \mathrm{~Hz}$ & $<200 \mathrm{~Hz}$ \\
$\mathrm{~F}_{\text {max }}$ steady-state & $>100 \mathrm{~Hz}$ & $<100 \mathrm{~Hz}$ \\
& & \\
\hline Robust stuttering & $\sim 60 \%$ & $\sim 3 \%$ \\
Low-threshold spikes & $\sim 2 \%$ & $\sim 40 \%$ \\
\hline
\end{tabular}

Phenotypic properties are arranged in 5 groups: laminar position, axonal distributions, neurochemical content, electrophysiological parameters and firing properties. Inequalities in the electrophysiological parameter group apply to at least $90 \%$ of each population. 


\section{REFERENCES}

Agmon A, Yang LT, O'Dowd DK, Jones EG (1993) Organized growth of thalamocortical axons from the deep tier of terminations into layer IV of developing mouse barrel cortex. J Neurosci 13:5365-5382.

Beierlein M, Gibson JR, Connors BW (2003) Two dynamically distinct inhibitory networks in layer 4 of the neocortex. J Neurophysiol 90:2987-3000.

Butt SJ, Fuccillo M, Nery S, Noctor S, Kriegstein A, Corbin JG, Fishell G (2005) The temporal and spatial origins of cortical interneurons predict their physiological subtype. Neuron 48:591-604.

Castellani V, Bolz J (1997) Membrane-associated molecules regulate the formation of layer-specific cortical circuits. PNAS 94:7030-7035.

Castellani V, Yue Y, Gao PP, Zhou R, Bolz J (1998) Dual action of a ligand for Eph receptor tyrosine kinases on specific populations of axons during the development of cortical circuits. J Neurosci 18:4663-4672.

Chattopadhyaya B, Di Cristo G, Higashiyama H, Knott GW, Kuhlman SJ, Welker E, Huang ZJ (2004) Experience and activity-dependent maturation of perisomatic GABAergic innervation in primary visual cortex during a postnatal critical period. J Neurosci 24:9598-9611.

DeFelipe J (1999) Chandelier cells and epilepsy. Brain 122 ( Pt 10):1807-1822.

DeFelipe J, Jones EG (1988) Cajal on the Cerebral Cortex. New York: Oxford University Press.

Deuchars J, Thomson AM (1995) Innervation of burst firing spiny interneurons by pyramidal cells in deep layers of rat somatomotor cortex: paired intracellular recordings with biocytin filling. Neuroscience 69:739-755.

Eadie LA, Parnavelas JG, Franke E (1987) Development of the ultrastructural features of somatostatin-immunoreactive neurons in the rat visual cortex. J Neurocytol 16:445-459.

Erisir A, Lau D, Rudy B, Leonard CS (1999) Function of specific K(+) channels in sustained high-frequency firing of fast-spiking neocortical interneurons. J Neurophysiol 82:2476-2489.

Freund TF, Buzsaki G (1996) Interneurons of the hippocampus. Hippocampus 6:347-470.

Gabbott PL, Dickie BG, Vaid RR, Headlam AJ, Bacon SJ (1997) Local-circuit neurones in the medial prefrontal cortex (areas 25,32 and 24b) in the rat: morphology and quantitative distribution. J Comp Neurol 377:465-499. 
Galarreta M, Hestrin S (2002) Electrical and chemical synapses among parvalbumin fastspiking GABAergic interneurons in adult mouse neocortex. PNAS 99:12438-12443.

Goldberg JH, Lacefield CO, Yuste R (2004) Global dendritic calcium spikes in mouse layer 5 low threshold spiking interneurones: implications for control of pyramidal cell bursting. J Physiol 558:465-478.

Goldstein SA, Bockenhauer D, O'Kelly I, Zilberberg N (2001) Potassium leak channels and the KCNK family of two-P-domain subunits. Nat Rev Neurosci 2:175-184.

Good PI (1999) Resampling Methods. Boston: Birkhauser.

Gulyas AI, Miles R, Hajos N, Freund TF (1993) Precision and variability in postsynaptic target selection of inhibitory cells in the hippocampal CA3 region. Eur J Neurosci 5:1729-1751.

Gupta A, Wang Y, Markram H (2000) Organizing principles for a diversity of GABAergic interneurons and synapses in the neocortex. Science 287:273-278.

Hand D, Mannila H, Smyth P (2001) Principles of Data Mining. Cambridge, MA: MIT Press.

Jin X, Hu H, Mathers PH, Agmon A (2003) Brain-derived neurotrophic factor mediates activity-dependent dendritic growth in nonpyramidal neocortical interneurons in developing organotypic cultures. J Neurosci 23:5662-5673.

Jin X, Mathers PH, Szabo G, Katarova Z, Agmon A (2001) Vertical bias in dendritic trees of non-pyramidal neocortical neurons expressing GAD67-GFP in vitro. Cereb Cortex 11:666-678.

Katarova Z, Mugnaini E, Sekerkova G, Mann JR, Aszodi A, Bosze Z, Greenspan R, Szabo G (1998) Regulation of cell-type specific expression of lacZ by the 5'-flanking region of mouse GAD67 gene in the central nervous system of transgenic mice. Eur J Neurosci 10:989-999.

Katz LC, Callaway EM (1992) Development of local circuits in mammalian visual cortex. Annu Rev Neurosci 15:31-56.

Kawaguchi Y (1993) Groupings of nonpyramidal and pyramidal cells with specific physiological and morphological characteristics in rat frontal cortex. J Neurophysiol 69:416-431.

Kawaguchi Y (1995) Physiological subgroups of nonpyramidal cells with specific morphological characteristics in layer II/III of rat frontal cortex. J Neurosci 15:26382655. 
Kawaguchi Y, Kubota Y (1996) Physiological and morphological identification of somatostatin- or vasoactive intestinal polypeptide-containing cells among GABAergic cell subtypes in rat frontal cortex. J Neurosci 16:2701-2715.

Kawaguchi Y, Kubota Y (1997) GABAergic cell subtypes and their synaptic connections in rat frontal cortex. Cereb Cortex 7:476-486.

Kawaguchi Y, Shindou T (1998) Noradrenergic excitation and inhibition of GABAergic cell types in rat frontal cortex. J Neurosci 18:6963-6976.

Kawaguchi Y, Kondo S (2002) Parvalbumin, somatostatin and cholecystokinin as chemical markers for specific GABAergic interneuron types in the rat frontal cortex. $\mathrm{J}$ Neurocytol 31:277-287.

Kubota Y, Hattori R, Yui Y (1994) Three distinct subpopulations of GABAergic neurons in rat frontal agranular cortex. Brain Res 649:159-173.

Levitt P, Eagleson KL, Powell EM (2004) Regulation of neocortical interneuron development and the implications for neurodevelopmental disorders. Trends Neurosci 27:400-406.

Lewis DA, Hashimoto T, Volk DW (2005) Cortical inhibitory neurons and schizophrenia. Nat Rev Neurosci 6:312-324.

Lien CC, Jonas P (2003) Kv3 potassium conductance is necessary and kinetically optimized for high-frequency action potential generation in hippocampal interneurons. $\mathrm{J}$ Neurosci 23:2058-2068.

Lobo MK, Karsten SL, Gray M, Geschwind DH, Yang XW (2006) FACS-array profiling of striatal projection neuron subtypes in juvenile and adult mouse brains. Nat Neurosci 9:443-452.

Long MA, Cruikshank SJ, Jutras MJ, Connors BW (2005) Abrupt maturation of a spikesynchronizing mechanism in neocortex. J Neurosci 25:7309-7316.

Lorente de No R (1992) The cerebral cortex of the mouse (a first contribution--the "acoustic" cortex). Somatosens Mot Res 9:3-36.

Lupica CR, Bell JA, Hoffman AF, Watson PL (2001) Contribution of the hyperpolarization-activated current $(\mathrm{I}(\mathrm{h}))$ to membrane potential and GABA release in hippocampal interneurons. J Neurophysiol 86:261-268.

Maccaferri G, McBain CJ (1996) The hyperpolarization-activated current (Ih) and its contribution to pacemaker activity in rat CA1 hippocampal stratum oriens-alveus interneurones. J Physiol 497 ( Pt 1):119-130. 
Manly BFJ (2005) Multivariate Statistical Methods: A Primer. Boca Raton: Chapman \&Hall/CRC.

Markram H, Toledo-Rodriguez M, Wang Y, Gupta A, Silberberg G, Wu C (2004) Interneurons of the neocortical inhibitory system. Nat Rev Neurosci 5:793-807.

McBain CJ, Fisahn A (2001) Interneurons unbound. Nat Rev Neurosci 2:11-23.

McDonald JK, Parnavelas JG, Karamanlidis AN, Brecha N (1982) The morphology and distribution of peptide-containing neurons in the adult and developing visual cortex of the rat. II. Vasoactive intestinal polypeptide. J Neurocytol 11:825-837.

Meyer AH, Katona I, Blatow M, Rozov A, Monyer H (2002) In vivo labeling of parvalbumin-positive interneurons and analysis of electrical coupling in identified neurons. J Neurosci 22:7055-7064.

Migliore M, Shepherd GM (2005) Opinion: an integrated approach to classifying neuronal phenotypes. Nat Rev Neurosci 6:810-818.

Miller MW (1986a) The migration and neurochemical differentiation of gammaaminobutyric acid (GABA)-immunoreactive neurons in rat visual cortex as demonstrated by a combined immunocytochemical-autoradiographic technique. Brain Res 393:41-46.

Miller MW (1986b) Maturation of rat visual cortex. III. Postnatal morphogenesis and synaptogenesis of local circuit neurons. Brain Res 390:271-285.

Minelli A, Alonso-Nanclares L, Edwards RH, DeFelipe J, Conti F (2003) Postnatal development of the vesicular GABA transporter in rat cerebral cortex. Neuroscience 117:337-346.

Mott DD, Turner DA, Okazaki MM, Lewis DV (1997) Interneurons of the dentate-hilus border of the rat dentate gyrus: morphological and electrophysiological heterogeneity. $\mathrm{J}$ Neurosci 17:3990-4005.

Mugnaini E, Oertel WH (1985) An atlas of the distribution of GABAergic neurons and terminals in the rat CNS as revealed by GAD immunohistochemistry. In: Handbook of Chemical Neuroanatomy (Bjorklund A, Hokfelt T, eds). Amsterdam: Elsevier.

Oliva AA, Jr., Jiang M, Lam T, Smith KL, Swann JW (2000) Novel hippocampal interneuronal subtypes identified using transgenic mice that express green fluorescent protein in GABAergic interneurons. J Neurosci 20:3354-3368.

Parra P, Gulyas AI, Miles R (1998) How many subtypes of inhibitory cells in the hippocampus? Neuron 20:983-993. 
Perez-Reyes E (2003) Molecular physiology of low-voltage-activated t-type calcium channels. Physiol Rev 83:117-161.

Porter JT, Johnson CK, Agmon A (2001) Diverse types of interneurons generate thalamus-evoked feedforward inhibition in the mouse barrel cortex. J Neurosci 21:26992710 .

Shlosberg D, Patrick SL, Buskila Y, Amitai Y (2003) Inhibitory effect of mouse neocortex layer I on the underlying cellular network. Eur J Neurosci 18:2751-2759.

Sidow A, Bowman BH (1991) Molecular phylogeny. Curr Opin Genet Dev 1:451-456.

Soltesz I (2005) Diversity in the Neuronal Machine: Oxford University Press.

Somogyi P, Klausberger T (2005) Defined types of cortical interneurone structure space and spike timing in the hippocampus. J Physiol 562:9-26.

Staiger JF, Zilles K, Freund TF (1996) Distribution of GABAergic elements postsynaptic to ventroposteromedial thalamic projections in layer IV of rat barrel cortex. Eur $\mathrm{J}$ Neurosci 8:2273-2285.

Sugino K, Hempel CM, Miller MN, Hattox AM, Shapiro P, Wu C, Huang ZJ, Nelson SB (2006) Molecular taxonomy of major neuronal classes in the adult mouse forebrain. Nat Neurosci 9:99-107.

Szabo G, Katarova Z, Kortvely E, Greenspan RJ, Urban Z (1996) Structure and the promoter region of the mouse gene encoding the $67-\mathrm{kD}$ form of glutamic acid decarboxylase. DNA Cell Biol 15:1081-1091.

Thomson AM, West DC, Hahn J, Deuchars J (1996) Single axon IPSPs elicited in pyramidal cells by three classes of interneurones in slices of rat neocortex. J Physiol 496 ( Pt 1):81-102.

Toledo-Rodriguez M, Blumenfeld B, Wu C, Luo J, Attali B, Goodman P, Markram H (2004) Correlation maps allow neuronal electrical properties to be predicted from singlecell gene expression profiles in rat neocortex. Cereb Cortex 14:1310-1327.

Valcanis H, Tan SS (2003) Layer specification of transplanted interneurons in developing mouse neocortex. J Neurosci 23:5113-5122.

Wahle P (1993) Differential regulation of substance P and somatostatin in Martinotti cells of the developing cat visual cortex. J Comp Neurol 329:519-538.

Wang Y, Gupta A, Toledo-Rodriguez M, Wu CZ, Markram H (2002) Anatomical, physiological, molecular and circuit properties of nest basket cells in the developing somatosensory cortex. Cereb Cortex 12:395-410. 
Wang Y, Toledo-Rodriguez M, Gupta A, Wu C, Silberberg G, Luo J, Markram H (2004) Anatomical, physiological and molecular properties of Martinotti cells in the somatosensory cortex of the juvenile rat. J Physiol 561:65-90.

Whittington MA, Traub RD (2003) Interneuron Diversity series: Inhibitory interneurons and network oscillations in vitro. Trends Neurosci 26:676-682.

Woolsey TA, Dierker ML, Wann DF (1975) Mouse SmI cortex: qualitative and quantitative classification of golgi- impregnated barrel neurons. PNAS 72:2165-2169.

Xu Q, de la Cruz E, Anderson SA (2003) Cortical interneuron fate determination: diverse sources for distinct subtypes? Cereb Cortex 13:670-676.

Xu Q, Cobos I, De La Cruz E, Rubenstein JL, Anderson SA (2004) Origins of cortical interneuron subtypes. J Neurosci 24:2612-2622.

Yunker AM (2003) Modulation and pharmacology of low voltage-activated ("T-Type") calcium channels. J Bioenerg Biomembr 35:577-598.

Yuste R (2005) Origin and classification of neocortical interneurons. Neuron 48:524-527.

Zhang L, McBain CJ (1995) Potassium conductances underlying repolarization and afterhyperpolarization in rat CA1 hippocampal interneurones. J Physiol 488 ( Pt 3):661-672. 


\section{Chapter Three}

Somatostatin-containing GABAergic interneurons are the major source of inhibition during high frequency network activity in layer 4 of mouse somatosensory cortex 


\begin{abstract}
GABAergic inhibitory interneurons play a pivotal role in balancing neuronal activity in the neocortex. In the somatosensory cortex, somatostatin-containing interneurons (SOM+ cells) mediate disynaptic inhibition in supragranular and infragranular layers. However, the roles of layer $4 \mathrm{SOM}+$ cells remain largely unknown. To explore this issue, we used dual whole-cell recording to elucidate the synaptic connections made by and upon layer 4 $\mathrm{SOM}+$ cells and their participation in high-frequency network activity. We found that layer $4 \mathrm{SOM}+$ cells received strong facilitating excitatory input from excitatory regularspiking (RS) cells, which were mostly spiny stellate cells, and that SOM+ cells generated relatively slow rising inhibitory postsynaptic currents (IPSCs) in postsynaptic targets, compared to IPSCs evoked by parvalbumin-containing (PV+), fast-spiking (FS) cells. Strikingly, the present study revealed that layer $4 \mathrm{SOM}+$ cells evoked strong synaptic inhibition in FS cells, with connection probability $>0.9$. Moreover, $100 \%$ of tested SOM+ cells were electrically coupled to each other with higher coupling ratio $(\sim 10 \%)$ compared to that between electrically coupled FS cells $(\sim 3 \%)$. In order to examine the function of $\mathrm{SOM}+$ cells during network activity, we applied $0 \mathrm{Mg}^{2+}$ artificial cerebrospinal fluid (ACSF) to induce episodes of high frequency network activity. During episodes of network activity, SOM+ cells fired robustly, synchronously and more frequently than FS cells, and produced strong inhibition in RS and FS cells, especially in the latter. We conclude that SOM+ cells are the major source of inhibitory effect in layer 4 during high frequency network activity.
\end{abstract}




\section{INTRODUCTION}

Layer 4 of the rodent somatosensory ("barrel") cortex is the major recipient of thalamocortical inputs conveying sensory information originating in the facial vibrissae. Understanding how neurons in layer 4 of barrel cortex execute their functions is crucial to understanding cortical information processing. Layer 4 is composed of three major types of neurons - excitatory "regular-spiking" (RS) cells, inhibitory parvalbumin-containing $(\mathrm{PV}+)$, "fast-spiking" (FS) cells, and inhibitory somatostatin-containing $(\mathrm{SOM}+)$ cells. $\mathrm{SOM}+$ cells are the second largest group of inhibitory interneuron, after PV + cells (Amitai et al., 2002). Because PV+ cells are easily identified electrophysiologically as FS cells, they have been studied extensively. SOM+ cells in layer 4 of somatosensory cortex, however, are more difficult to identify electrophysiologically (Ma et al., 2006).

In the neocortex, SOM+ cells in the infragranular layers (Goldberg et al., 2004; Silberberg and Markram, 2007; Kapfer et al., 2007) and in the supragranular layers (Kaiser et al, 2004; Kapfer et al., 2007) were previously studied. These other types of $\mathrm{SOM}+$ cells exhibit similar features: they are parvalbumin immunonegative (Wang et al., 2004) and they receive facilitating excitatory inputs, display spike frequency adaptation, and importantly, mediate disynaptic inhibition (Silberberg and Markram, 2007; Kapfer et al., 2007). Synaptic properties of non-FS layer 4 cells (Gibson et al., 1999, Beierlein et al., 2003; Porter et al., 2001) were also studied, but these non-FS cells may have belonged to diverse subtypes.

Spontaneous semi-periodic synaptic network activity $(<1 \mathrm{~Hz})$ has been reported in cortical areas in vitro and in vivo (Steriade et al., 1993; Shu et al., 2003; Haider et al., 2006). The semi-periodic oscillations consist of "UP" states, with characteristic robust synaptic barrages, and "DOWN" states, the relative quiescent phase. Activation of both excitatory and inhibitory neurons is involved in the "UP" states (Steriade et al., 1993; Shu et al., 2003). UP-DOWN oscillations can be mimicked in vitro by lowering extracellular calcium and magnesium concentrations (Shu et al., 2003). Similar, but not identical bouts of network activity, in which all neuronal subtypes participate, can be induced in vitro by removing extracellular $\mathrm{Mg}^{2+}$ (Flint et al., 1997; Kawaguchi, 2001). Although the function of layer $4 \mathrm{SOM}+$ cells during network activity has been studied by applying a specific 
agonist for SOM+ cells (Beierlein et al., 2000), the network function of layer $4 \mathrm{SOM}+$ cells during high frequency network activity in which all neuronal subtypes are active has not been examined previously.

In the present study, using transgenic mice in which green fluorescent protein-expressing $(\mathrm{GFP}+)$ cells in the barrel cortex are $\mathrm{SOM}+$ cells, we investigated the synaptic properties of layer $4 \mathrm{SOM}+$ cells, and their potential role in episodic network activity induced by removal of extracellular $\mathrm{Mg}^{2+}$. 


\section{MATERIALS AND METHODS}

Slice preparation. Juvenile mice (postnatal age 15-19 days) were anaesthetized deeply with halothane and decapitated. The brains were removed and submerged in ice-cold artificial cerebrospinal fluid (ACSF) containing (in $\mathrm{mM}$ ): $126 \mathrm{NaCl}, 3 \mathrm{KCl}, 1.25$ $\mathrm{NaH}_{2} \mathrm{PO}_{4}, 2 \mathrm{CaCl}_{2}, 1.3 \mathrm{MgSO}_{4}, 26 \mathrm{NaHCO}_{3}$, and $20 \mathrm{D}$-glucose. For induction of network activity, we replaced $1.3 \mathrm{mM} \mathrm{MgSO} 4$ with $1.3 \mathrm{mM} \mathrm{CaCl}_{2}$ for a total of $3.3 \mathrm{CaCl}_{2}$. Coronal cerebral slices (250-300 $\mu \mathrm{m}$ thick) were cut using a vibraslicer. After about 40 min of incubation in oxygenated $\mathrm{ACSF}$ at $34^{\circ} \mathrm{C}$, slices were incubated at room temperature until they were transferred to the recording chamber, where each slice was continuously superfused at $\sim 32^{\circ} \mathrm{C}$ with ACSF saturated with $95 \% \mathrm{O}_{2} / 5 \% \mathrm{CO}_{2}$ at a rate of $1.5-2 \mathrm{ml} / \mathrm{min}$.

Electrophysiological recording. Simultaneous dual whole-cell recordings were performed from pairs of neurons in the same barrel in layer 4 of somatosensory cortex, in both current clamp mode (Axoclamp 2B) and voltage clamp mode (Axopatch 200B, Molecular Devices). To target SOM+ cells and PV+ cells, we used two transgenic mouse lines, in which layer 4 cells expressing green fluorescent protein (GFP) are $\mathrm{SOM}+$ and PV+/FS cells, respectively (Chattopadhyava et al., 2004; Ma et al., 2006). We also recorded from non-GFP expressing FS cells, which were identified electrophysiologically. Patch pipettes (5-8 M $\Omega$ ) pulled from borosilicate glass capillaries (O.D./I.D., 1.2/0.68 $\mathrm{mm}$, WPI) were filled with intracellular solution containing (in $\mathrm{mM}$ ): $134 \mathrm{~K}$-gluconate, $3.5 \mathrm{KCl}, 0.1 \mathrm{CaCl}_{2}$, 10 HEPES, 1.1 EGTA, 4 ATP-Mg, and 10 Phosphocreatine-Tris, $\mathrm{pH}$ 7.2-7.3, 285-295 mOsm; $2 \mathrm{mg} / \mathrm{ml}$ biocytin was routinely included in the pipette solution. The low chloride $(3.7 \mathrm{mM})$ intracellular solution created a measured reversal potential of around $-82 \mathrm{mV}$ for inhibitory currents (uncorrected for liquid junction potential). Liquid junction potential was $13 \mathrm{mV}$ with our solutions; i.e. all reported membrane potentials are positively biased by $13 \mathrm{mV}$.

To examine the kinetics of IPSCs, a short (4 ms) depolarizing current pulse was injected into presynaptic interneurons at intervals of 8 seconds to trigger single action potentials 
(AP), while postsynaptic cells were held at $-50 \mathrm{mV}$. To study short-term IPSC dynamics, eight presynaptic APs were elicited at $20 \mathrm{~Hz}$ with same short positive current injection as above. We defined the paired-pulse ratio (PPR) and steady state ratio (SSR) as the amplitude of the $2^{\text {nd }}$ IPSC, and the average of the $6^{\text {th }}-8^{\text {th }}$ IPSCs, respectively, normalized by the $1^{\text {st }}$ IPSC. We tested for recovery by evoking a single recovery test response (RTR) in postsynaptic cells, by triggering a presynaptic AP $500 \mathrm{~ms}$ after the $8^{\text {th }} \mathrm{AP}$ in the spike train (Gupta et al., 2000). To examine short-term dynamics of excitatory postsynaptic responses, postsynaptic interneurons were held in current clamp mode at $-70 \mathrm{mV}$, and 8-20 APs were triggered at $20 \mathrm{~Hz}$ in presynaptic RS cells. The recorded postsynaptic responses were filtered at $2 \mathrm{kHz}$ and digitized at $20 \mathrm{kHz}$ with a National Instruments ADC board.

Cell type identification. During recording, RS cells were identified by the distinctive after-depolarization in their action potentials, which resulted in a characteristic "doublet" of spikes in the initial segment of their firing train. RS cell identities were also confirmed by the nature of the excitatory postsynaptic potential (EPSP) produced by them and by their spiny dendrites revealed by post-hoc histochemical reactions. FS cells not expressing GFP were distinguished from other types of inhibitory cells by their low input resistances, abrupt spike firing, their narrow spike widths and little frequency adaptation (Fig. 3.1).

Data analysis. Pipette access resistance was monitored and compensated (at 50\% for voltage-clamp recording) during the recording. IPSCs obtained with series resistances $>30 \mathrm{M} \Omega$, or with series resistance changes $>15 \%$, were excluded from analysis of their kinetics, synaptic strength and synaptic potency. Synaptic strength was defined as the amplitude of an average IPSC, including synaptic transmission failures. Synaptic potency was defined as the average amplitudes of IPSCs excluding failures. Rise times and decay times of average IPSCs were measured in the range of $20-80 \%$ and $10-70 \%$, respectively. All measurements were done on 6-50 averaged sweeps. Before averaging IPSCs, presynaptic spike peaks were aligned to eliminate "jitter". For electrical coupling analysis, we averaged the ratio of pre-to-postjunctional voltage deflection (about $20 \mathrm{mV}$ 
depolarization from rest in the prejunctional cell) in both directions for each coupled cell pair. For cross-correlation analysis between cell pairs, we used simultaneous records of subthreshold voltage fluctuations during network episodes; the reported cross-correlation value for each pair is an average from at least 10 network episodes. Statistical significance was tested with student $t$-test. Data are presented as mean $\pm \mathrm{SD}$, unless noted otherwise. 


\section{RESULTS}

Using paired recording, we examined inhibitory outputs and excitatory and inhibitory inputs of layer $4 \mathrm{SOM}+$ and FS cells in coronal neocortical slices. In total, we recorded from 57 pairs of SOM+-RS cells, 35 pairs of SOM+-FS cells, 38 pairs of FS-RS cells, 16 pairs of FS-FS cells and 11 pairs of SOM+-SOM+ cells. Cells in each pair were in the same barrel, as determined in the brightfield DIC image. Intersomatic distances for all pairs were within $\leq 60 \mu \mathrm{m}$, measured on the display monitor. The synaptic connection probabilities between different cell pairs are summarized in Fig. 3.2. Reciprocal connectivities (i.e., paired cells connected in both directions) of SOM+-RS, SOM+-FS, FS-RS and FS-FS cell pairs were $53.5 \%(n=43), 18.5 \%(n=27), 23.7 \%(n=38)$ and $30.8 \%$ $(n=13)$, respectively, which were close to the expected values if connections in the two directions were independent $(48.2 \%, 16.9 \%, 23.7 \%$ and $32.6 \%$, respectively). Notably, we found no chemical synaptic connections between SOM+ cells.

\section{RS to SOM+ synapses displayed pronounced facilitation}

All 20 RS to SOM+ excitatory connections whose dynamics were examined showed strong facilitation at $20 \mathrm{~Hz}$ (Fig. 3.3A). We analyzed 16 connections quantitatively. In response to a train of 20 presynaptic APs at $20 \mathrm{~Hz}$, the amplitudes of the $1^{\text {st }}, 8^{\text {th }}$ and $20^{\text {th }}$ excitatory postsynaptic potential (EPSP) in SOM+ cells were $0.74 \pm 0.78,0.91 \pm 0.95$, and $2.64 \pm 1.61 \mathrm{mV}(\mathrm{n}=16)$, respectively. For each connection, we normalized the averaged EPSP amplitudes to the $1^{\text {st }}$ EPSP. The normalized amplitudes of the $8^{\text {th }}$ and $20^{\text {th }}$ EPSPs were $140 \pm 66 \%$ and $524 \pm 345 \%$ (n=16, Fig. 3.3B).

In contrast, all 10 tested RS-to-FS excitatory connections exhibited clear depression (Fig. 3.3C). The $1^{\text {st }}$ and $8^{\text {th }}$ EPSP had amplitudes of $4.63 \pm 4.42$ and $1.80 \pm 2.16 \mathrm{mV}(\mathrm{n}=10)$. The normalized amplitude of the $8^{\text {th }}$ EPSP was $34 \pm 16 \%$ ( $n=10$, Fig. 3.3D).

\section{Synapses made by SOM+ cells exhibited less short-term depression and relatively long-term facilitation compared to those by FS cells}

We used the synaptic responses at $20 \mathrm{~Hz}$ to describe both short- and (relatively) longterm synaptic dynamics of unitary inhibitory postsynaptic currents (uIPSCs) mediated by 
$\mathrm{SOM}+$ and FS interneurons. We analyzed 35 inhibitory connections made by SOM+cells, including 16 onto RS cells and 19 onto FS cells, and 12 synapses made by FS cells, including 8 onto RS and 4 onto FS cells. Because no significant difference in synaptic dynamics existed within each group of connections (Fig. 3.4), that is, IPSCs evoked by SOM+ cells and IPSCs made by FS cells, we pooled the responses within each group. Paired-pulse ratio (PPR), steady state ratio (SSR) and recovery Test Response (RTR) of uIPSCs generated by SOM+ cells were $0.85 \pm 0.11,0.92 \pm 0.20$ and $1.19 \pm 0.21$ compared to $0.70 \pm 0.08(\mathrm{p}<0.001), 0.42 \pm 0.11 \quad(\mathrm{p}<0.001)$ and $0.55 \pm 0.09 \quad(\mathrm{p}<0.001)$ by FS cells, respectively (Fig. 3.4, n=35, 12 for SOM+ and FS cells, respectively).

\section{Stronger electrical coupling existed between SOM+ cells compared to those between FS cells}

We tested 11 SOM+-SOM+ cell pairs and 16 FS-FS cell pairs for electrical coupling. Both cell types were often electrically coupled to same-type neighbors (Fig. 3.5A,B) (but never to other type neighbors). Strikingly, the electrical connection probability was $100 \%$ between SOM+ cells and only 50\% between FS cells (Fig. 3.5C). The average ratio of postjunctional / prejunctional voltage deflection (coupling coefficient) was much higher between coupled SOM+ cells than that between coupled FS cells $(10.8 \pm 3.1 \%, \mathrm{n}=11$ vs. $2.7 \pm 1.3 \%, \mathrm{n}=8$, respectively, excluding 8 FS-FS pairs which were not coupled) $(\mathrm{p}<0.001)$ (Fig. 3.5C,D). We did not observe any correlation between coupling strength and intersomatic distances $\left(\mathrm{R}^{2}=0.0042\right.$ and 0.067 for SOM+ and FS pairs, respectively) (Fig. 3.5D). All electrical connections were reciprocal and there was no prominent polarity between the two connection directions, and no obvious rectification.

\section{Kinetics of IPSCs generated by SOM+ and FS cells}

We analyzed 11 IPSCs made by FS cells, and 28 IPSCs by SOM+ cells onto RS and onto FS cells (Fig. 3.6A). The $20-80 \%$ rise times of IPSCs in the FS $\rightarrow$ RS and FS $\rightarrow$ FS pairs were very similar $(0.32 \pm 0.03 \mathrm{~ms}$ vs. $0.32 \pm 0.04 \mathrm{~ms}$, respectively, $\mathrm{p}=0.84$, Fig. 3.6B). We combined them into a single group to facilitate statistical analysis. Rise times of IPSCs produced by SOM+ cells into RS and FS cells $(0.57 \pm 0.09 \mathrm{~ms}, \mathrm{n}=12$, and $0.44 \pm 0.06 \mathrm{~ms}$, $n=16$, respectively, Fig. 3.6B) were significantly longer than those of IPSCs made by FS 
cells $(\mathrm{p}<0.001)$, which suggested that $\mathrm{SOM}+$ cells make more distal synaptic contacts compared to FS cells. Additionally, rise times of IPSCs produced by SOM+ cells in RS cells were longer relative to IPSCs in FS cells $(\mathrm{p}<0.001)$ (Fig. 3.6B). The decay times of IPSCs made in RS cells by $\mathrm{SOM}+$ and FS cells were not significantly different $(4.91 \pm 1.13 \mathrm{~ms}(\mathrm{n}=11)$ vs. $5.01 \pm 1.09 \mathrm{~ms}(\mathrm{n}=8)$, respectively, $\mathrm{p}=0.98)$. However, decay time of IPSCs evoked by both SOM+ and FS cells were longer in RS cells than those in FS cells (Fig. 3.6C). In summary, rise time was strongly dependent on the presynaptic cell type, and decay time was mostly dependent on the postsynaptic cell type.

\section{Differential inhibition by SOM+ cells onto RS and FS cells}

We examined the current-voltage (I-V) curve for IPSCs mediated by SOM+ to FS and $\mathrm{SOM}+$ to RS connections (Fig. 3.7A). Both IPSCs had similar reversal potentials $(-81.3 \pm 3.5 \mathrm{mV}$ vs. $-82.5 \pm 1.8 \mathrm{mV}$, respectively) (Fig. 3.7B, Left), but IPSCs from SOM+ to FS cells had 3-fold bigger conductances compared to SOM+ to RS IPSCs $(1.86 \pm 1.06$ $\mathrm{nS}$ vs. $0.62 \pm 0.37 \mathrm{nS}, \mathrm{p}<0.01$ ) (Fig. 3.7B, right). Stronger synaptic inhibition generated by $\mathrm{SOM}+$ cells in FS than in RS cells was also reflected in terms of higher synaptic strength (127.9 $\pm 64.4 \mathrm{pA}$ vs. $22.94 \pm 17.0 \mathrm{pA}, \mathrm{p}<0.001, \mathrm{n}=17$ and 27 , respectively), higher synaptic potency ( $127.9 \pm 64.4 \mathrm{pA}$ vs. $24.5 \pm 16.1 \mathrm{pA}, \mathrm{p}<0.001$, same sample size as above) and smaller failure rate ( 0 vs. $15.1 \% \pm 17.6 \%, p<0.001$, same sample size as above) (Fig. 3.7C). In contrast, FS did not exhibit differential inhibition onto FS and RS cells: synaptic strength, $84.1 \pm 54.4$ vs. $77.0 \pm 95.1 \mathrm{pA}$; synaptic potency, $84.7 \pm 53.8 \mathrm{pA}$ vs. $77.6 \pm 94.7 \mathrm{pA}$; failure rate, $1.1 \% \pm 1.6 \%$ vs. $4.4 \% \pm 7.2 \%, \mathrm{n}=6$ and 8 , respectively, $\mathrm{p}>0.05$ ) (Fig. 3.7D).

\section{SOM+ cells were strongly excited during high frequency network activity}

Based on their facilitating excitatory inputs and their strong inhibition onto FS cells, we hypothesized that $\mathrm{SOM}+$ cells may play a critical inhibitory role during high-frequency excitation. In normal ACSF, we observed occasional occurrence of episodes of network activity, during which $\mathrm{SOM}+$ cells fired robustly. In order to induce the occurrence of network activity more frequently, we applied $0 \mathrm{Mg}^{2+}$ ACSF while recording pairwise from $\mathrm{SOM}+, \mathrm{FS}$, and RS cells. Episodes of network activity were consistently induced 
after 10-15 min superfusion of $0 \mathrm{Mg}^{2+} \mathrm{ACSF}$ (Fig. 3.8A, 3.9A). In most cases, episodes occurred simultaneously in both pair-recorded cells, but were most robust in SOM+cells. Episodes appeared at a frequency of $\sim 2 / \mathrm{min}$, each episode lasting on average $784 \pm 451$ ms ( $n=14$ pairs, $62 \pm 56$ episodes averaged per pair). Each episode consisted of barrages of synaptic potentials, typically generating 5-15 $\mathrm{mV}$ depolarization and, in some cases, high-frequency firing (Fig. 3.8B, 3.9B). To quantify relative activity, we used two measures: average fractional firing per episode, and total fractional firing. Average fractional firing per episode was defined as the average of (cell\#1 spike number / (cell\#1 spike number + cell\#2 spike number)). Total fractional firing was defined as (total cell\#1 spike number for all episodes / (total cell\#1 spike number + total cell\#2 spike number)). Fractional firing per episode, and total fractional firing for simultaneous recorded SOM+ and FS cells, were $59 \pm 19 \%$ vs. $41 \pm 19 \%$, and $70 \pm 13 \%$ vs. $30 \pm 13 \%$, respectively ( $\mathrm{n}=8$ pairs). For pair-recorded SOM+ and RS cells, fractional firing per episode, and total fractional firing were similar to those in SOM-FS pairs - $64 \pm 26 \%$ vs. $36 \pm 26 \%$, and $70 \pm 29 \%$ vs. $30 \pm 29 \%$, respectively ( $\mathrm{n}=8$ pairs). In other words, during network episodes, $\mathrm{SOM}+$ cells fired more than twice the total number of spikes, compared to either FS or RS cells recorded simultaneously.

In many of the recorded SOM+-FS pairs, we observed clearly that in the early phase of each episode FS cells received excitatory inputs (hollow arrowhead in Fig. 3.8C), however, later in the episode SOM+ cells started to discharge and inhibitory inputs (filled arrowheads in Fig. 3.8C), most likely from SOM+ cells, appeared to override the excitatory inputs in FS cells. Although we observed initial excitatory inputs in RS cells (hollow arrowhead in Fig. 3.9C), we only occasionally found strong inhibitory inputs to RS cells (filled arrowheads in left of Fig. 3.9C). These occasional initial inhibitory inputs (shown in right panel of Fig. 3.9C), were possibly generated by FS cells.

\section{SOM+ cells exhibited strong synchrony during network episodes}

During episodes of network activity, we observed strong synchrony of excitatory events in pair-recorded SOM+ cells (Fig. 3.10A), including suprathreshold firing (Fig. 3.10B) and subthreshold EPSPs ((Fig. 3.10C). The average cross-correlation at 0 lag - between 
subthreshold voltage fluctuations in coupled $\mathrm{SOM}+$ cells was $0.88 \pm 0.03$ ( $\mathrm{n}=3$ pairs, at least 10 episodes per pair). Fig. 3.10D showed the cross-correlation of EPSPs between two simultaneously recorded SOM+ cells. 


\section{DISCUSSION}

\section{Driving forces to layer $4 \mathrm{SOM}+$ cells}

In this study, we examined properties of synaptic inputs and outputs of SOM+ and FS cells. Our main findings are summarized in Table 3.1. Layer 4 of the somatosensory cortex is the major recipient of thalamic input relaying sensory information, and the thalamus is the only source of extracortical excitatory inputs to layer 4 cells. The other main source of excitatory inputs to layer 4 cells is intracortical inputs, which are mostly the excitatory driving force from layer 4 spiny stellate or pyramidal RS cells, although there are some degree of axonal projections to layer 4 from layer 6 corticothalamic pyramidal cells and layers 2/3 pyramidal cells (see Fig. 1.1 in Chapter 1). Our data show that layer $4 \mathrm{SOM}+$ cells received strongly facilitating excitatory inputs from RS cells. Thus, RS cells are a major excitatory driving force onto SOM+ cells. Regarding inhibitory inputs, SOM+ cells received only low probability $(<20 \%)$ connections from FS cells and received no chemical synaptic inputs from other SOM+ cells. In other words, layer $4 \mathrm{SOM}+$ cells are RS cell-driven, excitatory-dominated inhibitory interneurons. Similar to previous reports, the excitatory input from RS cells to SOM+ cells showed prominent facilitation (Thomson et al., 1995; Ali and Thomson, 1998; Gibson et al., 1999; Beierlein et al., 2003; Kaiser et al., 2004; Pouille and Scanziani, 2004; Silberberg and Markram, 2007). Considering also the temporal summation of postsynaptic potentials, one would expect that SOM+ cells would become highly excitable during high-frequency cortical activity.

\section{Presumed distal synaptic contacts made by SOM+ cells}

The rise time of IPSCs is thought to be an indicator of synaptic location, that is, longer rise times suggest relatively more distal synaptic contacts and shorter ones imply closer synaptic locations relative to the soma (Maccaferri et al., 2000). In the present study, IPSCs generated by SOM+ cells displayed slower rise time compared to those evoked by FS cells. The fast rise times of IPSCs generated by FS cells are consistent with somatic or proximal dendritic-targeting contacts of FS cells onto pyramidal cells (Tamas et al., 1997; Maccaferri et al., 2000; Amitai et al., 2002; Xiang et al., 2002), other types of 
interneurons (Tamas et al., 1998, 2000; Staiger et al., 2002), and even themselves (autapses) (Tamas et al., 1997). In contrast, slow rise times of IPSCs evoked by SOM+ cells suggest that $\mathrm{SOM}+$ cells make synaptic contacts on relatively more distal dendrites of their postsynaptic target cells. However, it is difficult to rule out the possibility that the slower rise time of SOM+-mediated IPSCs reflected differences in intrinsic properties of postsynaptic receptors or prolonged synaptic release.

In contrast to differences in rise times, our recording did not show differences in decay times of IPSCs produced by SOM+ cells, compared to IPSCs mediated by FS cells; instead, we found decay times of IPSCs evoked by both SOM+ and FS cells were longer in RS cells compared to those in FS cells. Similar results were also reported from dentate gyrus (Bartos et al., 2001, 2002). Specifically, PV+-basket cells generated slower decay time of IPSCs in RS cells compared to those in other PV+-basket cells.

The most likely mechanism for differences in IPSC decay time is differential expression of $\mathrm{GABA}_{\mathrm{A}}$ receptors between excitatory and inhibitory cells (Xiang et al., 1998; Kraushaar and Jonas, 2000). A pharmacological study on decay times of IPSCs between different subgroups of interneurons also implies that the subunit composition of $\mathrm{GABA}_{\mathrm{A}}$ receptors is postsynaptic-dependent (Bacci et al., 2003). Other factors that may affect IPSC decay time are the phosphorylation state of the $\mathrm{GABA}_{\mathrm{A}}$ receptor (Poisbeau et al., 1999), the temporal pattern of neurotransmitter release (Williams et al., 1998), electrotonic filtering (Spruston et al., 1994) or the lack of voltage clamp at the more distal processes (Spruston et al., 1993). The similarity in decay times of IPSCs generated by SOM+ and FS cells in RS cells may be explained by two reasons. First, differences in somatodendritic location are only slightly reflected in decay times of IPSCs (Maccaferri et al., 2000; Xiang et al., 2002). Second, the slight difference in decay time of IPSCs is minimized by the electronic compactness of layer 4 RS cells (Segev et al., 1995).

\section{Differential inhibition produced by SOM+ cells onto RS and FS cells}

Our present study showed that SOM+ cells generated about 6-fold smaller amplitude unitary IPSCs in RS than in FS cells. A similar difference was not apparent in the outputs of FS cells. The smaller amplitude of IPSCs in RS cells may reflect smaller conductance of the postsynaptic $\mathrm{GABA}_{\mathrm{A}}$ receptors, fewer receptors per postsynaptic domain, lower 
release probability, smaller number of contacts, and postsynaptic filtering. Because the rise times of IPSCs evoked by SOM+ cells in RS cells were longer than those evoked in FS cells (as shown in Fig. 3.6B), we propose that electrotonic dendritic filtering at least partially contributed to the differences in IPSC amplitudes. However, the significant difference in synaptic conductances recorded in voltage-clamp mode, which minimizes the electrotonic filtering effects, suggested that other underlying mechanisms existed. For instance, the number of synapses made by SOM+ cells on FS cells may be larger than that on RS cells. It is also possible that different subunit compositions of $\mathrm{GABA}_{\mathrm{A}}$ receptors might mediate these two types of IPSCs.

\section{Short-term dynamics of IPSCs produced by SOM+ and FS cells in layer 4}

IPSCs generated by FS cells in all targets displayed similar, strongly depressing dynamics, while IPSCs generated by SOM+ cells exhibited much less short-term depression and relatively more long-term facilitation. This result is consistent with previous studies that suggested that all the synapses established by one interneuron onto diverse postsynaptic targets show identical synaptic dynamics (Tamas et al., 1998; Gupta et al., 2000; Maccaferri et al., 2000). Unusually, however, heterogeneous IPSP dynamics might also exist (Blatow et al., 2003), which puts in question the principle of presynaptic dependency of dynamics. It is worth noting that previous categorization of the dynamics of IPSCs (Gupta et al., 2000) did not include the pattern generated by SOM+ cells.

What is the basis for these differential dynamics? Presynaptic quantal size is determined by neurotransmitter amount in synaptic vesicles at a presynaptic bouton. During a stimulation train, the new recycled vesicle size could be regulated and the neurotransmitter content of synaptic vesicles could be changed (Graham et al., 2002; Chen et al., 2004). Therefore, during a stimulation train, different amount of released neurotransmitter could be released and produce different amplitudes of postsynaptic responses. The size of the readily releasable vesicle pool may also contribute to distinct short-term synaptic plasticity (Pierce and Lewin, 1994; Dobrunz and Stevens, 1997), that is, larger releasable pool may undergo less degree of changes of postsynaptic responses compared to smaller releasable vesicle pool. Additionally, in response to presynaptic 
action potentials, differences in calcium channel types at presynaptic terminals may generate distinct dynamics of calcium ion influx, and in turn different dynamics of synaptic vesicle fusion. Specifically, synapses possessing presynaptic P/Q-type and Ntype calcium channels exhibit depressing and facilitating dynamics, respectively (Poncer et al., 1997; Ali and Thomson, 1998; Ali and Nelson, 2006). Presynaptic GABA B $_{3}$ receptors (Thomson et al., 2007) might also be differentially distributed at presynaptic terminals of SOM+ and FS cells, and contribute to the differences in the synaptic dynamics by reducing the probability of synaptic release.

Postsynaptically, differences in subunit composition of $\mathrm{GABA}_{\mathrm{A}}$ receptors (Wisden et al., 1992; Nusser et al., 1996) leading to differences in $\mathrm{GABA}_{\mathrm{A}}$ receptor desensitization (Overstreet et al., 2000) may also contribute to difference in synaptic dynamics of IPSPs.

\section{Strong electrical interconnection between SOM+ cells}

Electrical synapses, or gap junctions, mediate direct electrical communication between neurons. They are composed of clusters of ion channels (connexins) that span the plasma membrane of two cells (White and Paul, 1999). Gap junctions facilitate effectively synchronization of neuronal activity (Draguhn et al., 1998; Galarreta and Hestrin, 1999; Beierlein et al., 2000). The precision of synchrony increases as a function of coupling strength or coupling coefficient (Gibson et al., 2005). Layer 4 SOM+ cells displayed stronger electrical synapses, with about four times stronger coupling strength and two times higher probability of connection, compared to those between FS cells. A number of factors may have contributed to the differences in electrical coupling, including the conductance of single gap-junction channels, the total number of channels, the distance from electrical synapses to somata, the input resistance of postjunctional cells, and the presence of dendritic or somatic active conductances. The slightly higher input resistance of SOM+ cells compared with FS cells (Fig. 3.1) could have contributed to their higher coupling coefficient (Mann-Metzer and Yarom, 1999), but clearly, did not account for the full difference.

Unlike our results, previous studies in the rat showed that LTS, (presumably SOM+), cells had only slightly higher coupling strength, compared to FS cells (Gibson et al., 2005) and there was no statistical difference between these two types of couplings (Amitai et al., 
2002). The smaller difference in coupling strength shown in previous studies may be attributable to several reasons. First, mis-identification of SOM+ cells as FS cells, because layer $4 \mathrm{SOM}+$ cells exhibit quasi-FS properties (Ma et al., 2006), such as very high maximal firing frequency $(\geq 300 \mathrm{~Hz}$ ), small input resistance and narrow spike width. Second, there might be other electrically coupled, non-FS interneurons that have not been identified in layer 4, whose coupling could complicate the comparison. Third, it could arise from different patch targeting preference (Galarreta and Hestrin, 1999; Gibson et al., 1999); for example, our sample may be biased towards larger FS cells.

\section{Two systems of dendritic inhibition}

Excitatory inputs to SOM+ cells exhibit marked facilitation in the hippocampus (Ali and Thomson, 1998; Pouille and Scanziani, 2004) and the neocortex (Reyes et al., 1998; Gibson et al., 1999; Kaiser et al., 2004; Kapfer et al., 2007; Silberberg and Markram, 2007). As demonstrated in supragranular and infragranular layers, this facilitates recruitment of disynaptic inhibition mediated by Martinotti-SOM+ cells (Kapfer et al., 2007; Silberberg and Markram, 2007). Due to preferential synaptic termination of SOM+ cells onto distal dendrites (Leranth et al., 1990; Maccaferri et al., 2000), SOM+ cells are well placed to mediate dendritic inhibition. Due to dendritic targeting of excitatory inputs and the extensive existence of dendritic conductances (Nevian and Sakmann, 2004), $\mathrm{SOM}+$ cells may be important in regulating cellular responses to excitatory inputs.

Our present results demonstrate that layer $4 \mathrm{SOM}+$ cells also received facilitating excitatory inputs. Along with their presumed distal synaptic terminations, layer $4 \mathrm{SOM}+$ cells could perform similar disynaptic inhibition onto layer 4 RS cells. In other words, the neocortex may have two separate disynaptic self-inhibition systems: layer $4 \mathrm{SOM}+$ cells to layer 4 spiny stellate cells, and deep or superficial layers Martinotti cells to deep or superficial layers pyramidal cells.

\section{Inhibitory role of SOM+ cells during high frequency network activity}

In the present study, we used $0 \mathrm{Mg}^{2+}$ ACSF to remove the $\mathrm{Mg}^{2+}$ block on NMDA receptors to induce more frequent episodes of network activity. We found that during network activity $\mathrm{SOM}+$ cells were the most active cell type, and generated strong 
inhibition onto both FS and RS cells in layer 4. The higher excitability of SOM+ cells can be explained based on their unique inputs and outputs.

As far as inputs:

1) Excitatory inputs to layer $4 \mathrm{SOM}+$ cells exhibited strong facilitation compared to depression of excitatory inputs onto FS cells.

2) $\mathrm{SOM}+$ cells had longer EPSP decay time constant compared to FS cells (data not shown), which will facilitate the temporal summation of excitatory inputs (Tan et al., PNAS, in press).

3) $\mathrm{SOM}+$ cells were strongly electrically interconnected among themselves, which under some conditions may boost excitatory inputs to $\mathrm{SOM}+$ cells.

4) $\mathrm{SOM}+$ cells received no chemical inhibition from themselves and other $\mathrm{SOM}+$ cells and only received weak chemical inhibition from FS cells (indicated by the low probability of connection from FS to $\mathrm{SOM}+$ cells). Furthermore, inhibition to $\mathrm{SOM}+$ cells from FS cells decreased due to the prominent depression of excitatory inputs to FS cells during high frequency activity.

From output aspects, $\mathrm{SOM}+$ cells provided powerful inhibition during high frequency network activity, for the following reasons:

1) Once fired, $\mathrm{SOM}+$ cells generated strong inhibition in FS cells, curtailing FS cells firing and damping the inhibition from FS cells to RS cells and to SOM+cells. This would enhance further excitation of $\mathrm{SOM}^{+}$and $\mathrm{RS}$ cells, but may also enhance excitability of the network as a whole.

2) $\mathrm{SOM}+$ cells displayed high connectivity probabilities to both RS (>80\%) and FS cells $(>90 \%)$, much higher than the connectivity by FS cells ( $50 \%$ and $<60 \%$, respectively). This suggests that SOM+ cells may perform collective inhibition instead of cell-specific inhibition. Dynamically, the inhibitory outputs by $\mathrm{SOM}+$ cells had less short-term depression and relatively more long-term facilitation, which were strikingly different from strong depression by FS cells and also different from other previously described dynamic types (Gupta et al., 2000).

3) Electrical coupling facilitates synchronous firing (Galarreta and Hestrin, 1999; MannMetzer and Yarom, 1999; Beierlein et al., 2000; Gibson et al., 2005). The stronger 
electrical coupling between SOM+ cells compared to that between FS cells imparts on $\mathrm{SOM}+$ a strong tendency to fire synchronously (Fig. 3.10), which could enhance postsynaptic spatial summation of IPSPs, and in turn, the inhibitory effect of SOM+ cells.

Consistent with past reports, which show that each pyramidal cell only participates in a small proportion of synchronous cycles during high-frequency oscillations (Bragin et al., 1995; Chrobak and Buzsaki, 1996; Draguhn et al., 1998), not all RS cells fired during each episode of network activity in our recoding (data not shown). However, excitation of a small number of RS cells may be enough to recruit $\mathrm{SOM}+$ cells due to possible supralinear recruitment of SOM+ cells (Kapfer et al., 2007). Because episodes of network activity in RS cells (Fig. 3.9B) appear to begin at the same time as those in SOM+cells, these recorded RS cells might not be the source of initial excitatory inputs to recorded $\mathrm{SOM}+$ cells. Therefore, the trigger for episodes of network activity might be the firing of a small number of RS cells. Because NMDA receptors participate in cortical slow oscillation (Steriade et al., 1993), distinct expression of NMDA receptors in RS, SOM and FS cells (Standaert et al., 1996; Lu et al., 2007) may also contribute to their different performance in $0 \mathrm{Mg}^{2+} \mathrm{ACSF}$.

Because there is high frequency excitation during "UP" states during natural sleep (Steriade et al., 1993), layer 4 SOM+ cells may be activated to suppress thalamocortical external sensory inputs to cerebral cortex and to allow high quality of sleep. Layer 4 $\mathrm{SOM}+$ cells could also be excited during exploratory whisking, or during pathological epileptic activity. On one hand, the excitation of layer $4 \mathrm{SOM}+$ cells can suppress dendritic excitatory inputs to RS cells, and in turn, curtail the genesis and spread of network activity and prevent cortical hyperexcitation. On the other hand, recruitment of layer 4 SOM+ cells may "dis-excite" FS cells and may preserve FS cells' normal function. Inhibition of FS cells by SOM+ interneurons could balance the reduction of dendritic excitatory inputs by the same $\mathrm{SOM}+$ interneurons, thereby maintaining the overall excitability level. Taken together, during high frequency network activity, there is a shift from FS cell-mediated proximal inhibition to $\mathrm{SOM}+$ cells-produced distal inhibition, which suggest that layer $4 \mathrm{SOM}+$ cells may isolate postsynaptic somata from the 
influence of dendritic excitatory input to curtail and prevent cortical hyperexcitation, while preserving FS cells' functions.

\section{Comparison with previously described network events}

The network activity we studied here is different from previous layer 4 studies, in which the network activity was induced by bath application of ACPD, an mGluR agonist (Beierlein et al., 2000). In our study, application of $0 \mathrm{Mg}^{2+}$ ACSF triggered the full cortical circuit to generate network activity, and activation of layer $4 \mathrm{SOM}+$ cells reflected the intrinsic connectivity pattern of the cortical circuit.

Our observations appear to be slightly different also from a previous study in frontal cortex, which used $0 \mathrm{Mg}^{2+}$ ACSF (Kawaguchi, 2001). In that study, they observed specific "long-burst" firing patterns. In our recording, such long-bursts were absent, which may be attributable to the immature development of intrinsically burst spiking (IB) pyramidal cells (Flint et al., 1997), also could reflect the different cortical circuitry between frontal cortex and barrel cortex, different species (rat vs. mouse), or differences in ACSF composition.

Spontaneous semi-periodic network activity, under relatively physiological conditions, has been described in cortical areas in vitro (Shu et al., 2003) and in vivo (Steriade et al., 1993). In the present study, the network activity induced by $0 \mathrm{Mg}^{2+} \mathrm{ACSF}$ was similar to the semi-periodic activity mentioned above in several ways. First, the network activity in our study also consisted of episodes of neuronal activity, analog to "UP" states, and relatively quiescent periods, equivalent to "DOWN" states. Second, both inhibitory and excitatory synaptic barrages were also demonstrated in our recorded episodes of network activity. Third, the use of coronal slice in our experiments assured that the network activity in our study was, like UP states, also independent of thalamic inputs (MacLean et al., 2005). On the other hand, we also noticed that the episode occurrence rate in our recording was relatively lower and more variable compared to the "UP-DOWN" oscillation mentioned above. In short, the network activity recorded in our experiment 
could mimic, to a considerable degree, network activity occurring under normal physiological conditions.

During network episodes, FS cells will fire early, but later will be inactivated because of their depressing excitatory inputs and strong inhibition from SOM+ cells. However, the subsequent activation of SOM+ cells would keep the excitability in the cortical network balanced. This capability of self-balancing of the cortex may be compromised in some pathophysiological situations such as epilepsy, which involves hyperexcitation of cortical circuits. Indeed, number of SOM+ cells in the hippocampus CA1 area in an experimental epilepsy model is decreased (Cossart et al., 2001). 
This page is intentionally blank. 


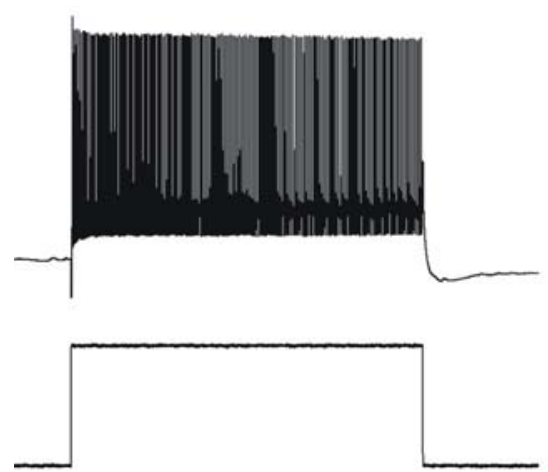

FS cell
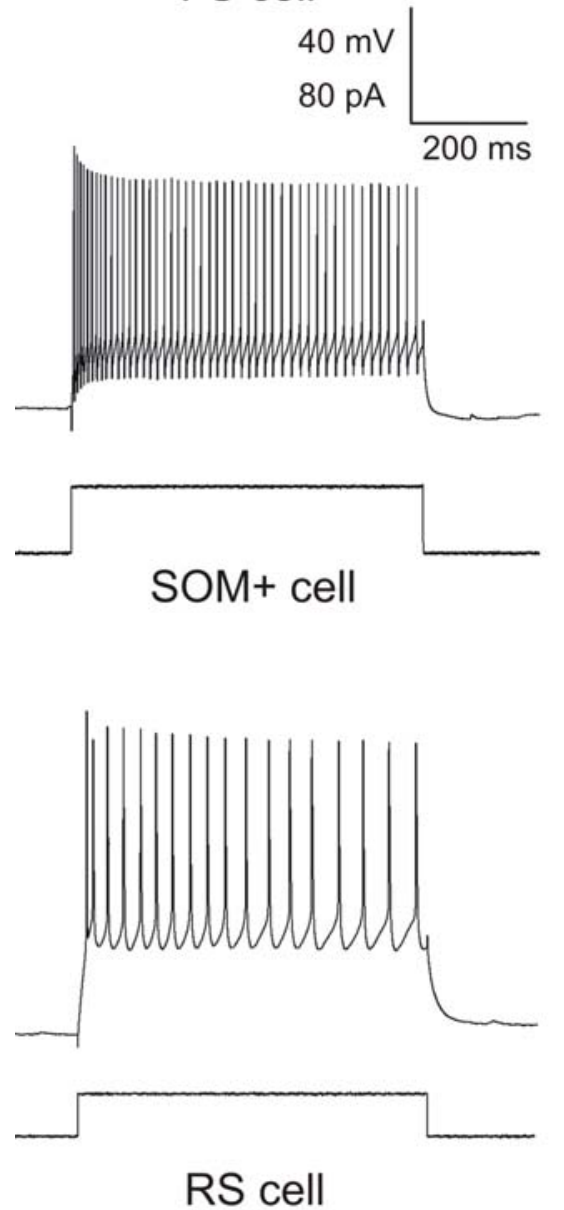
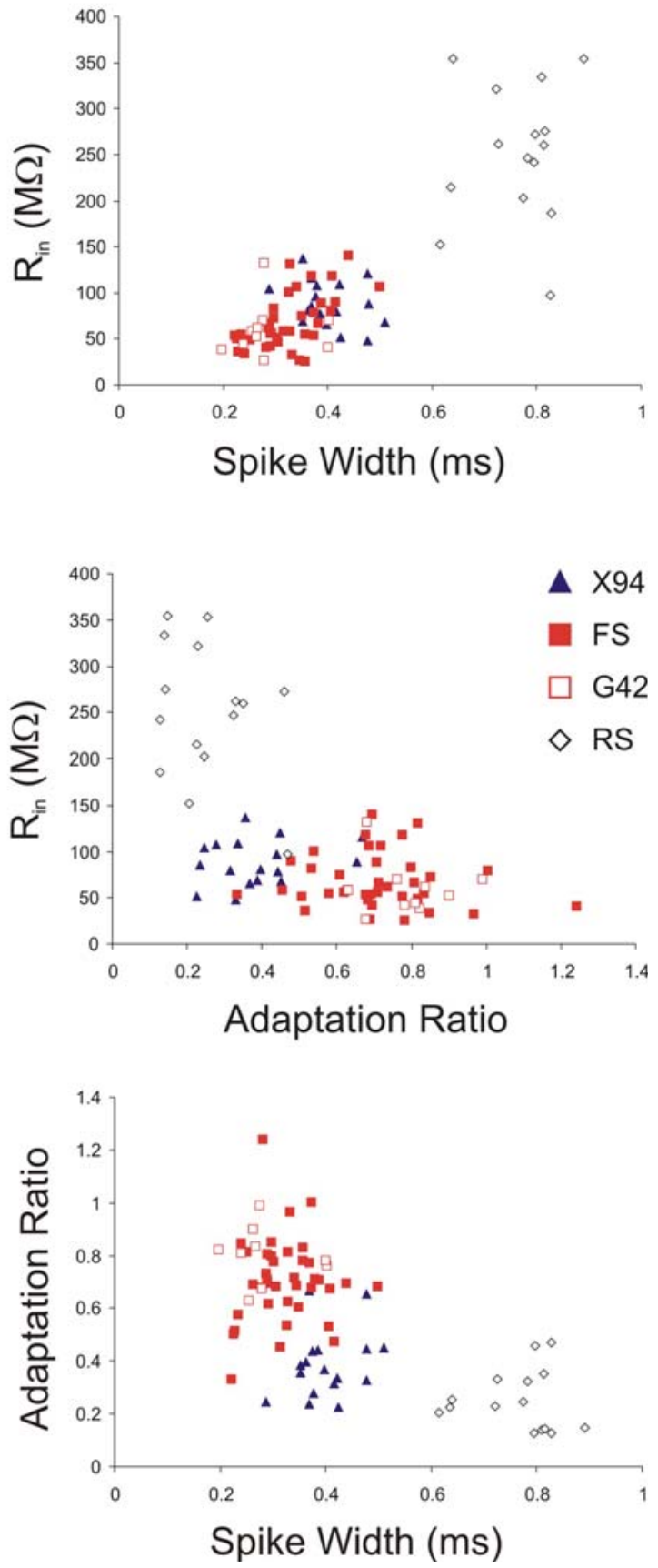

Figure 3.1. Electrophysiological characterization of the different cell types studied. Left column, the firing patterns of each cell types; right column, three basic electrophysiological parameters of the three cell types. 


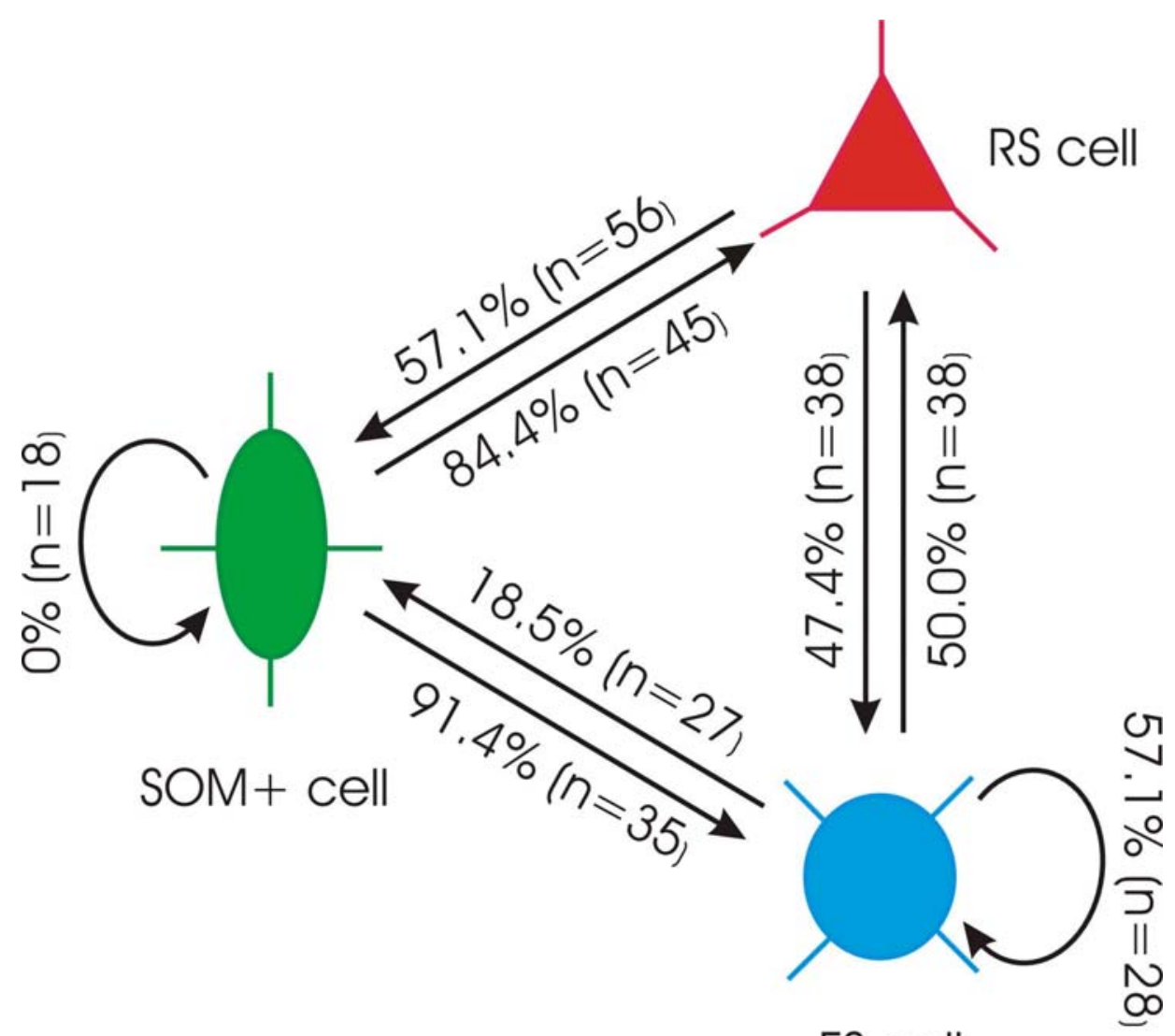

FS cell

Figure 3.2. Studied synaptic connections and their connection probabilities. Note, 1) only chemical connections are shown; 2) because " $n$ " indicates connection number, its values for SOM+ and FS cells have been doubled, given that each direction for a given cell pair is considered as one tested connection. 
A

B
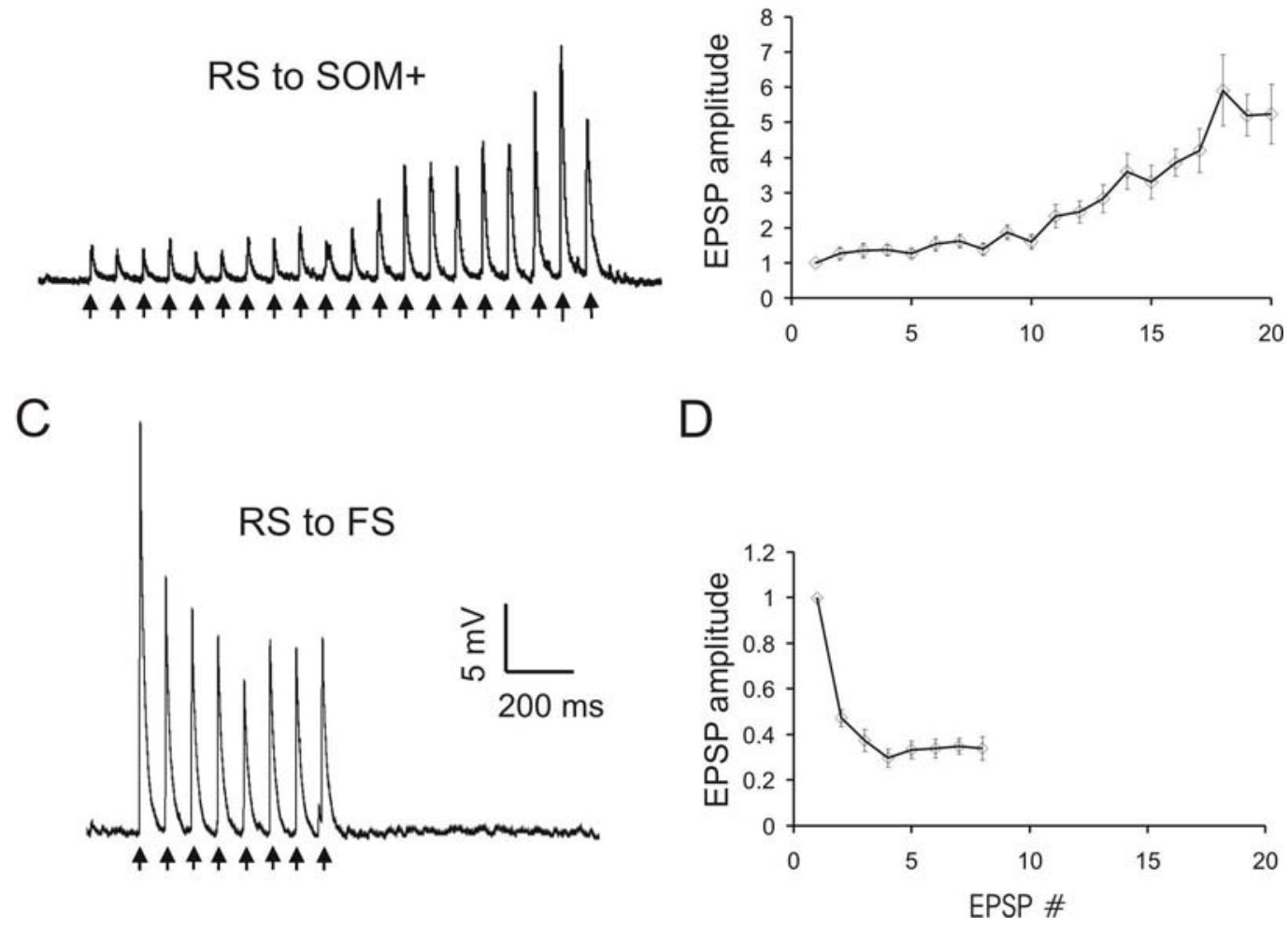

Figure 3.3. Facilitation of evoked unitary EPSPs generated in SOM+ cells by RS cells compared with depression of those in FS cells. A and C, representative average examples of the two types of excitatory synaptic connections. The arrows below the EPSP traces represent presynaptic action potentials at $20 \mathrm{~Hz}$. B and D, EPSP amplitudes (normalized to the $1^{\text {st }}$ EPSP) in a SOM+ cell $(B)(n=16)$ and an FS cell (D) $(n=10)$. Note, in both synaptic connections, presynaptic stimulation was at $20 \mathrm{~Hz}$, while the spike number was 20 and 8 for RS to $\mathrm{SOM}+$, and RS to FS connections, respectively (we used a longer spike train in RS to SOM+ connection, because of the slower rise to steady-state level). The error bars indicate standard error of the mean (SEM). 

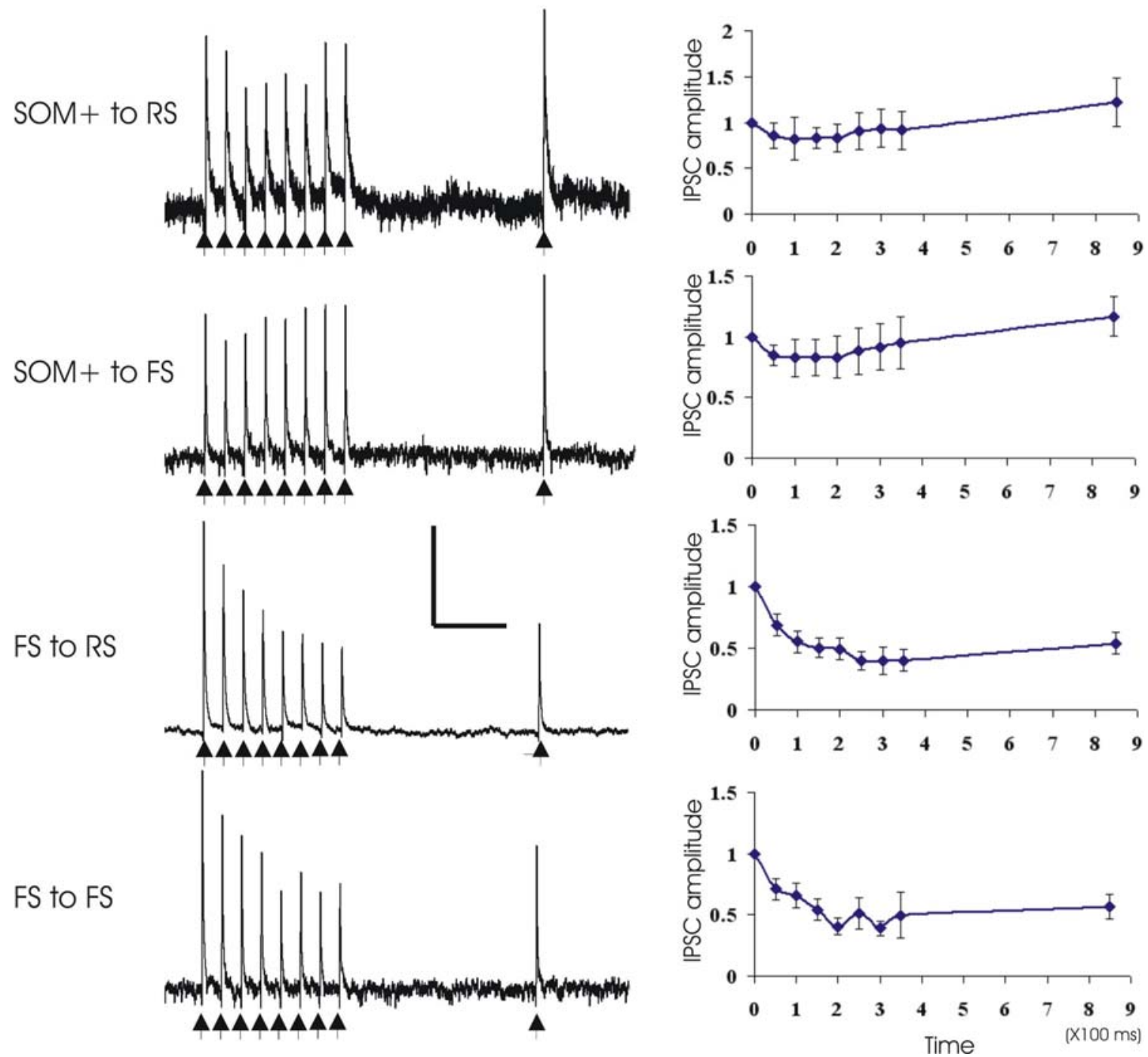

Figure 3.4. Well-sustained inhibitory output of SOM+ cells compared to the depressing output of FS cells. Left column: average IPSCs evoked by SOM+ and FS cells in RS and FS targets. The presynaptic spike train, indicated by arrows, consisted of initial 8 spikes at $20 \mathrm{~Hz}$ and one delayed recovery test pulse (RTP, $500 \mathrm{~ms}$ after the $8^{\text {th }}$ spike). Right column: normalized dynamics of the four types of connections. From top to bottom, sample sizes are 16,19, 8 and 4 cell pairs, respectively. In the left column, vertical scale bar is 20, 50, 50 and $30 \mathrm{pA}$ (top to bottom); horizontal bar is $200 \mathrm{~ms}$. Error bars are standard deviation (SD). 

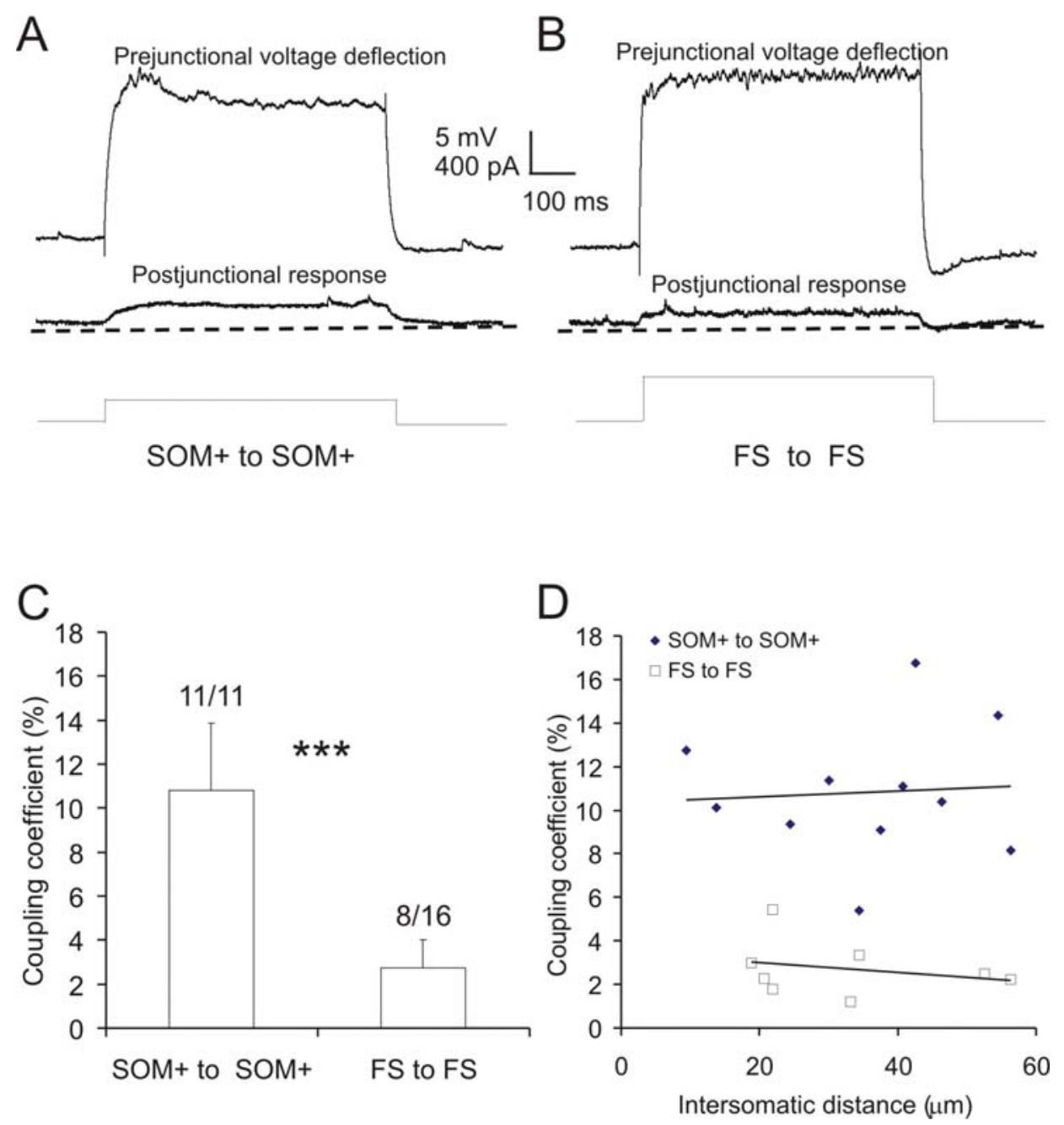

Figure 3.5. Stronger electrical coupling between SOM+ cells compared to that between FS cells. A, B, voltage deflection in the postjunctional cell in response to a depolarizing current pulse in the prejunctional cell, in a SOM+ pair (A) and an FS pair (B). C, the average coupling coefficient and connection probability of each pair type. FS-FS coupling coefficient average indicated only the 8 connected pairs. *** indicates $\mathrm{p}<0.001$. D, relationship between the coupling coefficient and intersomatic distance of coupled pairs from each group. Regression lines indicated that there were no correlation between the coupling coefficient and intersomatic distance $\left(\mathrm{R}^{2}=0.0042\right.$ and 0.067 , respectively). Error bars are SD. 


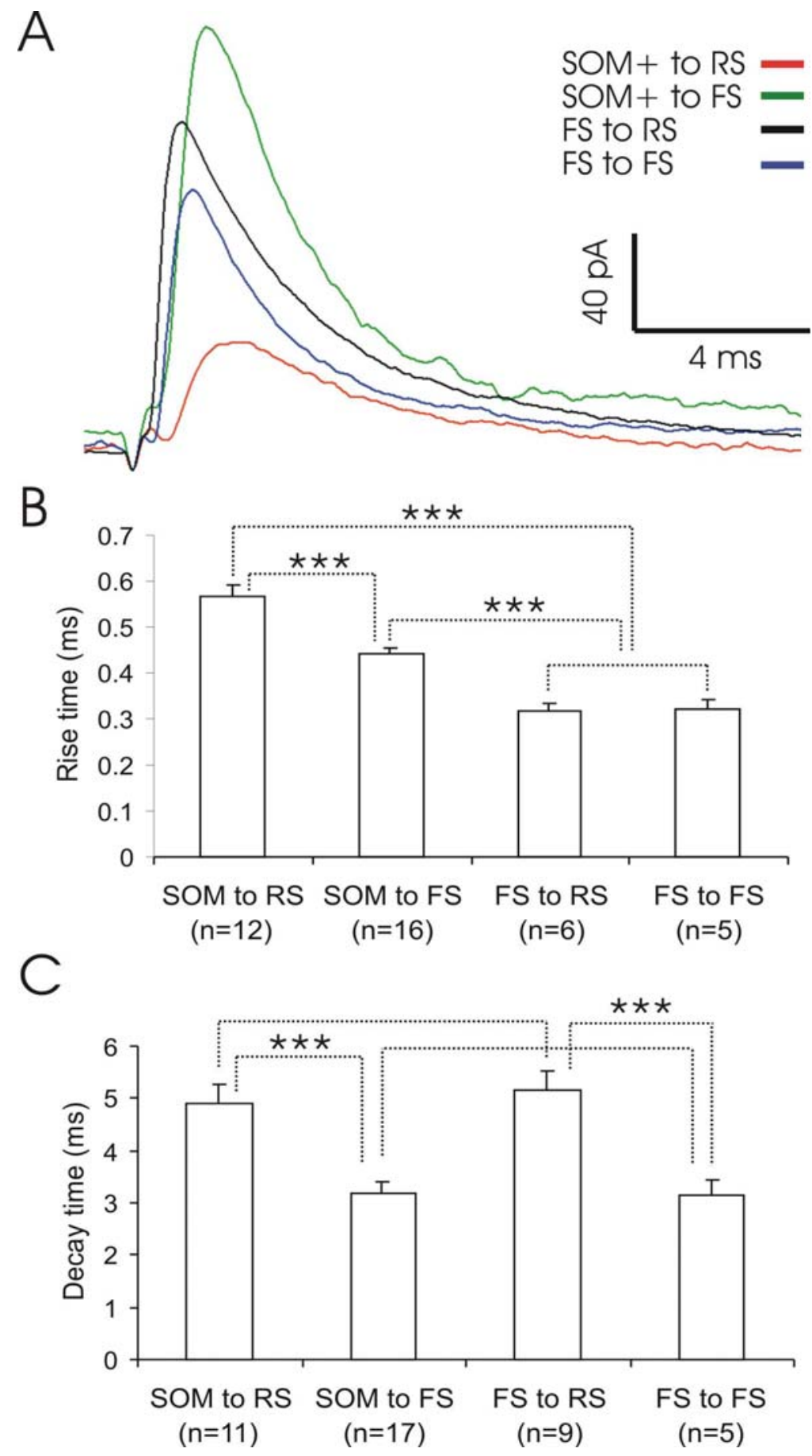

Figure 3.6. Comparison of the kinetics of IPSCs generated by SOM+ cells and FS cells. A, superimposed representative averaged IPSCs mediated by four different types of synaptic connections, indicated by different colors. B, SOM+ cells generated IPSCs with longer rise time compared to FS cells. C, decay times of IPSCs in RS cells produced by SOM+ and FS cells were significantly longer than those of IPSCs generated in FS cells. Error bars are SEM. 


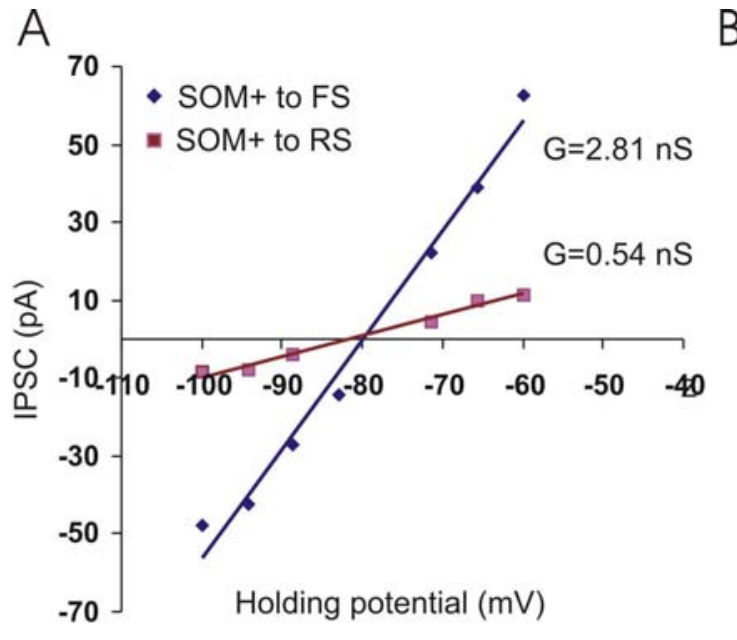

B
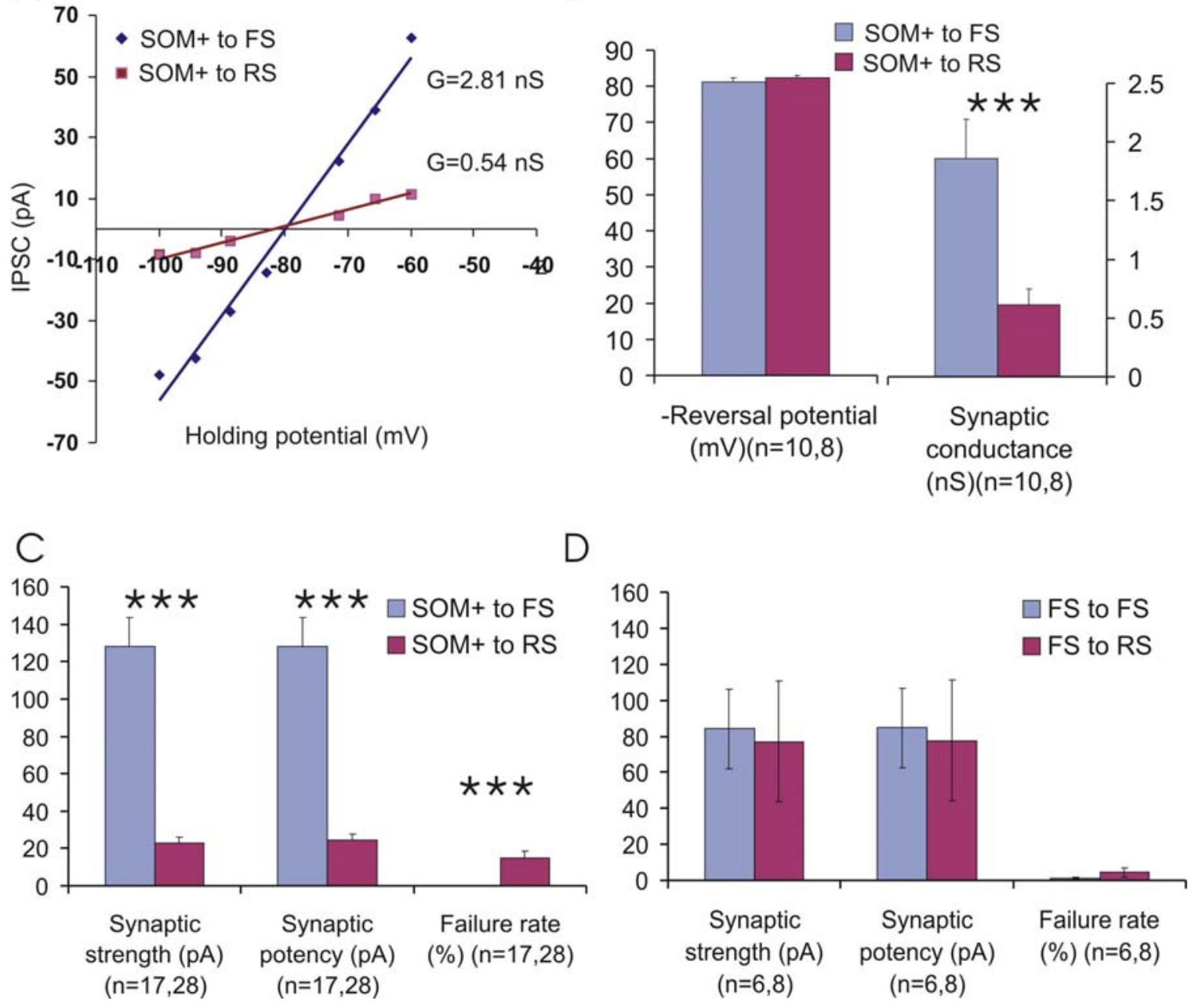

Figure 3.7. Differential inhibition on RS and FS cells evoked by SOM+ cells. A, representative current-voltage (I-V) curves of a SOM+ to RS cell pair and a $\mathrm{SOM}+$ to FS cell pair. B, synaptic conductances had different average amplitudes but similar reversal potentials. C, significant differences in synaptic parameters between synapses made by SOM+ cells onto RS and FS cells. Note that failure rate of $\mathrm{SOM}+$ to $\mathrm{FS}$ was $0 \%$, so synaptic strength = synaptic potency. D, synapses made by FS cells did not exhibit the above differential inhibition. The error bars are SEM. *** indicates $\mathrm{p}<0.001$. 

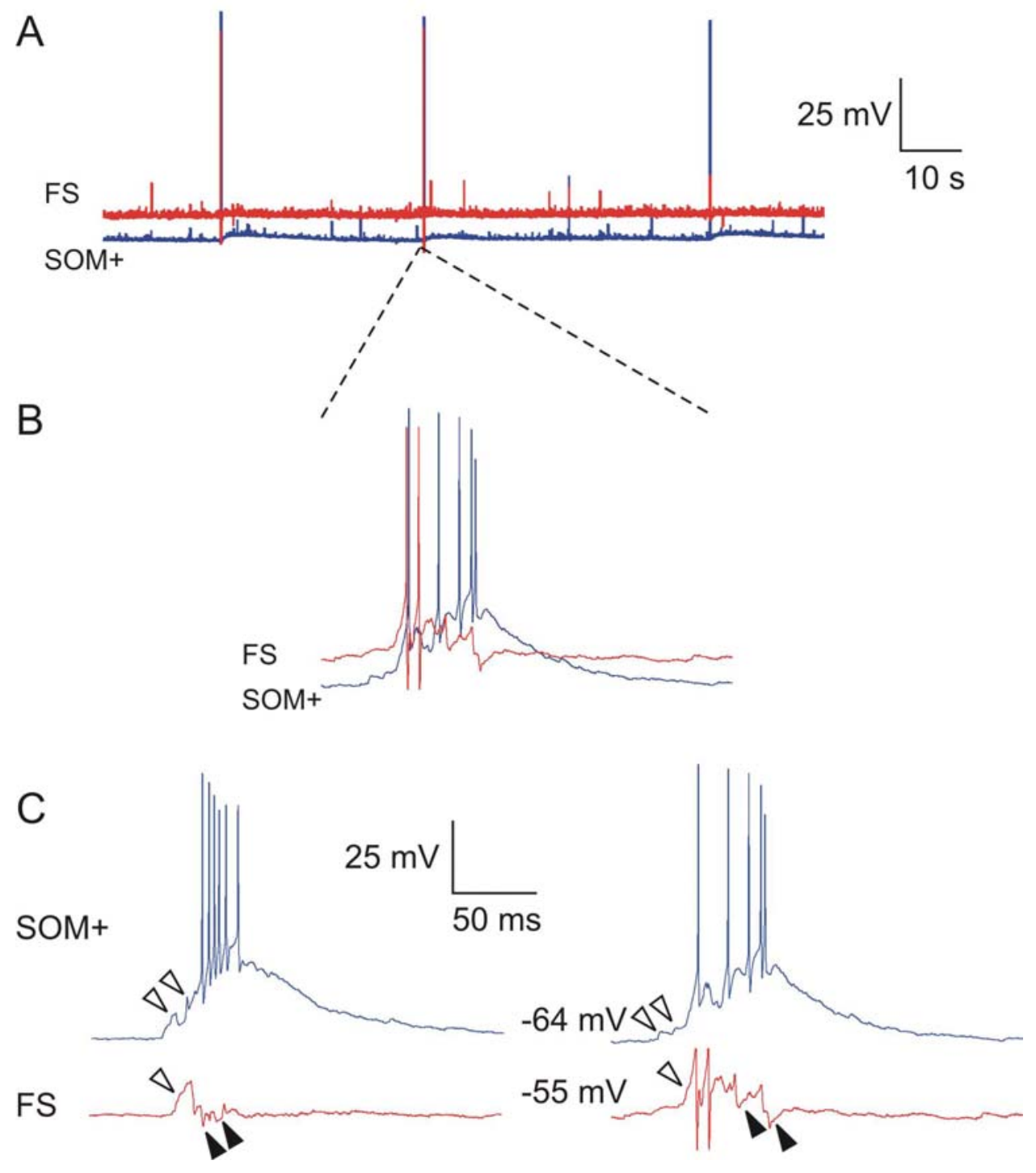

Figure 3.8. Differential activation of SOM+ and FS cells during episodes of network activity in $0 \mathrm{Mg}^{2+} \mathrm{ACSF}$. A, $0 \mathrm{Mg}^{2+}$ ACSF induced episodes of network activity at a rate of $\sim 2 / \min$. B, expansion of an episode of the trace in A. C, simultaneous recording of an FS (red trace) and a SOM+ cell (blue trace) during two episode of network activity. Note that the FS cell remained subthreshold at left, even though its membrane potential was more depolarized than that of the $\mathrm{SOM}+$ cell. The FS cell fired two spikes (truncated) during the episode at right. Hollow arrowheads indicate EPSPs; filled ones indicate IPSPs. 

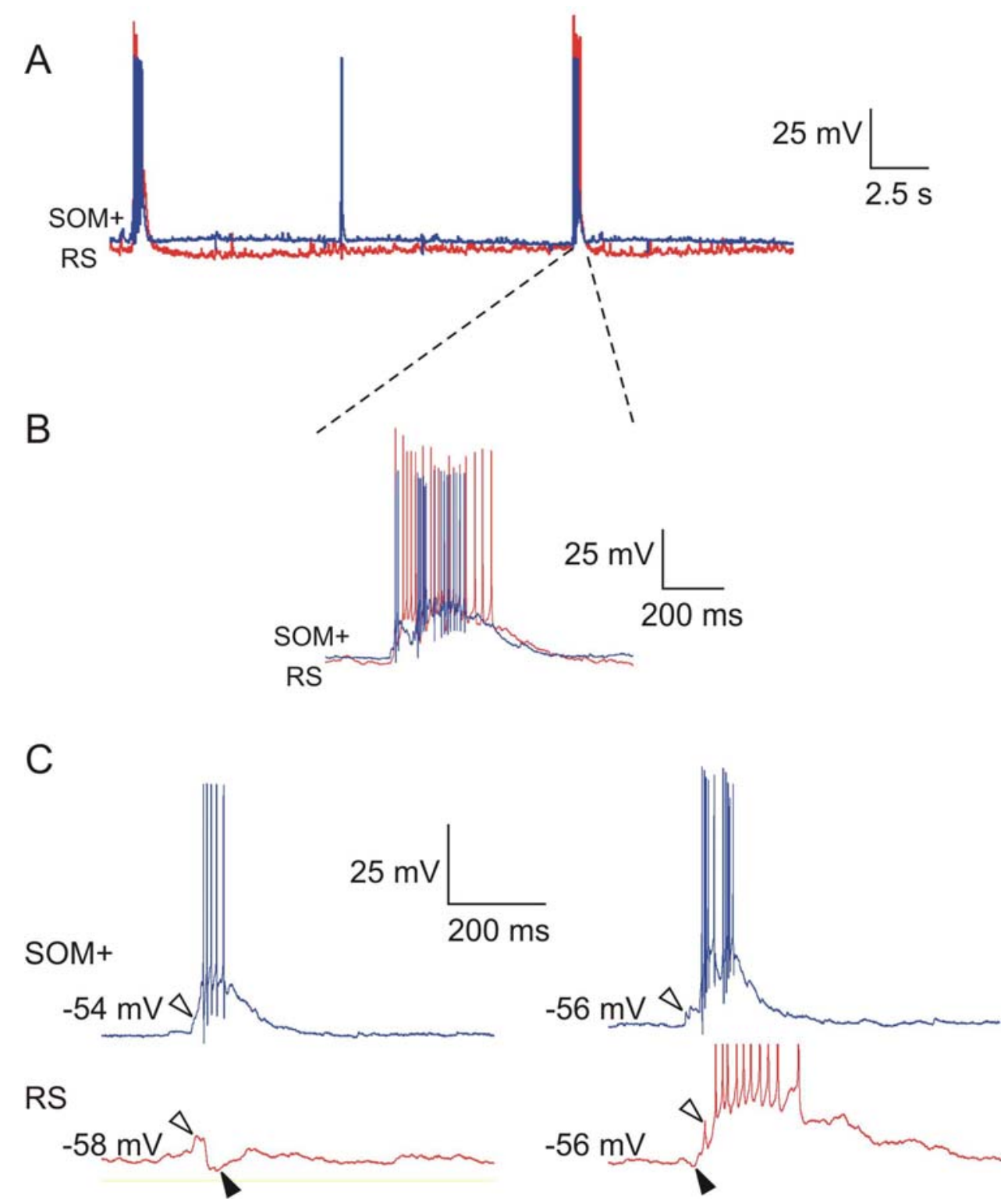

Figure 3.9. Responses of SOM+ (blue trace) and RS cells (red trace) during episodes of network activity in $0 \mathrm{Mg}^{2+}$ ACSF. A, three episodes of network activity induced by $0 \mathrm{Mg}^{2+} \mathrm{ACSF}$. B, expansion of one episode from the trace in A. C, simultaneous recording of an RS and a SOM+ cell during two episode of network activity. Note that the RS cell remained subthreshold at left. The action potentials of RS cell during the episode at right are truncated. Hollow arrowheads indicate EPSPs; filled arrowheads indicate IPSPs. 
A

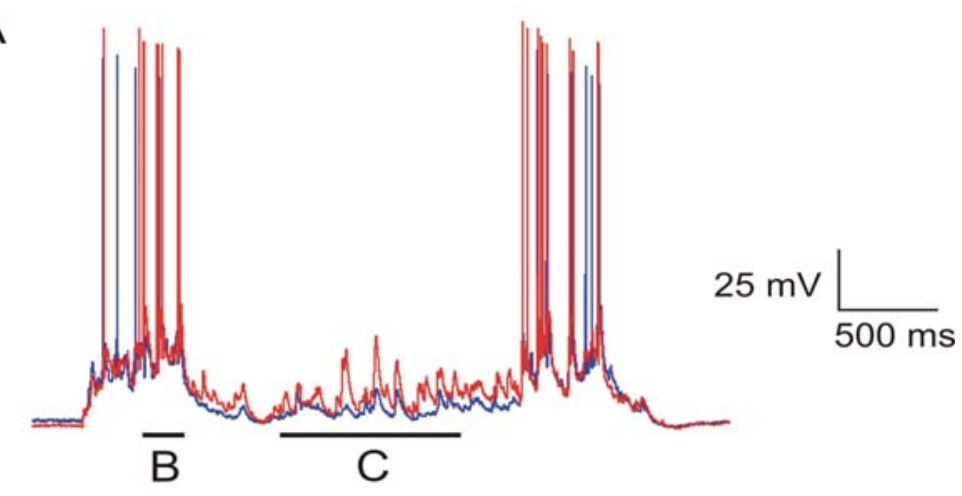

B

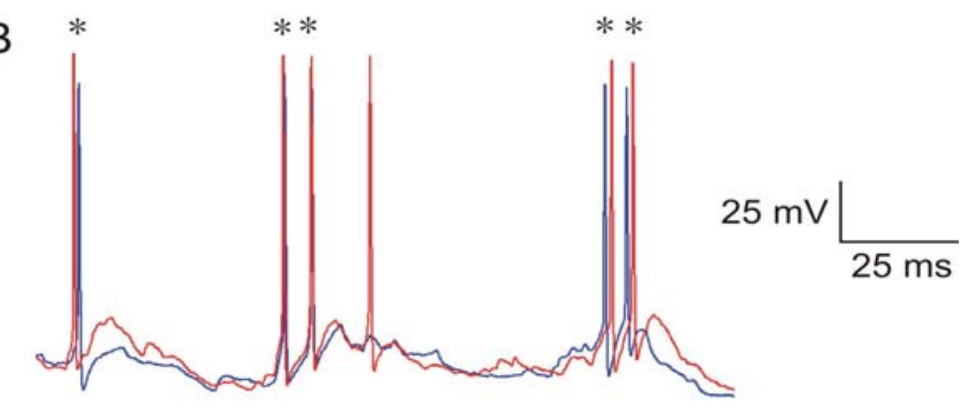

C

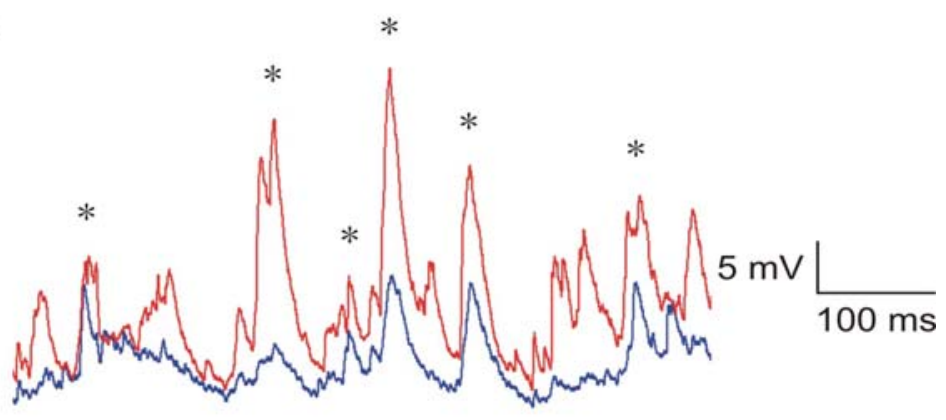

D

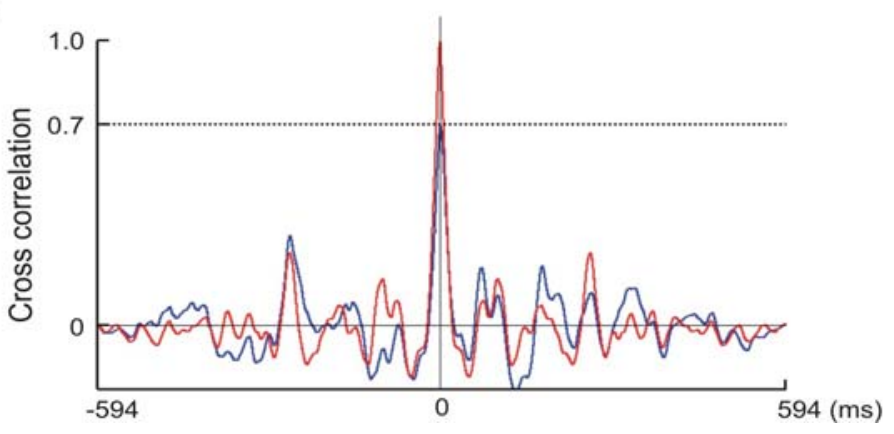

Figure 3.10. Correlated voltage responses of a pair of SOM+cells during an episode of network activity. A, responses of two simultaneously recorded, electrically coupled $\mathrm{SOM}+$ cells during a network episode. B and $\mathrm{C}$, expansion of the underlied sequences in $\mathrm{A}$, to demonstrate synchronous firing (B) and subthreshold EPSPs (C). Black asterisks in B and C indicate synchrony of the spikes and EPSPs, respectively. D, the cross-correlation (blue trace) of the EPSPs in panel $\mathrm{C}$ was 0.7 . Red trace is the auto-correlation of the $\mathrm{SOM}+$ cell in red. 
Table 3.1. Summary of IPSC parameters mediated by four types of inhibitory synapses

\begin{tabular}{|c|c|c|c|c|}
\hline & SOM $+\rightarrow$ FS & SOM $+\rightarrow$ RS & FS $\rightarrow$ FS & $\mathbf{F S} \rightarrow \mathbf{R S}$ \\
\hline $\mathbf{P}_{\text {connection }}$ & $\begin{array}{l}91.4 \% \\
(n=35)\end{array}$ & $\begin{array}{l}84.4 \% \\
(\mathrm{n}=45)\end{array}$ & $\begin{array}{l}57.1 \% \\
(\mathrm{n}=28)\end{array}$ & $\begin{array}{l}50.0 \% \\
(\mathrm{n}=38)\end{array}$ \\
\hline $\mathbf{P}_{\text {failure }}$ & $\begin{array}{c}0 \\
(\mathrm{n}=17)\end{array}$ & $\begin{array}{c}15.1 \pm 17.6 \% \\
(\mathrm{n}=28)\end{array}$ & $\begin{array}{c}1.1 \pm 1.6 \% \\
(\mathrm{n}=6)\end{array}$ & $\begin{array}{c}4.4 \pm 7.2 \\
(n=8)\end{array}$ \\
\hline $\mathbf{I}_{\text {synaptic }}$ & $\begin{array}{c}127.9 \pm 64.4 \\
(\mathrm{n}=17)\end{array}$ & $\begin{array}{c}22.9 \pm 17.0 \\
(\mathrm{n}=28)\end{array}$ & $\begin{array}{c}84.1 \pm 54.4 \\
(\mathrm{n}=6)\end{array}$ & $\begin{array}{c}77.0 \pm 95.1 \\
(\mathrm{n}=8)\end{array}$ \\
\hline PPR of IPSC & $\begin{array}{c}0.84 \pm 0.08 \\
(\mathrm{n}=19)\end{array}$ & $\begin{array}{c}0.85 \pm 0.14 \\
(\mathrm{n}=16)\end{array}$ & $\begin{array}{c}0.71 \pm 0.09 \\
(n=4)\end{array}$ & $\begin{array}{c}0.69 \pm 0.09 \\
(\mathrm{n}=8)\end{array}$ \\
\hline SSR of IPSC & $\begin{array}{c}0.92 \pm 0.20 \\
(\mathrm{n}=19)\end{array}$ & $\begin{array}{c}0.92 \pm 0.21 \\
(\mathrm{n}=16)\end{array}$ & $\begin{array}{c}0.47 \pm 0.13 \\
(\mathrm{n}=4)\end{array}$ & $\begin{array}{c}0.40 \pm 0.09 \\
(\mathrm{n}=8)\end{array}$ \\
\hline RTR of IPSC & $\begin{array}{c}1.17 \pm 0.16 \\
(\mathrm{n}=19)\end{array}$ & $\begin{array}{c}1.22 \pm 0.27 \\
(\mathrm{n}=16)\end{array}$ & $\begin{array}{c}0.57 \pm 0.10 \\
(\mathrm{n}=4)\end{array}$ & $\begin{array}{c}0.54 \pm 0.09 \\
(\mathrm{n}=8)\end{array}$ \\
\hline $\begin{array}{l}\text { Rise time of } \\
\text { IPSC (ms) }\end{array}$ & $\begin{array}{c}0.44 \pm 0.06 \\
(\mathrm{n}=16)\end{array}$ & $\begin{array}{c}0.57 \pm 0.09 \\
(\mathrm{n}=12)\end{array}$ & $\begin{array}{c}0.32 \pm 0.04 \\
(\mathrm{n}=5)\end{array}$ & $\begin{array}{c}0.32 \pm 0.03 \\
(\mathrm{n}=6)\end{array}$ \\
\hline $\begin{array}{l}\text { Decay time of } \\
\text { IPSC (ms) }\end{array}$ & $\begin{array}{c}3.19 \pm 0.86 \\
(\mathrm{n}=17)\end{array}$ & $\begin{array}{c}4.91 \pm 1.13 \\
(\mathrm{n}=11)\end{array}$ & $\begin{array}{c}3.14 \pm 0.68 \\
(n=5)\end{array}$ & $\begin{array}{c}5.16 \pm 1.12 \\
(n=9)\end{array}$ \\
\hline
\end{tabular}

Note: $\mathrm{P}_{\text {connection, }}$ probability for chemical connection; $\mathrm{P}_{\text {failure}}$, synaptic transmission

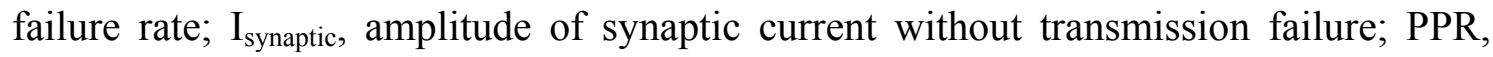
paired-pulse ratio; SSR, steady-state ratio; RTR, recovery test response. 
This page is intentionally blank. 


\section{REFERENCES}

Ali AB, Nelson C (2006) Distinct Ca2+ channels mediate transmitter release at excitatory synapses displaying different dynamic properties in rat neocortex. Cereb Cortex 16: 38693.

Ali AB, Thomson AM (1998) Facilitating pyramid to horizontal oriens-alveus interneurone inputs: dual intracellular recordings in slices of rat hippocampus. J Physiol 507: 185-99.

Amitai Y, Gibson JR, Beierlein M, Patrick SL, Ho AM, Connors BW, Golomb D (2002) The spatial dimensions of electrically coupled networks of interneurons in the neocortex. J Neurosci 22: 4142-52.

Bacci A, Rudolph U, Huguenard JR, Prince DA (2003) Major differences in inhibitory synaptic transmission onto two neocortical interneuron subclasses. J Neurosci 23: 966474.

Bartos M, Vida I, Frotscher M, Geiger JR, Jonas P (2001) Rapid signaling at inhibitory synapses in a dentate gyrus interneuron network. J Neurosci 21: 2687-98.

Bartos M, Vida I, Frotscher M, Meyer A, Monyer H, Geiger JR, Jonas P (2002) Fast synaptic inhibition promotes synchronized gamma oscillations in hippocampal interneuron networks. PNAS 99: 13222-7.

Beierlein M, Gibson JR, Connors BW (2000) An electrically coupled network of interneurons drives synchronized inhibition in neocortex. Nat Neurosci 3: 904-910.

Beierlein M, Gibson JR, Connors BW (2003) Two dynamically distinct inhibitory networks in layer 4 of the neocortex. J Neurophysiol 90: 2987-3000.

Blatow M, Rozov A, Katona I, Hormuzdi SG, Meyer AH, Whittington MA, Caputi A, Monyer H (2003) A novel network of multipolar bursting interneurons generates theta frequency oscillations in neocortex. Neuron 38: 805-17.

Bragin A, Jando G, Nadasdy Z, Hetke J, Wise K, Buzsaki G (1995) Gamma (40-100 Hz) oscillation in the hippocampus of the behaving rat. J Neurosci 15: 47-60.

Chattopadhyava B, Di Cristo G, Higashiyama H, Knott GW, Kuhlman SJ, Welker E, Huang ZJ (2004) Experience and activity-dependent maturation of perisomatic GABAergic innervation in primary visual cortex during a postnatal critical period.

J Neurosci 24: 9598-611.

Chen G, Harata NC, Tsien RW (2004) Paired-pulse depression of unitary quantal amplitude at single hippocampal synapses. PNAS 101: 1063-8. 
Chrobak JJ, Buzsaki G (1996) High-frequency oscillations in the output networks of the hippocampal-entorhinal axis of the freely behaving rat. J Neurosci 16: 3056-66.

Cossart R, Dinocourt C, Hirsch JC, Merchan-Perez A, De Felipe J, Ben-Ari Y, Esclapez M, Bernard C (2001) Dendritic but not somatic GABAergic inhibition is decreased in experimental epilepsy. Nat Neurosci 4: 52-62.

Dobrunz LE, Stevens CF (1997) Heterogeneity of release probability, facilitation, and depletion at central synapses. Neuron 18: 995-1008.

Draguhn A, Traub RD, Schmitz D, Jefferys JG (1998) Electrical coupling underlies highfrequency oscillations in the hippocampus in vitro. Nature 394: 189-92.

Flint AC, Maisch US, Kriegstein AR (1997) Postnatal development of low [Mg2+] oscillations in neocortex. J Neurophysiol 78: 1990-6.

Galarreta M, Hestrin S (1999) A network of fast-spiking cells in the neocortex connected by electrical synapses. Nature 402: 72-75.

Galarreta M, Hestrin S (2002) Electrical and chemical synapses among parvalbumin fastspiking GABAergic interneurons in adult mouse neocortex. PNAS 99: 12438-12443.

Gibson JR, Beierlein M, Connors BW (2005) Functional properties of electrical synapses between inhibitory interneurons of neocortical layer 4. J Neurophysiol 93: 467-80.

Gibson JR, Beierlein M, Connors BW (1999) Two networks of electrically coupled inhibitory neurons in neocortex. Nature 402: 75-79.

Graham ME, O'Callaghan DW, McMahon HT, Burgoyne RD (2002) Dynamindependent and dynamin-independent processes contribute to the regulation of single vesicle release kinetics and quantal size. PNAS 99: 7124-9.

Gupta A, Wang Y, Markram H (2000) Organizing principles for a diversity of GABAergic interneuons and synapses in the neocortex. Science 287: 273-278.

Haider B, Duque A, Hasenstaub AR, McCormick DA (2006) Neocortical network activity in vivo is generated through a dynamic balance of excitation and inhibition. $\mathrm{J}$ Neurosci 26: 4535-45.

Kaiser K, Lubke J, Zilberter Y, Sakmann B (2004) Postsynaptic calcium influx at single synaptic contacts between pyramidal neurons and bitufted interneurons in layer $2 / 3$ of rat neocortex is enhanced by backpropagating action potentials. J Neuosci 24: 1319-1329).

Kapfer C, Glickfeld L, Atallah B, Scanziani M (2007) Supralinear increase of recurrent inhibition during sparse activity in the somatosensory cortex. Nat Neurosci 10: 743-753. 
Kawaguchi Y (2001) Distinct firing patterns of neuronal subtypes in cortical synchronized activities. J Neurosci 21: 7261-72.

Kraushaar U, Jonas P (2000) Efficacy and stability of quantal GABA release at a hippocampal interneuron-principal neuron synapse. J Neurosci 20: 5594-607.

Leranth C, Malcolm AJ, Frotscher M (1990) Afferent and efferent synaptic connections of somatostatin-immunoreactive neurons in the rat fascia dentata. J Comp Neurol 295: 111-22.

Lu JT, Li CY, Zhao JP, Poo MM, Zhang XH (2007) Spike-timing-dependent plasticity of neocortical excitatory synapses on inhibitory interneurons depends on target cell type. $\mathrm{J}$ Neurosci 27: 9711-20.

Ma Y, Hu H, Berrebi AS, Mathers PH, Agmon A (2006) Distinct subtypes of somatostatin-containing neocortical interneurons revealed in transgenic mice. J Neurosci 26: 5069-5062.

Maccaferri G, Roberts JDB, Szucs P, Cottingham CA, Somogyi P (2000) Cell surface domain specific postsynaptic currents evoked by identified GABAergic neurons in rat hippocampus in vitro. J Physiol 524: 91-116.

MacLean JN, Watson BO, Aaron GB, Yuste R (2005) Internal dynamics determine the cortical response to thalamic stimulation. Neuron 48: 811-23.

Mann-Metzer P, Yarom Y (1999) Electrotonic coupling interacts with intrinsic properties to generate synchronized activity in cerebellar networks of inhibitory interneurons. $\mathrm{J}$ Neurosci 19: 3298-306.

Nevian T, Sakmann B (2004) Single spine $\mathrm{Ca}^{2+}$ signals evoked by coincident EPSPs and backpropagating action potentials in spiny stellate cells of layer 4 in the juvenile rat somatosensory barrel cortex. J Neuosci 24: 1689-1699.

Nusser Z, Sieghart W, Benke D, Fritschy JM, Somogyi P (1996) Differential synaptic localization of two major gamma-aminobutyric acid type A receptor alpha subunits on hippocampal pyramidal cells. PNAS 93: 11939-44.

Overstreet LS, Jones MV, Westbrook GL (2000) Slow desensitization regulates the availability of synaptic GABA(A) receptors. J Neurosci 20: 7914-21.

Pierce JP, Lewin GR (1994) An ultrastructural size principle. Neuroscience 58: 441-6.

Poisbeau P, Cheney MC, Browning MD, Mody I (1999) Modulation of synaptic GABAA receptor function by PKA and PKC in adult hippocampal neurons. J Neurosci 19: 674-83. 
Poncer JC, McKinney RA, Gahwiler BH, Thompson SM (1997) Either N- or P-type calcium channels mediate GABA release at distinct hippocampal inhibitory synapses. Neuron 18: 463-72.

Porter JT, Johnson CK, Agmon A (2001) Diverse types of interneurons generate thalamus-evoked feedforward inhibition in the mouse barrel cortex. J Neurosci 21: 2699710.

Pouille F, Scanziani M (2004) Routing of spike series by dynamic circuits in the hippocampus. Nature 429: 717-23.

Reyes A, Lujan R, Rozov A, Burnashev N, Somogyi P, Sakmann B (1998) Target-cellspecific facilitation and depression in neocortical circuits. Nat Neurosci 1: 279-85.

Segev I, Friedman A, White EL, Gutnick MJ (1995) Electrical consequences of spine dimensions in a model of a cortical spiny stellate cell completely reconstructed from serial thin sections. J Comput Neurosci 2: 117-30.

Shu Y, Hasenstaub A, McCormick DA (2003) Turning on and off recurrent balanced cortical activity. Nature 423: 288-93.

Silberberg G, Markram H (2007) Disynaptic inhibition between neocoritcal pyramidal cells mediated by Martinotti cells. Neuon 53: 735-746.

Spruston N, Jaffe DB, Johnston D (1994) Dendritic attenuation of synaptic potentials and currents: the role of passive membrane properties. Trends Neurosci 17: 161-6.

Spruston N, Jaffe DB, Williams SH, Johnston D (1993) Voltage- and space-clamp errors associated with the measurement of electrotonically remote synaptic events. J Neurophysiol 70: 781-802.

Staiger JF, Schubert D, Zuschratter W, Kotter R, Luhmann HJ, Zilles K (2002) Innervation of interneurons immunoreactive for VIP by intrinsically bursting pyramidal cells and fast-spiking interneurons in infragranular layers of juvenile rat neocortex. Eur $\mathrm{J}$ Neurosci 16: 11-20.

Standaert DG, Landwehrmeyer GB, Kerner JA, Penney JB Jr, Young AB (1996) Expression of NMDAR2D glutamate receptor subunit mRNA in neurochemically identified interneurons in the rat neostriatum, neocortex and hippocampus. Brain Res Mol Brain Res 42: 89-102.

Steriade M, Nunez A, Amzica F (1993) A novel slow $(<1 \mathrm{~Hz})$ oscillation of neocortical neurons in vivo: depolarizing and hyperpolarizing components. J Neurosci 13: 3252-65.

Tamas G, Buhl EH, Lorincz A, Somogyi P (2000) Proximally targeted GABAergic synapses and gap junctions synchronize cortical interneurons. Nat Neurosci 3: 366-71. 
Tamas G, Buhl EH, Somogyi P (1997) Fast IPSPs elicited via multiple synaptic release sites by different types of GABAergic neurone in the cat visual cortex. J Physiol 500: 715-38.

Tamas G, Buhl EH, Somogyi P (1997) Massive autaptic self-innervation of GABAergic neurons in cat visual cortex. J Neurosci 17: 6352-64.

Tamas G, Somogyi P, Buhl EH (1998) Differentially interconnected networks of GABAergic interneurons in the visual cortex of the cat. J Neurosci 18: 4255-70.

Tan Z, Hu H, Huang ZJ, Agmon A (in press) Robust but Delayed Thalamocortical Activation of Dendritic-Targeting Inhibitory Interneurons. PNAS.

Thompson SE, Ayman G, Woodhall GL, Jones RS (2007) Depression of glutamate and GABA release by presynaptic GABA(B) receptors in the entorhinal cortex in normal and chronically epileptic rats. Neurosignals 15: 202-15.

Thomson AM, West DC, Hahn J, Deuchars J (1995) Properties of single axon excitatory postsynaptic potentials elicited in spiny interneurons by action potentials in pyramidal neurons in slices of rat neocortex. Neuroscience 69: 727-38.

Wang Y, Toledo-Rodriguez M, Gupta A, Wu C, Silberberg G, Luo J, Markram H (2004) Anatomical, physiological and molecular properties of Martinotti cells in the somatosensory cortex of the juvenile rat. J Physiol 561: 65-90.

White TW, Paul DL (1999) Genetic diseases and gene knockouts reveal diverse connexin functions. Annu Rev Physiol 61: 283-310.

Williams SR, Buhl EH, Mody I (1998) The dynamics of synchronized neurotransmitter release determined from compound spontaneous IPSCs in rat dentate granule neurones in vitro. J Physiol 510: 477-97.

Wisden W, Laurie DJ, Monyer H, Seeburg PH (1992) The distribution of 13 GABAA receptor subunit mRNAs in the rat brain. I. Telencephalon, diencephalon, mesencephalon. J Neurosci 12: 1040-62.

Xiang Z, Huguenard JR, Prince DA (1998) GABA $_{A}$ receptor-mediated currents in interneurons and pyramidal cells of rat visual cortex. J Physiol 506: 715-30.

Xiang Z, Huguenard JR, Prince DA (2002) Synaptic inhibition of pyramidal cells evoked by different interneuronal subtypes in layer $\mathrm{V}$ of rat visual cortex. J Neurophysiol 88:740 -750 . 
This page is intentionally blank. 
Chapter Four

General Discussion 


\section{DISCUSSION}

\section{Categorization of GABAergic interneurons, with focus on SOM+ cells}

As mentioned in the introduction, interneuron properties are highly variable, but neurochemical content could be used as a relatively reliable classification criterion for cortical interneurons (Kubota et al., 1994; Kawaguchi and Kuboda, 1996; ToledoRodriguez et al., 2004; Flames and Marin, 2005; Wonders and Anderson, 2006). While $\mathrm{SOM}+$ or suspected $\mathrm{SOM}+$ cells have been studied in the barrel cortex and elsewhere (Gibson et al., 1999; Porter et al., 2001; Amitai et al., 2002; Beierlein et al., 2003; Goldberg et al., 2004; Wang et al., 2004; Gibson et al., 2005), it was not known whether this important group of interneurons contains distinct subtypes. Transgenic mice technology provides a powerful tool to study properties of interneurons, since specific groups of interneurons with distinct molecular properties can be labeled with fluorescent proteins in transgenic animals. Using this technology, systematic and reproducible studies of many properties could be conducted on the same subtypes of cells in different animals. Using transgenic mice is especially helpful for targeting interneuron of relatively rare subtypes, especially given that all inhibitory interneurons are already a minority compared to excitatory cells.

Taking advantage of transgenic mice which were made by our lab and our co-workers, we studied systematically the properties of GFP-tagged SOM+ cells in the barrel cortex. We found that supragranular and infragranular $\mathrm{SOM}+$ cells were layer 1-targeting Martinotti cells. Consistent with previous studies, low-threshold spiking (LTS) cells were mostly distributed in deep layers. Most importantly, we observed that layer $4 \mathrm{SOM}+$ cells appeared to be a novel subtype of SOM+ interneurons. Morphologically, layer $4 \mathrm{SOM}+$ cells innervated mainly layer 4 and almost never layer 1 . Their main ascending axon originated from the either soma or a proximal dendrite. The main axon and its emitted branches descended back into the dendritic field, similar to previously described "arcade cells" (Kubota et al., 1994). Unlike supragranular and infragranular SOM cells, layer 4 SOM cells fired in a stuttering firing pattern. Another striking feature was their electrophysiological parameters, specifically, narrow spike width, small input resistance and high maximal firing frequency, which were very close to those of fast-spiking (FS) 
cells (for details, see Chapter Two). Thus, layer $4 \mathrm{SOM}+$ cells could be described as "quasi-FS", despite their relatively pronounced firing frequency adaptation. Whether there is a relation between high maximal firing frequency and expression of the potassium channel Kv3.2 in SOM+ cells (Chow et al., 1999) needs to be explored further. The similar electrophysiological properties of layer $4 \mathrm{SOM}+$ cells and FS cells make the distinction between these two cell types difficult without the benefit of GFP expression, which probably explains why this subtype was not reported previously.

The three most commonly reported interneuron subtypes in layer 4 are FS, RSNP and "LTS" cells, defined mostly based on electrophysiological properties (Gibson et al., 1999, 2005; Beierlein et al., 2000, 2003; Deans et al., 2001; Porter et al., 2001). One thing I need to point out is that these "LTS" cells in layer 4 are not real "LTS" like those found in layers 5/6 (Goldberg et al., 2004), because when injected with depolarizing current at hyperpolarized potential they do not generate low-threshold calcium spikes. Based on the calculation of cell percentages, previous studies may have lumped together a variety of non-FS interneurons as "LTS" or RSNP cells (Porter et al., 2001; Beierlein et al., 2003). Indeed, immunostaining in layer 4 shows that $\mathrm{SOM}+$ cells only constitute about one-half of the non-FS cells (Amitai et al., 2002). A Similar proportion of SOM+ interneurons was also reported in visual cortex (Gonchar and Burkhalter, 1997).

\section{Similarity of the synaptic properties of SOM+ cells in the cerebral cortex}

SOM + cells have been studied in layers 2/3 (Kaiser et al, 2004; Kapfer et al., 2007), layer 4 (Gibson et al., 1999; Beierlein et al., 2003, this study) and layer 5 (Silberberg and Markram, 2007), as well as in hippocampus (Pouille and Scanziani, 2004). All of these $\mathrm{SOM}+$ cells display similar properties. First, they receive facilitating excitatory inputs (Gibson et al., 1999; Silberberg and Markram, 2007; Kapfer et al., 2007; this study). Second, SOM + cells mediate disynaptic inhibition (Pouille and Scanziani, 2004; Silberberg and Markram, 2007; Kapfer et al., 2007). Third, they target relatively distal dendrites of postsynaptic targets (Maccaferri et al., 2000; Silberberg and Markram, 2007). In our results, rise times of IPSCs evoked by FS cells in both FS and RS cells were faster than rise times of IPSCs produced by SOM+ cells, consistent with somatic or proximal 
dendritic-targeting of FS cells contacts onto their postsynaptic targets (Maccaferri et al., 2000; Xiang et al., 2002), and suggested that relatively more distal synaptic contacts were made by layer $4 \mathrm{SOM}+$ cells. Interestingly, the IPSCs produced by SOM+ cells have relatively longer rise times in RS cells than those in FS cells. The relation of IPSC rise times suggested the following relative synaptic distances from the postsynaptic soma: SOM+-to-RS $>$ (i.e. more distal) $>$ SOM-to-FS $>$ FS-to-RS $=$ FS-to-FS cells.

Martinotti cells in supragranular and infragranular layers make extensive axonal projections in layer 1 , and terminate on the distal tufts of dendrites of pyramidal cells. However, the case in layer 4 is different, given that the dendritic trees of the majority of RS cells in layer 4 are confined to their home layer, and the axonal trees of SOM+cells are similarly confined to layer 4. Based on the slower rise times of IPSCs generated in RS cells by SOM+ cells compared to those by FS cells, we propose that layer 4 has its own distal-dendrites inhibitory system. In other words, there may be two dendritic targeting systems in barrel cortex: dendrites of pyramidal cells in layers 2,3,5,6 are contacted by Martinotti cells in those layers, and dendrites of RS cells in layer 4 (mostly spiny stellate cells) are contacted by layer 4 or layer 5B SOM+cells.

\section{Electrical coupling between SOM+ cells}

Electrical coupling between interneurons can synchronize neuronal activity (Draguhn et al., 1998; Galarreta and Hestrin, 1999; Mann-Metzer and Yarom, 1999; Beierlein et al., 2000). Given the $100 \%$ electrical connectivity we found between adjacent layer $4 \mathrm{SOM}+$ cells, SOM + cells may function as a large, continuous syncytium that works synchronously as an integrative network. Before reaching spiking threshold, the electrical interconnection will tend to reduce the magnitude of depolarization happening in one given cell (due to current spread to coupled cells); however, if a sodium spike is triggered, current spread may help synchronize adjacent cells.

\section{Synaptic properties of layer 4 SOM+ vs. FS interneurons}

FS cells are generally considered to be the most prominent inhibitory cells in the cortex, for several reasons. First, in response to depolarizing current injection, FS cells can fire at very high frequencies for long periods. Second, they innervate the somatic and proximal 
regions of principal cells and efficiently control the gain of synaptic inputs (Tamas et al., 2000). Third, FS cells exhibit divergent innervation of both interneurons and principal cells (Tamas et al., 1998). Fourth, from their input aspect, FS neurons receive fast excitatory synaptic current onto their somatic and proximal region, which generates a highly precise spike-to-spike transmission at unitary pyramidal-FS cell connections (Fricker and Miles, 2001; Galarreta and Hestrin, 2001). Fifth, FS cells form electrical synapses between themselves (Galarreta and Hestrin, 1999; Gibson et al., 1999).

In contrast, I suggest that during high frequency network activity, layer $4 \mathrm{SOM}+$ cells can generate stronger inhibition than FS cells, based on the following reasons.

1) Layer $4 \mathrm{SOM}+$ cells received weak individual unitary EPSPs, which made them difficult to recruit during transient activity. However, at high frequency, unitary EPSPs to SOM+ cells displayed strong frequency-dependent facilitation (Gibson et al., 1999, and this study), while excitatory inputs to FS cells exhibit strong depression, which would reduce the recruitment of FS cells (Beierlein et al., 2003). Therefore, SOM+ cells are well-placed to participate in high frequency network activity.

2) SOM+ cells received no chemical inhibition from themselves and only weak chemical inhibition from FS cells, as indicated by the low connectivity from FS to SOM+ cells. In contrast, FS cells received stronger inhibition from themselves and even stronger inhibition from SOM+ cells, as shown in Fig. 4.1.

3) As introduced earlier, owing to the short latency of electrical coupling, action potentials in one SOM+ cell could induce fast depolarization in the coupled cells, which will interact with subthreshold mechanisms to facilitate synchronous firing (Galarreta and Hestrin, 1999; Mann-Metzer and Yarom, 1999; Beierlein et al., 2000; Gibson et al., 2005). Moreover, enhancement of neuronal synchrony is positively correlated with electrical coupling strength (Gibson et al., 2005). Therefore, the stronger electrical coupling between SOM+ cells compared to that between FS cells (Fig. 4.1) will enable SOM + cells to fire synchronously. The synchrony of SOM+ discharge could significantly enhance their inhibitory effect due to the spatial summation in postsynaptic cells. Previous modeling studies indicate that, given a fixed total coupling strength, either electrical coupling alone or inhibition alone are better at enhancing neural synchrony than 
a combination of electrical and inhibitory coupling (Lewis and Rinzel, 2003). The exclusively electrical but not chemical connections between SOM+cells will therefore endow them with an important role in network synchronous activity. Notably, similar features are shared by inhibitory interneurons in the thalamic reticular nucleus (RTN) (Landisman et al., 2002).

4) SOM+ cells had high connectivity probabilities to both RS and FS cells, as shown in

Fig. 3.1, which were much higher than the connectivity of FS cells (this study). Furthermore, dynamically, the inhibitory outputs by SOM+ cells had less short-term depression and relatively more long-term facilitation, which were strikingly different from the strong depression of IPSPs originating in FS cells. Therefore, SOM+ cells may perform sustained, collective inhibition.

5) SOM+ cells are enriched with mGluR receptors (Baude et al., 1993; McBain et al., 1994; Whittington et al., 1995; Beierlein et al., 2000; Stinehelfer et al., 2000; van Hoof et al., 2000) and muscarinic acetylcholine (mAChR) receptors (Kawaguchi, 1997; Xiang et al., 1998), compared to FS cells (van Hooft et al., 2000; Kawaguchi and Kondo, 2002). Thus, SOM+ cells are closely regulated by neuromodulators. Their endogenous ligands are likely released at high level during behavioral states such as alert wakefulness and rapid eye movement phase in sleep, which are associated with strong cortical activity and increased input from the cholinergic basal forebrain (Steriade, 1997; Cape et al., 2000). Possibly, binding of neuromodulators to $\mathrm{SOM}+$ cells can change their input resistances and their membrane potentials, and in turn change the responsiveness of SOM cells.

\section{Role of SOM+ cells during high frequency network activity}

Taken together, the above features predict that SOM+ cells would be strongly excited during high frequency network activity. This prediction was confirmed by recording from $\mathrm{SOM}+$, FS and $\mathrm{RS}$ cells during $0 \mathrm{Mg}^{2+}$ induced network events. $\mathrm{SOM}+$ cells were the most active cell type, fired robustly, synchronously and more frequently than FS cells. The synchronous firing of SOM+ cells generated strong inhibition in both RS and FS cells, especially the latter, confirming that SOM+ interneurons are the major source of inhibition in layer 4 during high frequency network activity. 
Based on these findings, layer $4 \mathrm{SOM}+$ cells could potentially be recruited during both physiological and pathological states of high frequency firing. This can occur, for example, during the three activity states described below:

1) Given that layer 4 is the major recipient of excitatory thalamocortical projections belonging to the vibrissal trigeminal system, layer $4 \mathrm{SOM}+$ cells may be recruited during exploratory activity of rodents, during which multiple whiskers are presumably manipulated.

Three natural behavioral states are often seen in rodents such as rat. During "quiet" behavior rats are standing or sitting still and their whiskers are not moving; in "whisker twitching" behavior rats are also still but twitch their whiskers in very rhythmic, smallamplitude movement at a frequency of $7-12 \mathrm{~Hz}$; during "whisking", rats move their whiskers back and forth at a rate of $\sim 4-6 \mathrm{~Hz}$ (Fanselow et al., 2001; Nicolelis and Fanselow, 2002). Well-trained rats can discriminate between a smooth surface and one with $50 \mu \mathrm{m}$ spaced shallow grooves. Considering that during whisking behavior, each whisker is moving at $10-20 \mathrm{~mm} / \mathrm{s}$, the rat must be sensing vibrissal vibrations of $200-400$ $\mathrm{Hz}$ (Simons, 1995). Through trigeminal nuclei, exploratory inputs from the whiskers reach and excite excitatory relay cells in the thalamic VPM nucleus (Fig. 1.1 in Chapter 1). Two major types of VPM relay cells are single-whisker excitation (SWE) and multiple-whisker excitation (MWE) cells (Brecht and Sakmann, 2002b). Unlike SWE cells, which can be depolarized by deflection of a single principal whisker, MWE cells are depolarized by deflection of several whiskers, which presumably happens during exploratory behaviors of rats. Importantly, the generation of action potentials in MWE cells are often associated with putative low-threshold calcium spiking, which could interact with hyperpolarization-activated cation current to generate thalamocortical oscillation with high frequency firing (McCormick and Pape, 1990). The high frequency firing of thalamic relay cells can excite layer 4 excitatory regular-spiking (RS) cells in the barrels (Brecht and Sakmann, 2002a). Simultaneous stimulation of multiple whiskers can evoke response facilitation in both thalamic VPM nucleus (Ghazanfar and Nicolelis, 1997) and RS cells in the barrel cortex (Shimegi et al., 1999), the latter facilitation arising from excitation of adjacent barrels by excitation of single and multiple whiskers. The 
excitation of layer 4 RS cells could be at high frequency, due to high frequency inputs from individual whiskers, simultaneous stimulation of multiple whiskers, burst firing of thalamic MWE cells, efficient interconnection between layer 4 RS cells (Feldmeyer et al., 1999) and response facilitation from neighboring barrels. Therefore, layer 4 RS cells may fire at high frequency during exploratory whisking activity. The high frequency firing of layer 4 RS cells, may in turn recruit layer $4 \mathrm{SOM}+$ cells due to facilitation of EPSPs from $\mathrm{RS}$ to $\mathrm{SOM}+$ cells.

2) Cortical slow oscillations $(<1 \mathrm{~Hz})$ occur during natural sleep and certain forms of anesthesia (Steriade et al., 1993a, 1993b) and consist of alternating synaptically-active "UP" state and quiet "DOWN" state. During "UP" states, pyramidal cells across the cerebral cortex can fire at a frequency of $>30 \mathrm{~Hz}$ (Steriade et al., 1993a, 1993b), which may also include high frequency firing of layer 4 RS cells which, then, could activate layer $4 \mathrm{SOM}+$ cells. Thus, layer $4 \mathrm{SOM}+$ cells could be involved in "UP" states occurring under normal physiological conditions.

3) Pathologically, during some forms of seizures, high frequency epileptic activity can spread throughout the cerebral cortex. During the spread of epileptic activity, layer 4 RS cells could fire at high frequency, and in turn recruit layer $4 \mathrm{SOM}+$ cells.

The recruitment of layer 4 SOM cells may have different effects through inhibition of RS and FS cells.

1) Inhibition of RS cells: Activation of layer $4 \mathrm{SOM}+$ cells may inhibit dendrites of four types of RS cells - distal dendrites of layer 4 RS cells; basal dendrites of layers $2 / 3$ pyramidal cells; apical dendrites of layer 5 pyramidal cells, which pass through layer 4 , and apical dendritic tufts of layer 6 corticothalamic cells, which distribute in layer 4 (Fig. 4.1). All these four types of RS cells may be involved in generating hyperexcitation of cortical activity. For example, layer 4 RS cells are the main recipient of excitatory thalamocortical inputs; layers $2 / 3$ pyramidal cells are involved in strong intracortical connections (Feldmeyer et al., 2006); layer 5 pyramidal cells have dendritic initiation zone for calcium burst spiking (Larkum and Sakmann, 1999); layer 6 corticothalamic pyramidal cell can interact with thalamus to generate thalamic and cortical oscillations (Contreras et al., 1996; Contreras and Steriade, 1996). Considering the potential roles of 
the above four types of RS cells, given that excitatory inputs onto excitatory cells mostly target dendrites (Williams and Stuart, 2002) and considering the high inhibitory connection probability of SOM+ cells to RS cells, dendritic inhibition generated by layer $4 \mathrm{SOM}+$ cells may suppress excitatory inputs, curtail the genesis and spread of network activity and prevent cortical hyperexcitation. Because Martinotti cells have similar facilitating excitatory inputs and also generate dendritic inhibition (Silberberg and Markram, 2007; Kapfer et al., 2007), both cell types could work together to balance cortical excitation. During "UP" states in natural sleep, the recruitment of layer 4 SOM+ cells may be important in reducing external environment inputs relayed by the thalamocortical pathway to the cerebral cortex, which may be helpful in assuring high quality sleep. This inference is indirectly supported by in vivo recording of layers $2 / 3$ in rat barrel cortex, which show that spontaneous "UP" states inhibit the sensory responses evoked by whisker deflection (Petersen et al., 2003). One possible explanation is that "UP" states recruit layer $4 \mathrm{SOM}+$ cells, which inhibit the relay of sensory inputs from thalamus to layer 4 or from layer 4 to layers $2 / 3$.

2) Inhibition of FS cells: Layer $4 \mathrm{SOM}+$ interneurons recruited during high frequency network activity can generate strong inhibition in FS cells and "dis-excite" FS cells, which would allow FS cells to sustain their pool of readily releasable synaptic vesicles and thereby, at least partially, preserve the capability of FS cells to process thalamocortical inputs reliably and precisely. On the other hand, recruitment of layer 4 $\mathrm{SOM}+$ cells may release, to some degree, the proximal inhibition in RS cells generated by FS cells. The suppression of dendritic excitatory inputs and reduction of proximal inhibitory inputs could be balanced to dynamically maintain somatic excitability level (Shu et al., 2003).

Different oscillatory patterns occur in the cerebral cortex during different behavioral states. Specifically, theta oscillations are observed in the rat during exploration and rapideye-movement sleep (Buzsaki, 2002) and sharp-wave-associated ripples occur during slow-wave sleep, awake immobility and consumatory behaviors (Ylinen et al., 1995). During these diverse brain states, different neuromodulators may be released, such as acetylcholine (ACh) (Kawaguchi, 1997; Porter et al., 1999), serotonin (5-HT) (Ferezou et 
al., 2002), norepinephrine (NA) (Kawaguchi and Shindou, 1998) and dopamine (DA) (Le Moine and Gaspar, 1998). These neuromodulators differentially modulate the activity of diverse inhibitory interneurons, which could modulate membrane input resistance, change the AP waveform, and strongly modulate the strength of electrical coupling, thus regulating network synchrony. For instance, noradrenaline can depolarize $\mathrm{SOM}+$ cells via $\alpha$-adrenoceptors to spike firing, but NA-induced depolarization does not induce spike firing in FS cells (Kawaguchi and Shindou, 1998). Moreover, SOM+ cells can be fired by application of the cholinergic agonist carbachol, but FS cells do not respond to carbachol application (Kawaguchi, 1997). Differential neuromodulatory innervation, therefore, endows interneurons with different role under various brain states.

In sum, based on the specific effects of neuromodulators on SOM+ cells, their strong electrical coupling, their facilitating excitatory inputs, and their strong inhibition of FS cells, we predicted and confirmed that $\mathrm{SOM}+$ cells are the major source of inhibition in layer 4 during high frequency network activity, and we suggest that they function to prevent hyperexcitation of cortical circuitry and, possibly, to "dis-excite" FS cells, in turn, maintaining FS cells capacity for other functions. 


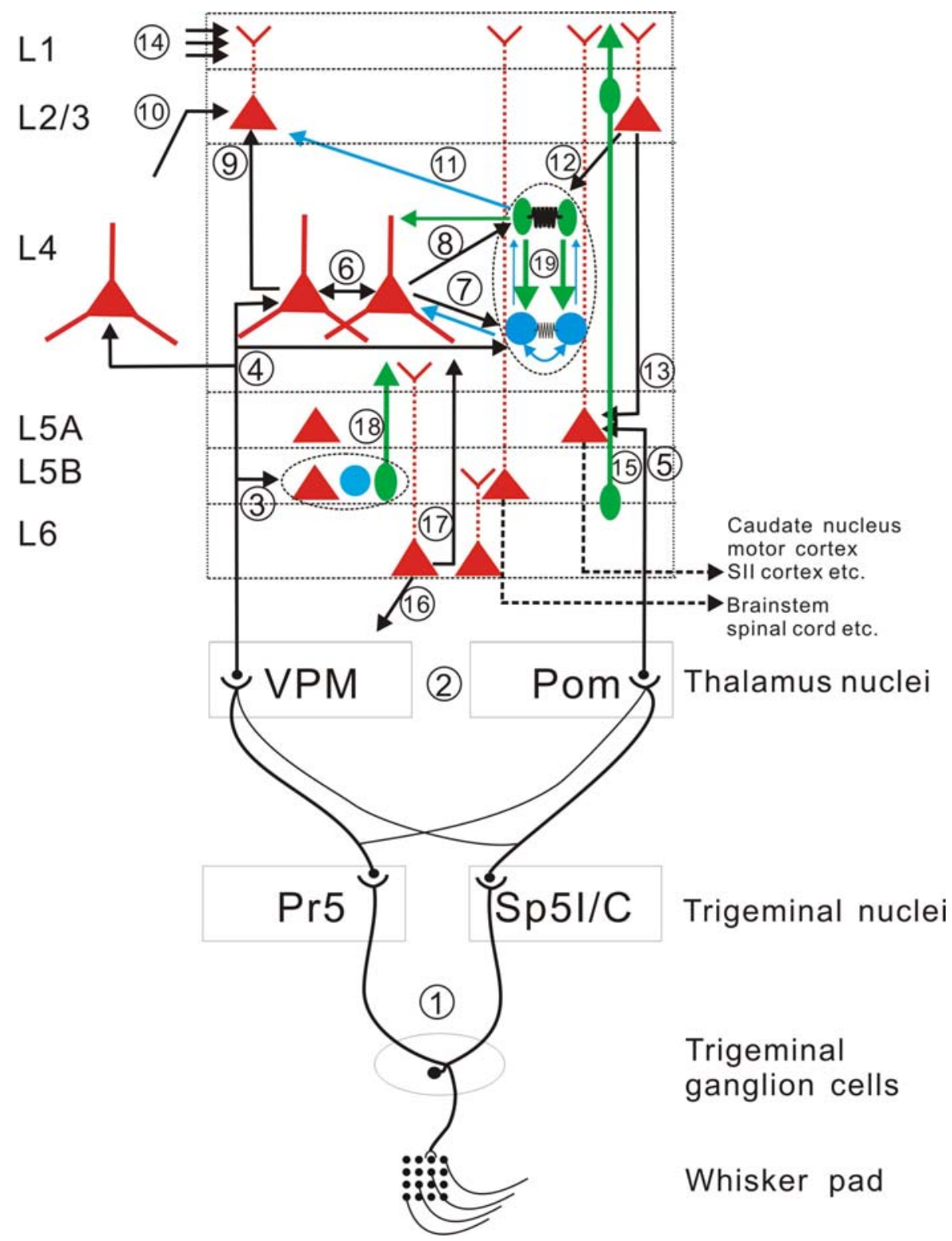

Fig. 4.1. Cortical circuit diagram (shown in Fig. 1.1) modified by the current study. Note the modifications in layer 4, including novel strong connection from SOM+ cells to FS cells, weak connection from FS cells to SOM+ cells, as well as stronger electrical coupling between SOM+ cells compared to FS cells. 
This page is intentionally blank. 


\section{REFERENCES}

Amitai Y, Gibson JR, Beierlein M, Patrick SL, Ho AM, Connors BW, Golomb D (2002) The spatial dimensions of electrically coupled networks of interneurons in the neocortex. J Neurosci 22: 4142-52.

Baude A, Nusser Z, Roberts JD, Mulvihill E, McIlhinney RA, Somogyi P (1993) The metabotropic glutamate receptor (mGluR1 alpha) is concentrated at perisynaptic membrane of neuronal subpopulations as detected by immunogold reaction. Neuron 11: 771-87.

Beierlein M, Gibson JR, Connors BW (2000) A network of electrically coupled interneurons drives synchronized inhibition in neocortex. Nat Neurosci 3: 904-10.

Beierlein M, Gibson JR, Connors BW (2003) Two dynamically distinct inhibitory networks in layer 4 of the neocortex. J Neurophysiol 90: 2987-3000.

Brecht M, Sakmann B (2002a) Dynamic representation of whisker deflection by synaptic potentials in spiny stellate and pyramidal cells in the barrels and septa of layer 4 rat somatosensory cortex. J Physiol 543: 49-70.

Brecht M, Sakmann B (2002b) Whisker maps of neuronal subclasses of the rat ventral posterior medial thalamus, identified by whole-cell voltage recording and morphological reconstruction. J Physiol 538: 495-515.

Buzsaki G (2002) Theta oscillations in the hippocampus. Neuron 33: 325-40.

Cape EG, Manns ID, Alonso A, Beaudet A, Jones BE (2000) Neurotensin-induced bursting of cholinergic basal forebrain neurons promotes gamma and theta cortical activity together with waking and paradoxical sleep. J Neurosci 20: 8452-61.

Chow A, Erisir A, Farb C, Nadal MS, Ozaita A, Lau D, Welker E, Rudy B (1999) K(+) channel expression distinguishes subpopulations of parvalbumin- and somatostatincontaining neocortical interneurons. J Neurosci 19: 9332-45.

Contreras D, Destexhe A, Sejnowski TJ, Steriade M (1996) Control of spatiotemporal coherence of a thalamic oscillation by corticothalamic feedback. Science 274: 771-4.

Contreras D, Steriade M (1996) Spindle oscillation in cats: the role of corticothalamic feedback in a thalamically generated rhythm. J Physiol 490: 159-79.

Deans MR, Gibson JR, Sellitto C, Connors BW, Paul DL (2001) Synchronous activity of inhibitory networks in neocortex requires electrical synapses containing connexin 36 . Neuron 31: 477-85.

Draguhn A, Traub RD, Schmitz D, Jefferys JG (1998) Electrical coupling underlies highfrequency oscillations in the hippocampus in vitro. Nature 394: 189-92. 
Fanselow EE, Sameshima K, Baccala LA, Nicolelis MA (2001) Thalamic bursting in rats during different awake behavioral states. PNAS 98: 15330-5.

Feldmeyer D, Egger V, Lubke J, Sakmann B (1999) Reliable synaptic connections between pairs of excitatory layer 4 neurones within a single 'barrel' of developing rat somatosensory cortex. J Physiol 521: 169-90.

Feldmeyer D, Lubke J, Sakmann B (2006) Efficacy and connectivity of intracolumnar pairs of layer 2/3 pyramidal cells in the barrel cortex of juvenile rats. J Physiol 575: 583602.

Ferezou I, Cauli B, Hill EL, Rossier J, Hamel E, Lambolez B (2002) 5-HT3 receptors mediate serotonergic fast synaptic excitation of neocortical vasoactive intestinal peptide/cholecystokinin interneurons. J Neurosci 22: 7389-97.

Flames N, Marin O (2005) Developmental mechanisms underlying the generation of cortical interneuron diversity. Neuron 46: 377-81.

Fricker D, Miles R (2001) EPSP amplification and the precision of spike timing in hippocampal neurons. Neuron 28: 559-69.

Galarreta M, Hestrin S (1999) A network of fast-spiking cells in the neocortex connected by electrical synapses. Nature 402: 72-5.

Galarreta M, Hestrin S (2001) Spike transmission and synchrony detection in networks of GABAergic interneurons. Science 292: 2295-9.

Ghazanfar AA, Nicolelis MA (1997) Nonlinear processing of tactile information in the thalamocortical loop. J Neurophysiol 78: 506-10.

Gibson JR, Beierlein M, Connors BW (2005) Functional properties of electrical synapses between inhibitory interneurons of neocortical layer 4. J Neurophysiol 93: 467-80.

Gibson JR, Beierlein M, Connors BW (1999) Two networks of electrically coupled inhibitory neurons in neocortex. Nature 402: 75-9.

Goldberg JH, Lacefield CO, Yuste R (2004) Global dendritic calcium spikes in mouse layer 5 low threshold spiking interneurones: implications for control of pyramidal cell bursting. J Physiol 558: 465-78.

Gonchar Y, Burkhalter A (1997) Three distinct families of GABAergic neurons in rat visual cortex. Cereb Cortex 7: 347-58. 
Kaiser K, Lubke J, Zilberter Y, Sakmann B (2004) Postsynaptic calcium influx at single synaptic contacts between pyramidal neurons and bitufted interneurons in layer $2 / 3$ of rat neocortex is enhanced by backpropagating action potentials. J Neuosci 24: 1319-1329).

Kapfer C, Glickfeld L, Atallah B, Scanziani M (2007) Supralinear increase of recurrent inhibition during sparse activity in the somatosensory cortex. Nat Neurosci 10: 743-753.

Kawaguchi Y (1997) Selective cholinergic modulation of cortical GABAergic cell subtypes. J Neurophysiol 78: 1743-7.

Kawaguchi Y, Kondo S (2002) Parvalbumin, somatostatin and cholecystokinin as chemical markers for specific GABAergic interneuron types in the rat frontal cortex. J Neurocytol 31: 277-87.

Kawaguchi Y, Kubota Y (1996) Physiological and morphological identification of somatostatin- or vasoactive intestinal polypeptide-containing cells among GABAergic cell subtypes in rat frontal cortex. J Neurosci 16: 2701-15.

Kawaguchi Y, Shindou T (1998) Noradrenergic excitation and inhibition of GABAergic cell types in rat frontal cortex. J Neurosci 18: 6963-76.

Kubota Y, Hattori R, Yui Y (1994) Three distinct subpopulations of GABAergic neurons in rat frontal agranular cortex. Brain Res 649: 159-73.

Landisman CE, Long MA, Beierlein M, Deans MR, Paul DL, Connors BW (2002) Electrical synapses in the thalamic reticular nucleus. J Neurosci 22: 1002-9.

Larkum ME, Kaiser KM, Sakmann B (1999) Calcium electrogenesis in distal apical dendrites of layer 5 pyramidal cells at a critical frequency of back-propagating action potentials. PNAS 96: 14600-4.

Le Moine C, Gaspar P (1998) Subpopulations of cortical GABAergic interneurons differ by their expression of D1 and D2 dopamine receptor subtypes. Brain Res Mol Brain Res 58: 231-6.

Lewis TJ, Rinzel J (2003) Dynamics of spiking neurons connected by both inhibitory and electrical coupling. J Comput Neurosci 14: 283-309.

Ma Y, Hu H, Berrebi AS, Mathers PH, Agmon A (2006) Distinct subtypes of somatostatin-containing neocortical interneurons revealed in transgenic mice. J Neurosci 26: 5069-82.

McBain CJ, DiChiara TJ, Kauer JA (1994) Activation of metabotropic glutamate receptors differentially affects two classes of hippocampal interneurons and potentiates excitatory synaptic transmission. J Neurosci 14: 4433-45. 
Maccaferri G, Roberts JD, Szucs P, Cottingham CA, Somogyi P (2000) Cell surface domain specific postsynaptic currents evoked by identified GABAergic neurones in rat hippocampus in vitro. J Physiol 524: 91-116.

Mann-Metzer P, Yarom Y (1999) Electrotonic coupling interacts with intrinsic properties to generate synchronized activity in cerebellar networks of inhibitory interneurons. J Neurosci 19: 3298-306.

McCormick DA, Pape HC (1990) Properties of a hyperpolarization-activated cation current and its role in rhythmic oscillation in thalamic relay neurons. J Physiol 431: 291318.

Nicolelis MA, Fanselow EE (2002) Thalamocortical optimization of tactile processing according to behavioral state. Nat Neurosci 5: 517-23.

Petersen CCH, Hahn TTG, Mehta M, Grinvald A, Sakmann B (2003) Interaction of sensory responses with spontaneous depolarization in layer $2 / 3$ barrel cortex. PNAS 100: 13638-43.

Porter JT, Cauli B, Tsuzuki K, Lambolez B, Rossier J, Audinat E (1999) Selective excitation of subtypes of neocortical interneurons by nicotinic receptors. J Neurosci 19: 5228-35.

Porter JT, Johnson CK, Agmon A (2001) Diverse types of interneurons generate thalamus-evoked feedforward inhibition in the mouse barrel cortex. J Neurosci 21: 2699710 .

Shimegi S, Ichikawa T, Akasaki T, Sato H (1999) Temporal characteristics of response integration evoked by multiple whisker stimulations in the barrel cortex of rats. J Neurosci 19: 10164-75.

Shu Y, Hasenstaub A, McCormick DA (2003) Turning on and off recurrent balanced cortical activity. Nature 423: 288-93.

Silberberg G, Markram H (2007) Disynaptic inhibition between neocoritcal pyramidal cells mediated by Martinotti cells. Neuon 53: 735-746.

Simons DJ (1995) Neuronal integration in the somatosensory whisker/barrel cortex. In: The Barrel Cortex of Rodentse edited by Jones EG and Diamond IT. New York: Plenum, p.263-97.

Steriade M (1997) Synchronized activities of coupled oscillators in the cerebral cortex and thalamus at different levels of vigilance. Cereb Cortex 7: 583-604.

Steriade M, Nunez A, Amzica F (1993a) A novel slow ( $<1 \mathrm{~Hz})$ oscillation of neocortical neurons in vivo: depolarizing and hyperpolarizing components. J Neurosci 13: 3252-65. 
Steriade M, Nunez A, Amzica F (1993b) Intracellular analysis of relations between the slow $(<1 \mathrm{~Hz})$ neocortical oscillation and other sleep rhythms of the electroencephalogram. J Neurosci 13: 3266-83.

Stinehelfer S, Vruwink M, Burette A (2000) Immunolocalization of mGluR1alpha in specific populations of local circuit neurons in the cerebral cortex. Brain Res 861: 37-44.

Tamas G, Buhl EH, Lorincz A, Somogyi P (2000) Proximally targeted GABAergic synapses and gap junctions synchronize cortical interneurons. Nat Neurosci 3: 366-71.

Tamas G, Somogyi P, Buhl EH (1998) Differentially interconnected networks of GABAergic interneurons in the visual cortex of the cat. J Neurosci 18: 4255-70.

Toledo-Rodriguez M, Blumenfeld B, Wu C, Luo J, Attali B, Goodman P, Markram H (2004) Correlation maps allow neuronal electrical properties to be predicted from singlecell gene expression profiles in rat neocortex. Cereb Cortex 14: 1310-27.

van Hooft JA, Giuffrida R, Blatow M, Monyer H (2000) Differential expression of group I metabotropic glutamate receptors in functionally distinct hippocampal interneurons. J Neurosci 20: 3544-51.

Wang Y, Toledo-Rodriguez M, Gupta A, Wu C, Silberberg G, Luo J, Markram H (2004) Anatomical, physiological and molecular properties of Martinotti cells in the somatosensory cortex of the juvenile rat. J Physiol 561: 65-90.

Whittington MA, Traub RD, Jefferys JG (1995) Synchronized oscillations in interneuron networks driven by metabotropic glutamate receptor activation. Nature 373: 612-5.

Williams SR, Stuart GJ (2002) Dependence of EPSP efficacy on synapse location in neocortical pyramidal neurons. Science 295: 1907-10.

Wonders CP, Anderson SA (2006) The origin and specification of cortical interneurons. Nat Rev Neurosci 7: 687-96.

Xiang Z, Huguenard JR, Prince DA (1998) Cholinergic switching within neocortical inhibitory networks. Science 281: 985-8.

Xiang Z, Huguenard JR, Prince DA (1998) $\mathrm{GABA}_{\mathrm{A}}$ receptor-mediated currents in interneurons and pyramidal cells of rat visual cortex. J Physiol 506: 715-30.

Xiang Z, Huguenard JR, Prince DA (2002) Synaptic inhibition of pyramidal cells evoked by different interneuronal subtypes in layer $\mathrm{v}$ of rat visual cortex. J Neurophysiol 88 : $740-50$. 
Ylinen A, Bragin A, Nadasdy Z, Jando G, Szabo I, Sik A, Buzsaki G (1995) Sharp waveassociated high-frequency oscillation $(200 \mathrm{~Hz})$ in the intact hippocampus: network and intracellular mechanisms. J Neurosci 15(1 Pt 1): 30-46. 


\title{
Yunyong Ma
}

\author{
1 Medical Center Drive \\ Morgantown, WV 26506 \\ Tel: (304) 293-0601, Fax: (304) 293-8159 \\ Email: yma@hsc.wvu.edu
}

\section{EDUCATION}

08/2001 -Present Ph.D. Candidate, Dept. of Neurobiology and Anatomy, West Virginia University, WV USA

09/1998 - 07/2001 M.S., Capital University of Medical Sciences, Beijing, China

08/1997 - 08/1998 Psychiatrist in County Hospital of Licheng, Jinan, China

09/1992 - 07/1997 M.D., Jining Medical College, Jining, Shangdong, China

\section{RESEARCH EXPERIENCE}

08/2003 - Present

Graduate research assistant, Dr. Ariel Agmon`s lab, Dept. of Neurobiology and Anatomy, West Virginia University, WV, USA

Research project: to study the properties and functions of somatostatin-containing

GABAergic interneurons in acute cerebral cortical slices.

09/1998-07/2001

Graduate research assistant, Dr. Guowei Lu`s lab, Dept. of neurobiology, Capital University of Medical Sciences, Beijing, China

Research project: to study the role of adenine in cerebral hypoxia preconditioning.

\section{PROFESSIONAL MEMBERSHIP}

Society for Neuroscience, since 2003

\section{PUBLICATION AND ABSTRACTS}

1. Hu H, Ma Y, Berrebi A and Agmon A (2007) Distinguishing cerebellar granular layer inhibitory interneurons in transgenic mice. Abstract, Society for Neuroscience, $37^{\text {th }}$ Annual Meeting, San Diego, CA.

2. Ma Y, Agmon A (2006) Differential inhibition evoked by somatostatin-containing interneurons onto fast-spiking interneurons and excitatory regular-spiking neurons in layer 4 of mouse barrel cortex. Abstract. 2006 Barrels Meeting, Atlanta, Georgia.

3. Ma Y, Hu H, Berrebi AS, Mathers PH and Agmon A (2006) Distinct subtypes of somatostatin-containing neocortical interneurons revealed in transgenic mice. $\mathrm{J}$ Neurosci, 26(19): 5069-82.

4. Ma Y, Agmon A (2005) A novel subtype of layer 4 targeting, somatostatin-containing neocortical interneurons. Abstract, Society for Neuroscience, $35^{\text {th }}$ Annual Meeting, Washington DC. 